Running Head. Motivation Profiles

\title{
A Test of Work Motivation Profile Similarity across Four Distinct Samples of Employees
}

\author{
Nicolas Gillet* \\ Université de Tours, QualiPsy EE 1901, Tours, France \\ Alexandre J.S. Morin* \\ Substantive-Methodological Synergy Research Laboratory, Concordia University \\ Adama Ndiaye \\ Université de Tours, VALLOREM EA 6296, Tours, France \\ Philippe Colombat \\ Université de Tours, QualiPsy EE 1901, Tours, France \\ Evelyne Fouquereau \\ Université de Tours, QualiPsy EE 1901, Tours, France
}

\author{
Corresponding author: \\ Nicolas Gillet, \\ Université de Tours, \\ Faculté Arts et Sciences Humaines, \\ Département de psychologie, \\ 3 rue des Tanneurs, 37041 Tours Cedex 1, France \\ E-mail: nicolas.gillet@univ-tours.fr
}

* The first two authors (N.G. \& A.J.S.M) contributed equally to this article and their order was determined at random: Both should thus be considered first authors.

This is the prepublication version of the following manuscript:

Gillet, N., Morin, A. J. S., Ndiaye, A., Colombat, P., \& Fouquereau, E. (in press). A test of work motivation profile similarity across four distinct samples of employees. Journal of Occupational and Organizational Psychology. Early view. https://doi.org/10.1111/joop.12322

(C) 2020. This paper is not the copy of record and may not exactly replicate the authoritative document published in the Journal of Occupational and Organizational Psychology.

\begin{abstract}
The present study examines how the different forms of behavioral regulation proposed by selfdetermination theory combine within different profiles of workers and the extent to which these configurations are replicated among four samples of workers from distinct occupational groups (managers, nurses, physiotherapists, and hospital employees). In addition, this research investigates the role of workload (as a job demand), as well as perceived organizational, supervisor, and colleagues support (as job resources) in the prediction of profile membership. Finally, this research also documents the relation between motivation profiles and a series of adaptive (work performance) and maladaptive (presenteeism, turnover intentions, and absenteeism) work outcomes. Latent profile analyses revealed six similar motivation profiles among the four samples $(n=291$ managers, 249 hospital employees, 237 nurses, and 373 physiotherapists). The results also showed the highest levels of presenteeism and turnover intentions, and the lowest levels of work performance to be associated with the Externally Driven profile. Moreover, workload predicted a higher likelihood of membership into the Self-Driven Introjected and Externally Driven profiles relative to the Moderately Intrinsically Motivated, Highly Intrinsically Motivated, and Self-Driven Hedonist profiles. Finally, perceived colleagues support predicted a decreased likelihood of membership into the Externally Driven profile relative to the five other profiles, whereas higher levels of perceived organizational support predicted an increased likelihood of membership into the Self-Driven Introjected, Highly Intrinsically Motivated, and Value-Reward Self-Driven profiles relative to the Externally Driven and Self-Driven Hedonist ones.

Key words: Motivation; self-determination theory; occupational groups; social support; latent profile analyses; work performance.
\end{abstract}


Motivation Profiles 2 
Self-determination theory (SDT; Deci \& Ryan, 2000; Ryan \& Deci, 2017) conceptualizes work motivation as encompassing a series of distinct, yet complementary, forms of behavioral regulation that may coexist within employees, and which together play a role in the emergence of goal-directed behaviors. These regulations range from more autonomous forms of motivation, which characterize an engagement in activities driven by pleasure, volition, and choice, to more controlled forms of motivations, where activity engagement is driven by internal or external pressures. Numerous variable-centered studies have supported the existence of well-differentiated links between these types of behavioral regulation and a series of personal and work-related outcomes (Deci, Olafsen, \& Ryan, 2017). However, despite their interest, these studies are limited by their failure to consider the possible effects of different work motivation combinations. In contrast, person-centered analyses seek to identify subpopulations, referred to as profiles, characterized by distinct configurations on a set of interacting variables (Marsh, Lüdtke, Trautwein, \& Morin, 2009; Morin \& Wang, 2016), making them naturally suited to investigating the combined effects of behavioral regulations (Wang, Morin, Ryan, \& Liu, 2016). Recently, person-centered studies began to look at how the different forms of motivation proposed by SDT combine with one another within specific profiles of employees from a variety of work settings (i.e., Gillet, Becker, Lafrenière, Huart, \& Fouquereau, 2017; Gillet, Fouquereau, Vallerand, Abraham, \& Colombat, 2018; Graves, Cullen, Lester, Ruderman, \& Gentry, 2015; Howard, Gagné, Morin, \& Van den Broeck, 2016; Jansen in de Wal, den Brok, Hooijer, Martens, \& van den Beemt, 2014; Moran, Diefendorff, Kim, \& Liu, 2012; Van den Berghe et al., 2014; Van den Broeck, Lens, De Witte, \& Van Coillie, 2013).

Unfortunately, these prior investigations have not always considered all key facets of work motivation, have not relied on an operationalization of work motivation allowing them to differentiate employees' global levels of self-determination across all types of regulation from the unique quality associated with each unique type of regulation (Howard, Gagné, Morin, \& Forest, 2018), and have generally resulted in divergent conclusions regarding the relative importance of autonomous and controlled forms of motivation. Achieving this requires the adoption of a more comprehensive representation of the multidimensionality of work motivation measurement and profiles (Morin, Boudrias et al., 2016, 2017), which is the approach taken in the present study. To the best of our knowledge, only one recent study has adopted a similar approach to investigate nurses' motivation profiles (Fernet et al., 2020). However, this research was limited to nurses, and only considered a limited number of outcomes of these motivation profiles (i.e., emotional exhaustion, in-role performance, and intentions to leave the organization and the occupation), without also considering likely determinants of profile membership. More research is thus needed to obtain a clearer picture of the motivation configurations most frequently occurring across a variety of organizational settings, the factors influencing their development, and their effects on other work-related outcomes.

Morin, Meyer, Creusier, and Biétry (2016) recently proposed a way to test the generalizability of the profiles identified across subpopulations of participants. In the present study, we adopt this method to identify the work motivation profiles occurring within four distinct samples of employees. Our first sample includes managers. Our second sample includes employees working in a French hospital whose work involves no contact with the patients (e.g., electricians, computer scientists, plumbers), whereas our third sample includes nurses whose work involves direct interactions with patients. Finally, our fourth sample includes physiotherapists whose work also involves direct interactions with patients. Nurses and physiotherapists are comparable in that both are health care professionals, but they differ in education, responsibilities, and salaries. Although we relied on four different samples of workers, it is noteworthy that, with the exception of the managers, all participants worked in the health care sector and hence in a similar environment (i.e., a hospital) or system (i.e., health care system). By doing so, we acknowledge that we may increase our ability to identify similar profiles across samples relative to similar tests conducted across more diversified samples. However, we felt that the current sample composition already provided a strong first step toward the assessment of the similarity of motivational profiles for distinct types of workers.

More specifically, this study contributes to improve our understanding of work motivation by: (1) accounting for the inherent globality and specificity of all facets of work motivation (Howard et al., 2018); (2) systematically assessing the similarity of the profiles occurring across four distinct samples of employees; (3) assessing the construct validity of the profiles in relation to four key outcome variables (i.e., presenteeism, turnover intentions, work performance, and absenteeism); and (4) considering the role of sex, age, working time, tenure, perceived workload, as well as perceived organizational, supervisor, and colleagues support as possible predictors of motivation profiles.

Given that person-centered results tend to be more naturally aligned with managers tendency to think 
about their employees as corresponding to different categories (Morin, Morizot, Boudrias, \& Madore, 2011; Zyphur, 2009), our findings are likely to have important implications for practice. Thus, rather than having to decode complex patterns of interrelations and interactions between variables, person-centered results allows managers to easily identify types of employees with knowledge about the likely outcomes of corresponding to these various profiles, as well as actionable levers of intervention to increase the likelihood of more desirable motivation profiles. Furthermore, to ascertain that profiles represent substantively meaningful subpopulations, it is important to systematically assess the extent to which these profiles generalize to distinct groups of workers (Marsh et al., 2009; Meyer \& Morin, 2016; Morin, Meyer et al., 2016; Muthén, 2003). More precisely, evidence of generalizability would reinforce the idea that the profiles tap into some core psychological phenomenon for which generic interventions could be devised to differentially manage, support, select, or even promote employees irrespective of employment type, which is more parsimonious than having to develop context-specific strategies.

\section{Self-Determination Theory}

According to SDT (Deci \& Ryan, 2000; Ryan \& Deci, 2017), employees can be motivated by a variety of reasons. Intrinsic motivation represents volitional engagement in an activity for the pleasure and satisfaction that it affords. Identified regulation refers to engagement in an activity that serves a personallyendorsed value or objective. Intrinsic motivation and identified regulation are conceptualized as autonomous (i.e., self-driven) forms of motivation. Introjected regulation refers to engagement in an activity driven by internal pressures, such as the avoidance of guilt and shame, or the pursuit of pride. External regulation refers to engagement in an activity that is controlled by external sources, such as rewards, punishments, or constraints. Introjected and external regulations are conceptualized as controlled (driven by internal or external contingencies) forms of behavioral regulation. Finally, amotivation refers to the lack of motivation or intention to engage in the target behavior.

SDT does not conceptualize these types of motivation as mutually exclusive. Instead, these regulations are proposed to coexist within individual employees (Howard et al., 2016), and to follow a selfdetermination continuum, ranging from intrinsic motivation to amotivation (Deci \& Ryan, 2000). Multiple approaches have been previously utilized to test this continuum hypothesis, including some attempts to test a one-dimensional structure of motivation expected to reflect the hypothesized continuum, as well as multiple multidimensional approaches seeking to attain a more precise picture of associations between each type of regulation (Chemolli \& Gagné, 2014; Guay, Morin, Litalien, Valois, \& Vallerand, 2015; Howard, Gagné, \& Bureau, 2017; Sheldon, Osin, Gordeeva, Suchkov, \& Sychev, 2017; Wang et al., 2016). However, both approaches are incomplete. Indeed, multidimensional approaches are typically unable to achieve an explicit, and direct, representation of the continuum, whereas one-dimensional approaches are unable to do so while simultaneously taking into account the unique nature of each type of regulation (Ryan \& Deci, 2017).

Recent studies conducted in the work (Fernet et al., 2020; Howard et al., 2018) and educational (Litalien, Morin, Gagné et al., 2017) areas have demonstrated that bifactor exploratory structural equation models (bifactor-ESEM; Morin, Arens, \& Marsh, 2016) made it possible to simultaneously obtain a direct estimate of employees' global levels of self-determined work motivation and an equally direct estimate of the unique quality associated with each specific regulation. In these studies, participants' location on the self-determination continuum is operationalized by a global factor where the position of each motivation item on the self-determination continuum is reflected through factor loadings ranging from negative for amotivation items to strong and positive for intrinsic motivation items. In contrast, the unique quality of each specific form of behavioral regulation is operationalized by a series of additional factors reflecting what remains in items associated with the various motivation subscales once the global factor is taken into account. These studies showed that participants' global levels of self-determination tended to be the key component responsible for associations with a variety of covariates, underscoring the importance of considering global levels of self-determination in future research on work motivation. However, they also supported the additional value of considering the specific regulation factors in prediction.

Beyond these considerations of how to best reflect the dual global/specific nature of work motivation, numerous studies have also established the differential predictive validity of the different types of regulation proposed by SDT for a variety of work outcomes (Deci et al., 2017; Gagné \& Deci, 2005). These studies have generally supported SDT propositions in showing that autonomous forms of motivation tend to predict more positive outcomes than controlled forms of motivation and amotivation. Yet, some studies also showed that, contrary to expectations, controlled forms of motivation did not always 
lead to negative outcomes (e.g., Parker, Jimmieson, \& Amiot, 2010). Even more precisely, person-centered studies have shown that controlled forms of motivation may sometimes be associated with positive outcomes, but only when accompanied by high levels of autonomous motivation (e.g., Gillet, Becker et al., 2017; Moran et al., 2012), underscoring the importance of studying behavioral regulations in combination.

\section{Motivation Profiles}

Person-centered analyses are specifically designed to identify qualitatively distinct subpopulations of workers characterized by distinct configurations of behavioral regulations (Meyer \& Morin, 2016). For instance, a person-centered approach might identify a profile characterized by high levels of controlled motivation, whereas another one could be driven by a combination of intrinsic motivation and external regulation. Person-centered approaches thus make it possible to identify different types of workers engaging in their work for different reasons while jointly considering global and specific levels of motivation. This approach is directly aligned with SDT's assertion that workers are rarely driven by a single work motive, but rather by a complex configuration of behavioral regulations (Vallerand, 1997).

However, few person-centered studies have been conducted in the work area to identify employees' motivation profiles. In addition, among these studies, some have identified profiles based on a combination of motivation types proposed by SDT and additional constructs (e.g., positive affect and self-efficacy: Valero \& Hirschi, 2016), making it impossible to isolate the role of behavioral regulations. Among the studies that solely focused on motivation, many relied on global dimensions (e.g., autonomous and controlled motivations: Van den Berghe et al., 2014; Van den Broeck et al., 2013), rather than distinguishing all types of regulation proposed by SDT. Still, when we consider these studies as well as those in which a broader set of behavioral regulations has been considered (Gillet, Becker et al., 2017; Gillet et al., 2018; Graves et al., 2015; Howard et al., 2016; Jansen in de Wal et al., 2014; Moran et al., 2012), despite some variations, the results seem to converge on profiles characterized by: (a) high levels of autonomous motivation, and low levels of controlled motivation and amotivation (HAu-LC-LAm), (b) high levels of autonomous and controlled motivations, and low levels of amotivation (HAu-HC-LAm), (c) low levels of autonomous motivation, and high levels of controlled motivation and amotivation (LAu-HCHAm), and (d) low to moderate levels of autonomous motivation, controlled motivation, and amotivation (LAu-LC-LAm). Some of these studies (Gillet, Becker et al., 2017; Moran et al., 2012) have also supported the importance of differentiating among more specific types of regulation by the identification of profiles characterized by differentiated levels of introjected and external regulations.

A single study has simultaneously considered global and specific levels of work motivation (operationalized using bifactor-ESEM; Fernet et al., 2020) to identify motivation profiles among newly registered nurses. Interestingly, the results from this study revealed more refined distinctions among four distinct profiles based on both global, and specific, levels of motivation. A first, Moderately Motivated, profile displayed moderately high global levels of self-determination, low specific levels of intrinsic motivation, and average specific levels of the other behavioral regulations. A second, Poorly Motivated, profile displayed low global levels of self-determination, moderately high specific levels of amotivation, introjected regulation, and external regulation, and average or slightly below average specific levels of intrinsic motivation and identified regulation. A third, Self-Determined, profile displayed moderately high global levels of self-determination and specific levels of identified regulation and intrinsic motivation, and low specific levels of the other behavioral regulations. Finally, the Strongly Motivated profile was characterized by high global levels of self-determination and specific levels of identified, introjected, and external regulations, moderately high specific levels of amotivation, and average specific levels of intrinsic motivation. However, these results remain limited to a single sample of nurses, whereas person-centered evidence is known to emerge from the accumulation of research allowing one to better differentiate the core profiles that emerge systematically from those who only reflect sample-specific idiosyncrasies.

The present study addresses this important limitation by documenting work motivation profiles defined based on global and specific levels of work motivation among four distinct samples of employees to systematically provide evidence of generalizability across samples of employees, including a sample of nurses to ensure a valid comparison with Fernet et al.'s (2020) results. Importantly, by adopting an approach allowing us to differentiate the role played by employees' global levels of self-determination relative to that played by the specific quality of each type of behavioral regulation, this study will also help to verify SDT' assertion that both components of work motivation play a key role in driving employees' motivational orientation to work (Deci \& Ryan, 2000; Howard et al., 2017). Despite the limited evidence from work motivation research relying on a proper disaggregation of global versus specific ratings of 
motivation in the identification of employees' profiles, recent results (Fernet et al., 2020; Gillet et al., 2018; Howard et al., 2016; Moran et al., 2012) suggest the following hypotheses:

Hypothesis 1. Employees' motivation at work will be best represented by a relatively small number of profiles (i.e., between four and six).

Hypothesis 2. At least one profile will be characterized by high and matching levels of motivation across dimensions, such as the HAu-HC-LAm identified in previous studies, or the Strongly Motivated profile identified by Fernet et al. (2020).

Hypothesis 3. At least one profile will be dominated by autonomous forms of motivation, such as the HAu-LC-Lam identified previously, or the Self-Determined profile identified by Fernet et al. (2020).

Hypothesis 4. At least one profile will be dominated by controlled forms of regulation such as the LAuHC-Ham identified previously, or the Poorly Motivated profile identified by Fernet et al. (2020).

Hypothesis 5. At least one profile will be characterized by average and matching levels of motivation across dimensions such as the Moderately Motivated profile identified by Fernet et al. (2020).

Hypothesis 6. Additional profiles will be characterized by well-differentiated configurations of motivation across indicators, especially diverging levels of introjected and external regulations.

\section{Job Similarity}

The availability of a proper methodological and statistical approach to guide the comparisons of the findings obtained across samples of employees from different occupations is a fundamental aspect of research as it involves the demonstration of the generalizability of results, which would otherwise simply reflect sample-specific idiosyncrasies (Spector, Liu, \& Sanchez, 2015). As argued by Morin, Meyer et al. (2016, p. 233), "the only way to really support a substantive interpretation of the profiles is to embark on a process of construct validation to demonstrate that the profiles either meaningfully relate to covariates, or can reliably be replicated across samples". Their approach provides a rigorous method to systematically and quantitatively assess the extent to which a person-centered solution generalizes across samples, such as in the comparison between four occupational groups conducted in the present study. It involves a set of comparisons that allow for the detection of similarities and differences across work settings. However, differences do not necessarily reflect a limitation, but rather indicate limits to the generalizability of a solution that may deserve additional investigations (Morin, Meyer et al., 2016).

The key advantage of this approach resides in the ability to assess different types of generalizability, related to the number (configural similarity) and nature (structural similarity) of the profiles, the amount of inter-individual differences among members of a single profile (dispersion similarity), and the relative size of the profiles (distributional similarity). As noted above, the ability to devise interventions or recommendations that can be expected to generalize to various types of employees, work contexts, or situations is conditioned on the ability to demonstrate that the same set of profiles would appear with some regularity (i.e., configural and structural similarity). Importantly, these forms of similarity are not inconsistent with the acknowledgement that work motivation can be partly situational (Ratelle, Guay, Vallerand, Larose, \& Senécal, 2007) or context dependant (Gagné \& Deci, 2005) at the individual level. Likewise, it is also not incompatible with the possibility to intervene in order to modify employees' motivational profiles. Indeed, these contextual, situational, and interventional influences will be more clearly captured by the last type of similarity (distributional), which should reveal changes in the relative frequency of each profile as a function of these variations. When occupational groups are considered, the following considerations thus allow us to expect some variations in this regard.

For instance, De Cooman, Stynen, Van den Broeck, Sels, and De Witte (2013) showed that unskilled/semi-skilled blue-collar workers tended to report significantly less autonomous motivation than higher-level managers. Likewise, Howard et al. (2016) showed that white-collar technological employees presented a lower likelihood of membership into a profile characterized by low to very low levels of external regulation, introjected regulation, and amotivation, and average or slightly above average levels of identified regulation and intrinsic motivation, when compared to white-collar governmental employees and blue-collar employees. In contrast, white-collar governmental employees presented a greater likelihood of membership into a profile characterized by very high levels of amotivation and average to low levels on all other regulations when compared to white-collar technology sector and blue-collar employees.

Research shows that job demands (e.g., workload) and resources (e.g., organizational, supervisor, and colleagues support) are significantly associated with employees' autonomous and controlled forms of motivation (Fernet et al., 2020; Gillet, Gagné, Sauvagère, \& Fouquereau, 2013). For instance, Sandrin, Gillet, Fernet, Leloup, and Depin-Rouault (2019) showed that workload was positively related to controlled 
motivation. By this same reasoning, it is expected that managers, who are often facing a heavy workload and are highly vulnerable to workaholism (known to be strongly influenced by controlled motivation; van Beek, Taris, \& Schaufeli, 2011) would be more likely to correspond to profiles characterized by higher levels of controlled forms of motivation (e.g., the LAu-HC-Ham profile or the Poorly Motivated profile identified by Fernet et al., 2020).

Another important distinction among occupations is related to perceived social support at work. For nurses and physiotherapists, their relationships with their colleagues are seen as a central job component (Bonifas, 2015), one that requires a substantial level of commitment, dedication, and emotional engagement (Gray, 2010; Henderson, 2001). More precisely, colleagues support have many benefits for nurses and physiotherapists, being associated with higher levels of well-being, quality of care, and staff retention (e.g., van der Heijden et al., 2010). Furthermore, as managers, nurses and physiotherapists from the health care area have to accomplish their duties in a context where resources might already be depleted by additional work-related stressors (e.g., workload). Indeed, research has identified, among others, caseload quantity, complexity of patients, constant excessive workload, covering for staff on leave, and staff shortages as major sources of stress for physiotherapists (Lindsay, Hanson, Taylor, \& McBurney, 2008). Similarly, nursing is characterized by unpredictability, increasing nurses-to-patient ratio, and continuous confrontation with a broad range of diseases, injuries, and traumatic events (e.g., McVicar, 2016). In contrast, hospital employees whose work involves no direct contact with the patients may be characterized by a lower perception of workload, especially because they are facing lower levels of emotional demands due to their limited, indirect, and/or more sporadic contact with the patients (Fouquereau, Morin, Lapointe, Mokounkolo, \& Gillet, 2019). Indeed, although helping people in need is known to be a source of satisfaction and autonomous motivation for health care workers (Donoso, Demerouti, Garrosa Hernández, MorenoJiménez, \& Carmona Cobo, 2015), numerous studies have shown that workload perceptions were positively related to emotional demands (e.g., Andela, Truchot, \& Van der Doef, 2016; Gillet, Huyghebaert-Zouaghi, Réveillère, Colombat, \& Fouquereau, 2020).

Considering that job demands, which are thus more intensive for managers, nurses, and physiotherapists, lead to lower levels of autonomous motivation and to higher levels of controlled motivation and amotivation (Trépanier, Forest, Fernet, \& Austin, 2015), we expect membership into profiles characterized by higher levels of autonomous motivation and lower levels of controlled motivation and amotivation (e.g., the HAu-LC-Lam or Self-Determined profile) to be more frequent among hospital employees with no customer contact than among managers, nurses, and physiotherapists. Furthermore, because nurses and physiotherapists might benefit from higher levels of colleagues support to cope with professional duties, we also expect membership into motivational profiles characterized by higher levels of autonomous motivation and lower levels of controlled motivation and amotivation (e.g., the HAu-LC-Lam or Self-Determined profile) to be more frequent among nurses and physiotherapists than among managers.

Finally, when considering nurses and physiotherapists, it is noteworthy that the salary differential can be quite high between these two groups. More precisely, registered U.S. nurses earned an average annual salary of $\$ 73,550$ in 2016 , while the average annual salary for physical therapists was $\$ 88,080$ (U.S. Bureau of Labor Statistics). Yet, Kuvaas (2006) showed that higher salaries foster better performance and affective commitment through its positive effect on intrinsic work motivation. Likewise, Gagné and Forest (2008) argued that higher salaries foster higher levels of autonomous work motivation, partly because of desirable social comparisons and improved perceptions of distributive justice. Higher salaries also signal the recognition of high competence and the valuation of the employer-employee relationship. Thus, we expected motivational profiles characterized by higher levels of autonomous motivation and lower levels of controlled motivation and amotivation (e.g., the HAu-LC-Lam or Self-Determined profile) to be more frequent among physiotherapists than among nurses.

Research Question. Will the identified profiles display evidence similarity (in terms of number, structure, and levels of difference among profile members) across samples?

Hypothesis 7. The relative frequency of the profiles will differ across samples so that profiles characterized by higher levels of autonomous forms of motivation and lower levels of controlled motivation and amotivation (e.g., the HAu-LC-Lam or Self-Determined profile) should be: (a) more frequent among hospital employees with no customer contact than other types of employees; (b) more frequent among nurses and physiotherapists than among managers; and (c) more frequent among physiotherapists than among nurses. Matching differences are expected to occur, but in the opposite 
direction, for profiles characterized by lower levels of autonomous forms of motivation and higher levels of controlled forms of motivation and amotivation (e.g., the LAu-HC-Ham or Poorly Motivated profile).

\section{Outcomes of Motivation Profiles}

According to SDT more self-determined, or autonomously motivated, employees should perceive their job as more stimulating and agreeable, act in accordance with their personal values, and be able to take more decisions in their work. These employees are expected to take pleasure in their work, allowing to better sustain continuous efforts, which in turn should allow them to experience more positive outcomes (Sandrin et al., 2019). Conversely, SDT also expects workers experiencing higher levels of controlled motivation to be more importantly driven to action via the influence of external pressures (e.g., to cope with an authoritarian manager) and/or internal pressures (e.g., to avoid guilt or enhance their self- worth). This less self-determined approach to work means that these workers are more likely to see their job as being disconnected from their personal values, leading them to progressively exhaust their psychological resources while having less opportunities to replenish them, in turn leading them to experience more negative outcomes (Ryan \& Deci, 2017).

Consistent with these SDT predictions (Deci \& Ryan, 2000; Ryan \& Deci, 2017), previous studies (Moran et al., 2012; Van den Broeck et al., 2013) have shown that profiles characterized by high levels of autonomous motivation but low levels of controlled motivation and amotivation tended to be associated with the most positive work outcomes, whereas profiles characterized by low levels of autonomous motivation coupled with higher levels of controlled motivation and amotivation tended to be associated with the worst outcomes. Similarly, Fernet et al. (2020) showed that the Poorly Motivated profile was associated with the highest levels of turnover intentions and emotional exhaustion.

However, and contrary to SDT theoretical predictions, additional studies also showed that levels of controlled motivation generally had no impact on these outcomes when levels of autonomous motivation were also high (Gillet et al., 2018; Howard et al., 2016), thus calling into question theoretical predictions alluding to the undesirability of controlled types of motivation (Ryan \& Deci, 2017). However, these prior investigations also failed to explicitly take into account the levels of global self-determination which have been shown, in previous variable-centered studies (Howard et al., 2018; Litalien, Morin, Gagné et al., 2017), to represent a much stronger predictor of outcomes than the specific motivation factors reflecting the unique quality of employees' work motivation beyond their global level of self-determination.

Consequently, the estimation of work motivation profiles defined using explicit and non-redundant estimates of employees' global and specific levels of work motivation is likely to lead to a more nuanced understanding of associations between these profiles and outcomes (e.g., Morin, Boudrias et al., 2016, 2017).

In the Fernet et al.'s study (2020), the most adaptive outcomes (i.e., the lowest levels of emotional exhaustion, and intentions to leave, and the highest levels of performance) were observed in the Moderately Motivated and Strongly Motivated profiles. Furthermore, the Poorly Motivated and Self-Determined profiles also displayed the lowest levels of performance. However, the Self-Determined profile was unexpectedly found to be the second least desirable profile. Fernet et al. (2020) suggested that the characteristics of the nursing context might explain these unexpected results, but encouraged researchers to conduct additional studies to clarify the role of specific behavioral regulations within other occupational groups, once employees' global levels of self-determination are taken into account.

The present research aimed to enrich our understanding of the effects of employees' work motivation profiles on their work behaviors. To inform this issue, we rely on two outcomes related to participants' work behaviors already considered by Fernet et al. (2020) (turnover intentions and work performance) and on two additional outcomes (presenteeism and absenteeism) to extend research on work motivation profiles. These four outcomes were retained based on previously reported evidence showing that they all present differentiated relations with employees' levels of autonomous and controlled motivations (e.g., Fernet, Trépanier, Austin, Gagné, \& Forest, 2015; Gagné et al., 2015). For instance, numerous variablecentered studies showed that, contrary to controlled motivation, autonomous motivation was positively related to work performance (Thibault Landry et al., 2017). Gillet, Gagné et al. (2013) also demonstrated that autonomous and controlled motivations were respectively negatively and positively related to employees' levels of turnover intentions. Likewise, Williams et al. (2014) found negative relations between autonomous motivation and absenteeism. Taken together, these considerations lead us to propose that:

Hypothesis 8. Employees corresponding to profiles characterized by high levels of autonomous motivation and low levels of amotivation, regardless of their levels of controlled motivation (e.g., the HAu- 
HC-Lam, HAu-LC-Lam, or Strongly Motivated profile) will report the highest levels of work performance, and the lowest levels of presenteeism, turnover intentions, and absenteeism.

Hypothesis 9. Employees corresponding to profiles characterized by high levels of amotivation and low levels of autonomous motivation, regardless of their levels of controlled motivation (e.g., the LAu-HCHam or Poorly Motivated profile) will report the lowest levels of work performance, and the highest levels of presenteeism, turnover intentions, and absenteeism.

\section{Predictors of Motivation Profiles}

The present study focuses on workload, as well as perceived organizational, supervisor, and colleagues support as possible predictors of membership into the various motivation profiles, while controlling for the effects of sex, age, working time, and tenure. The decision to control for these variables is based on previous results showing that motivational processes tend to differ as a function of these demographic characteristics (Bonneville-Roussy, Evans, Verner-Filion, Vallerand, \& Bouffard, 2017; Gillet, Vallerand, \& Paty, 2013; Ratelle et al., 2007; Vallerand, Fortier, \& Guay, 1997). In regard to the predictors themselves, SDT proposes that social factors (e.g., organizational support) are major determinants of workers' motivation (Gagné \& Deci, 2005). However, SDT itself remains limited regarding the expected role of specific work-related factors in maximally supporting self-determination, beyond noting that importance of work characteristics helping to support employees' need for competence, relatedness and autonomy. This has led Van den Broeck, Ferris, Chang, and Rosen (2016) to encourage researchers to integrate SDT with other major theoretical frameworks.

In the present study, we draw on the job-demands resources model (Bakker \& Demerouti, 2007) to guide our understanding of the likely effects of work characteristics on employees' motivation. This model postulates that a process of psychological impairment is activated when excessive job demands are imposed on employees. Job demands refer to those aspects of a job that require sustained physical and/or psychological effort and that therefore take a physiological and/or psychological toll on employees. In contrast, job resources help to enhance employees' well-being by helping them to achieve their goals, by reducing the costs associated with job demands, and by stimulating personal development.

The effects of job demands (e.g., workload) have been previously examined and supported in relation to work motivation (Kim \& Beehr, 2018; Trépanier, Fernet, \& Austin, 2013), showing for instance that employees' job demands negatively predicted autonomous forms of motivation. SDT-based research has also supported the role of psychological need satisfaction as a mechanism liable to explain the negative effects of job demands on employees' functioning. More precisely, job demands are positively related to the frustration of psychological needs for autonomy, competence, and relatedness, in turn leading to higher levels of controlled motivation and lower levels of autonomous motivation (De Cooman et al., 2013; Olafsen \& Halvari, 2017; Trépanier et al., 2015).

In the present study, we focus on the effects of one type of job demands (i.e., workload) with a known influence on work motivation (e.g., Fernet, Trépanier, Austin, \& Levesque-Côté, 2016; Olafsen \& Halvari, 2017; Sandrin et al., 2019). More specifically, higher workloads are known to be associated with higher levels of controlled motivation and amotivation, and with lower levels of autonomous motivation, arguably because heavier workloads make it harder for workers to find time to engage in the aspects of their work most aligned with their personal values (Ryan \& Deci, 2017). Workload is also known to play an important role in the prediction of poor levels of health and work performance (Baeriswyl, Krause, Elfering, \& Berset, 2017; Ilies, Huth, Ryan, \& Dimotakis, 2015), possibly due to the resulting depletion of resources (Bakker \& Demerouti, 2007).

We also focus on employees' perceptions of social support from the organization, supervisor, and colleagues as predictors of their membership in the various motivation profiles (Eisenberger $\&$ Stinglhamber, 2011). Social support has the advantage of being easily amenable to interventions designed to improve employees' psychological health and motivation (Caesens, Stinglhamber, Demoulin, De Wilde, $\&$ Mierop, 2019). Numerous studies have also shown that social support perceptions were an important predictor of performance, psychological health, and intentions to stay in the organization (e.g., Kurtessis et al., 2017). When considering social support as a job resource, SDT (Ryan \& Deci, 2017) explicitly positions social support as a key driver of employees' basic psychological need satisfaction, seen as the foundation for autonomous forms of motivation. Supporting this assertion, these different sources of social support have been repeatedly found to predict employees' psychological need satisfaction at work, as well as a variety of desirable motivational outcomes (Gillet, Fouquereau, Forest, Brunault, \& Colombat, 2012; Gillet, Gagné et al., 2013). In addition, abundant variable-centered evidence (e.g., Battistelli, Galletta, 
Odoardi, Núñez, \& Ntalianis, 2017; Chambel, Castanheira, Oliveira-Cruz, \& Lopes, 2015), as well as emerging person-centered evidence focusing on generic perceptions of social support (Graves et al., 2015; Moran et al., 2012) also suggests that these three sources of social support at work should be particularly important in the prediction of the likelihood of membership into profiles characterized by high levels of autonomous motivation, and low levels of controlled motivation and amotivation. However, to the best of our knowledge, the current study represents the first attempt to examine the role of these three sources of social support at work in the prediction of membership in motivation profiles, aiming to provide a better understanding of the role of social support in the determination of employees' motivation.

Furthermore, recent research has called into question the previously assumed independence between job demands and resources. On the one hand, Fernet et al. (2015) showed that only job resources were associated with higher levels of autonomous motivation whereas job demands were associated with higher levels of controlled motivation. Similarly, Fernet et al. (2016) found a significant relation between work overload and controlled motivation, and a positive association between recognition and control, and autonomous motivation. On the other hand, Fernet et al. (2020) showed that job demands were not significantly associated with membership into any of their motivation profiles when job resources were taken into account. These results do not support assumptions from either SDT (Ryan \& Deci, 2017) or the job-demands resources model (Bakker \& Demerouti, 2007). However, it is noteworthy that job demands and resources were strongly correlated in the Fernet et al.'s (2020) study, suggesting that a balancing act might be at play between job demands and resources. Furthermore, although job demands and resources may differ in nature (e.g., emotional, physical, cognitive), Fernet et al. (2020) relied on global scores of job demands and resources and did not consider the particularities and different types of job demands and resources. Yet, various job demands and resources may act differently on job functioning (Podsakoff, LePine, \& LePine, 2007). The present research thus aimed to improve our understanding of the effects of various job demands and resources on employees' multidimensional work motivation profiles. Based on previous findings, we propose that:

Hypothesis 10. Higher workload perceptions will predict a greater likelihood of membership into profiles characterized by lower levels of autonomous motivation and higher levels of controlled motivation and amotivation (e.g., the LAu-HC-Ham or Poorly Motivated profile).

Hypothesis 11. Higher levels of perceived organizational, supervisor, and colleagues support will predict a greater likelihood of membership into the profiles characterized by higher levels of autonomous motivation and lower levels of controlled motivation and amotivation (e.g., the HAu-LC-Lam profile or Self-Determined profile).

\section{Procedure}

\section{Method}

Across all four samples involved in the present study, all potential participants received, when at work, a survey packet including the questionnaire, a cover letter explaining the study's purposes, and a consent form in which the anonymous and voluntary nature of their participation was emphasized. All participants who agreed to participate completed a paper-and-pencil questionnaire administered by members of our research team in 2016-2017. This data has not been previously published.

\section{Participants}

Sample 1. The first sample used in the present study includes a total of 291 managers (50 men and 241 women). These participants were recruited in various organizations located in France. Most participants worked full time (89.0\%) and occupied a permanent position (78.4\%). Respondents were aged between 23 and 62 years $(M=43.34, S D=8.76)$ and had an average organizational tenure of 11.16 years $(S D=8.95)$.

Sample 2. The second sample used in this study includes 249 participants ( 86 men; 163 women), all working in one French hospital, and occupying a position involving no contact with the patients (e.g., electrician, computer scientist, plumber). Most participants worked full time (90.8\%) and occupied a permanent position $(92.4 \%)$. Respondents were aged between 24 and 62 years $(M=43.82, S D=9.47)$ and had an average organizational tenure of 15.43 years $(S D=10.94)$.

Sample 3. The third sample used in this study includes 237 nurses (11 men; 226 women), working in three French hospitals. Most participants worked full time (75.5\%) and occupied a permanent position $(88.6 \%)$. Respondents were aged between 21 and 64 years $(M=35.08, S D=10.55)$ and had an average organizational tenure of 10.10 years $(S D=9.57)$.

Sample 4. The fourth sample used in this study includes 373 physiotherapists (94 men; 279 women, 
aged between 22 and 63 years, $M=34.38, S D=9.17$ ) working in France either within organizations or as self-employed workers. Due to the self-employed status of most participants, information about tenure, employment type, and work hours, was not available.

\section{Measures}

Work Motivation (Profile Indicators). Participants completed Gagné et al.’s (2015) Multidimensional Work Motivation Scale. This questionnaire includes 19 items, all rated on a sevenpoint response scale ranging from 1 (does not correspond at all) to 7 (corresponds very strongly). This instrument assesses six dimensions of work motivation: Intrinsic motivation (three items; e.g.,

"Because I have fun engaging in my job"; $M \alpha=.87$ across samples), identified regulation (three items; e.g., "Because putting efforts in my job has personal significance to $m e " ; M \alpha=.40$ ), introjected regulation (four items; e.g., "Because I have to prove to myself that I can"; $M \alpha=.68$ ), external regulation (six items; e.g., "Because others will reward me financially only if I put enough effort in my work"; $M \alpha=.70$ ), and amotivation (three items; e.g., "I do little because I don't think my job is worth putting efforts into"; $M \alpha=.74)$. The low level of reliability associated with the identified subscale underlines the need to rely on an approach allowing for some level of control for unreliability, as discussed below in the analysis section. More precise composite reliability coefficients, as well as evidence of measurement invariance across samples, are provided in the online supplements (see Tables S2 to S5 for the motivation measure, and Tables S7 to S10 for the other dimensions).

Perceived Support (Predictor). Perceived organizational support was assessed using the four-item version (Caesens, Stinglhamber, \& Luypaert, 2014; $M \alpha=.76$; e.g., "My organization really cares about my well-being") of Eisenberger, Huntington, Hutchison, and Sowa's (1986) Survey of Perceived Organizational Support. Perceived supervisor $(M \alpha=.86$; e.g., "My supervisor really cares about my well-being") and colleagues ( $M \alpha=.85$; e.g., "My colleagues really care about my wellbeing") support were both assessed using the same four items in which the word "organization" was replaced by either "supervisor" or "colleagues" (e.g., Caesens et al., 2014). All items were rated on a seven-point response scale ranging from "Strongly Disagree" to "Strongly Agree".

Workload (Predictor). Spector and Jex's (1998) five-item Quantitative Workload Inventory was used to measure participants' workload perceptions $(M \alpha=.78$; e.g., "How often does your job require you to work very hard?"). Responses were provided on a five-point response scale ranging from 1 (never) to 5 (always).

Presenteeism (Outcome). The six-item Stanford Presenteeism Scale (Koopman et al., 2002) was employed to measure presenteeism during the past month (e.g., "Because of my health problems, the stresses of my job were much harder to handle"; $M \alpha=.94)$. Responses were provided on a five-point response scale ranging from 1 (strongly disagree) to 5 (strongly agree).

Work Performance (Outcome). Performance was assessed with a single item developed by Kessler et al. (2003), and asking workers to indicate "On a scale ranging from 1 to 10, how would you rate you work performance over the past four weeks? (with 0 reflecting the worst work performance anyone could have and 10 the performance of a top worker)".

Turnover Intentions (Outcome). Turnover intentions were assessed with three items $(M \alpha=.90$; e.g., "I often think about quitting this organization") developed by Bentein, Vandenberghe, Vandenberg, and Stinglhamber (2005) and rated on a five-point response scale (1- strongly disagree to 5- strongly agree).

Absenteeism (Outcome). We relied on a single-item measure developed by Kessler et al. (2003) to assess absenteeism. This item asked participants to report the number of entire work days they missed during the last year because of problems related to their physical or mental health.

\section{Preliminary Analyses}

\section{Analyses}

Preliminary factor analyses were conducted to verify the psychometric properties of all measures. Factor scores (estimated in standardized units with a grand mean of $M=0$ and a grand $S D=1$ across samples) from these preliminary models were used as inputs for the main analyses. To ensure comparability in the measures across samples, these factor scores were saved from models in which the invariance of the measures across groups was established (Millsap, 2011). Although factor scores do not explicitly control for measurement errors the way latent variables do, they do provide a partial control for measurement errors by giving more weight to items presenting lower levels of measurement errors (Skrondal \& Laake, 2001). Furthermore, factor scores are able to preserve the 
nature of the underlying measurement structure (e.g., measurement invariance) better than scale scores (for a more extensive discussion of the advantages of factor scores in the estimation of latent profile analyses (LPA; see Morin, Boudrias et al., 2016; Morin, Meyer et al., 2016). Given the low level of reliability of some subscales (e.g., identified regulation) and the near impossibility to rely on a fully latent operationalisation of latent profile analyses (Meyer \& Morin, 2016), this approach was selected as providing the most optimal compromise solution. Details on these measurement models, their measurement invariance, and variable correlations are reported in the online supplements.

The motivation measurement models were estimated using bifactor exploratory structural equation modeling (ESEM) models (Morin, Arens, \& Marsh, 2016). This modeling decision is based on recent evidence supporting the superiority of bifactor-ESEM models for academic (Litalien, Morin, Gagné et al., 2017) and work (Howard et al., 2018) motivation measures. What these studies demonstrated is that bifactor-ESEM models made it possible to obtain a direct estimate of participants' location on the continuum of self-determination assumed by SDT to underpin ratings of motivation across all subscales (i.e., the global "quantity" of self-determination), together with equally direct estimates of the specificities remaining within all motivation facets covered in the measure (i.e., the "quality" of motivation). As in these previous studies, the results reported in the online supplements supported the superiority of a bifactor-ESEM representation relative to comparable confirmatory factor analyses (CFA), bifactor-CFA, and ESEM solutions, as well as its invariance across samples (see Tables S1S5). Due to the complexity of the models underlying all constructs assessed in the present study, preliminary analyses were conducted separately for the motivation measure and for the multi-items predictor (workload, perceived organizational, supervisor, and colleagues support) and outcome (presenteeism and turnover intentions) measures (see Tables S6-S10).

\section{Model Estimation}

All analyses conducted as part of this study were realized using the Maximum Likelihood Robust (MLR) estimator available in the Mplus 8 statistical package (Muthén \& Muthén, 2018). Full Information Maximum Likelihood (FIML) procedures were used to handle the limited missing amount of missing responses present in these data sets (Enders, 2010; additional details on missing responses frequencies are provided in the online supplements). All LPA were estimated with 5000 random sets of start values, 1000 iterations, and the 200 best solutions retained for final optimization (Hipp \& Bauer, 2006). These values were increased to 10000, 2000, and 1000 for the multi-sample solutions.

\section{Latent Profile Analyses}

LPA were first estimated separately in each sample using the six motivation factors (i.e., the global self-determination factor, and the specific factors reflecting the unique quality of employees' intrinsic motivation, identified regulation, introjected regulation, external regulation, and amotivation) as indicators to verify if the same number of profiles would be identified across samples. We examined sample-specific solutions including one to eight latent profiles in which the means and variances of the motivation factors were freely estimated in all profiles (Diallo, Morin \& Lu, 2016; Morin et al., 2011; Peugh \& Fan, 2013).

\section{Tests of Profile Similarity}

Once the optimal number of profiles has been selected in each sample, we integrated the four LPA solutions (one per sample) into a multigroup LPA to conduct tests of profile similarity. These tests were conducted following the sequential strategy proposed by Morin, Meyer et al. (2016). The first step, corresponding to the sample-specific LPA, verifies if the same number of profiles can be identified in each sample (configural similarity). Evidence of configural similarity would come from the selection of a similar number of profiles as the optimal solution in each sample, and is a prerequisite to all further tests of profile similarity (Morin, Meyer et al., 2016). In the second step, the structural similarity of the profiles is verified by including equality constraints across samples on the means of the profile indicators to test if the profiles retain the same shape across samples. The third step tests the dispersion similarity of the profiles by including equality constraints on the variances of the profile indicators to verify whether the within-profile variability is comparable across samples. The fourth step tests the distributional similarity of the solution by constraining the class probabilities to equality across samples to ascertain whether the size of the profiles remains unchanged.

\section{Predictors and Outcomes}

Multinomial logistic regressions were used to test the relations between the predictors (workload and perceived organizational, supervisor and colleagues support) and profile membership. In these analyses, the predictors were directly integrated into the most similar multigroup LPA solution 
identified in the previous stages of analyses, and used to predict the likelihood of profile membership while controlling for the effects of sex, age, tenure, and work time. Two alternative models were contrasted (Morin, Meyer et al., 2016) to assess whether the relations between predictors and profile membership could be assumed to generalize (predictive similarity) or not across samples. Outcomes (presenteeism, absenteeism, work performance, and turnover intentions) were also directly incorporated into the most similar multigroup LPA solution, and used to contrast models in which the relations between profile membership and outcome levels were either constrained to be equal (explanatory similarity) or not across samples (Morin, Meyer et al., 2016). The Mplus' MODEL CONSTRAINT function was used to test mean-level differences across profiles using the multivariate delta method (Raykov \& Marcoulides, 2004).

\section{Model Comparisons}

To select the optimal number of profiles that best represented the data in each sample, it is first important to carefully examine the theoretical conformity, meaning, and statistical adequacy of the alternative solutions (Bauer \& Curran, 2003; Marsh et al., 2009; Muthén, 2003). Fortunately, statistical indices are also available to guide this decision (McLachlan \& Peel, 2000). Thus, lower values on the Bayesian Information Criterion (BIC), sample-size Adjusted BIC (ABIC), Akaïke Information Criterion (AIC), and Consistent AIC (CAIC) indicate a better fitting model. In addition, a statistically significant p-value associated with the adjusted Lo, Mendell, and Rubin's (2001) Likelihood Ratio Test (aLMR) and the Bootstrap Likelihood Ratio Test (BLRT) supports the added value of a solution when contrasted with a solution including one less profile. Statistical studies support the accuracy of the CAIC, BIC, ABIC, and BLRT, but not that of the AIC and aLMR (Diallo et al., 2016, 2017; Henson, Reise, \& Kim, 2007; Nylund, Asparouhov, \& Muthén 2007; Peugh \& Fan, 2013; Tein, Coxe, \& Cham, 2013; Tofighi \& Enders, 2008; Yang, 2006). We thus only report these indicators (AIC and aLMR) for complete disclosure, but do not use them to guide the selection of the solutions.

Furthermore, all of these indicators remain heavily influenced by sample size, so that it often happens that they key on suggesting the addition of latent profiles to the solution without ever converging on a specific model (Marsh et al., 2009). In this situation, the point at which the decrease in the value of these indicators reaches a plateau, on a graphical display called an elbow plot, can be used to suggest the optimal solution (Morin et al., 2011). In practice, the various statistical indicators are typically inspected first, and use to select a range of acceptable solutions which are then inspected for theoretical conformity and evidence that additional profiles add meaning to the solution (e.g. Meyer \& Morin, 2016). In tests of profile similarity, Morin, Meyer et al. (2016) suggest that at least two indices out of the CAIC, BIC, and ABIC should be lower for the more "similar" model for the hypothesis of profile similarity to be supported. Finally, the entropy (ranging from 0 to 1 ) indicates the precision with which the cases are classified into the various profiles, but should not be used to guide model selection.

\section{Results}

\section{Latent Profile Analyses and Tests of Profile Similarity}

The fit indices associated with the sample-specific LPA are reported in Table S12 of the online supplements. Matching elbow plots are reported in Figure S1 of the online supplements. In Sample 1 (managers), the CAIC reached its lowest point for the five-profile solution and the BIC reached its lowest point for the six-profile solution. In Sample 2 (hospital workers) both of these indicators reached their lowest point for the seven-profile solution. In Sample 3 (nurses), the CAIC reached its lowest point for the six-profile solution and the BIC reached its lowest point for the seven-profile solution. In Sample 4 (physiotherapists) none of these indices converged on a specific solution. Likewise, across all four samples, neither the ABIC nor the BLRT converge on any specific solution. These results thus roughly suggest that the optimal number of profiles, across all samples, seems to be located between the five- and seven-profile solutions, an interpretation that is generally supported by the elbow plots. The five-, six-, and seven-profile solutions were thus more specifically examined. This examination revealed that all of these solutions were statistically proper, and already showed a high level of similarity across samples (with some more obvious differences associated with the nurse sample (Sample 3). This apparent similarity thus already provides some support to the configural similarity of the model across samples. Moreover, this examination revealed that up to six profiles, each increase resulted in the addition of a meaningful profile to the solution. In some cases, distinct profiles present in the five-profile solution appeared where they were previously missing when moving to the six-profile solution. In contrast, adding a seventh profile only resulted in the arbitrary 
division of an existing profile into smaller ones including five participants or less in two of the samples. Supporting Hypothesis 1 which led us to expect between four and six profiles, the six-profile solution was retained across samples and formed the baseline model of configural similarity used in tests of profile similarity.

The results from the multi-sample tests of profile similarity conducted on the basis of this sixprofile solution are reported Table 1. The next model of structural similarity, although it resulted in a slightly lower CAIC value than the model of configural similarity, also resulted in higher values on the BIC and ABIC, suggesting that the structure of the profiles may not be fully identical across the four samples. Following procedures outlined in Litalien, Morin, and McInerney (2017) for tests of partial structural similarity, we first conducted a detailed visual inspection of the nature of the profiles identified in each of the samples in the previous model of configural similarity. This examination suggested that at least five out of six profiles appeared to be roughly identical across all samples, while the remaining profile appeared different in the nurse sample (Sample 3). We thus re-estimated a model of partial structural similarity in which the structure of the first five profiles was constrained to equality across all samples, while the structure of the sixth profile was constrained to equality across Samples 1 (managers), 2 (hospital workers), and 4 (physiotherapists), but allowed to differ in the nurse sample (Sample 3). This model resulted in lower values on the CAIC and the BIC than the model of configural similarity, and was thus supported by the data. From this model, the next models of dispersion and distributional similarity also resulted in lower values on the CAIC and BIC, and were thus both supported by the data. Finding evidence of dispersion and distributional similarity, even for the profile that was structurally dissimilar across groups, suggests that this profile might possibly tap into similar psychological mechanisms for the nurses as it does in the other samples. Globally, these results address our Research Question by providing evidence of configural similarity, partial structural similarity, and dispersion similarity across samples. However, the observation of distributional similarity, in showing that the relative frequency of profiles remains the same across samples, fails to support Hypothesis 7.

\section{Profile Description}

This final model of dispersion and distributional similarity, build from the model of partial structural similarity, was thus retained for interpretation. This model is illustrated in Figure 1, and the exact parameter estimates from this solution are reported in Tables S13 and S14 of the online supplements. They reveal a high level of classification accuracy of participants into their most likely profiles, ranging from $86.1 \%$ to $94.6 \%$ across profiles in Sample 1 (managers), $84.2 \%$ to $96.7 \%$ for Sample 2 (hospital workers), $85.9 \%$ to $93.5 \%$ for Sample 3 (nurses), and $88.1 \%$ to 95.0\% for Sample 4 (physiotherapists), consistent with the high entropy value associated with this solution (.928).

Profile 1 characterized employees with moderately high levels of global self-determination coupled with moderately high specific levels of intrinsic motivation, average specific levels of external regulation, moderately low specific levels of identified regulation and amotivation, and very high specific levels of introjected regulation. This Self-Driven Introjected profile corresponded to $20.43 \%$ of the employees across samples and supports Hypothesis 5. Profile 2 characterized employees with very low levels of global self-determination, coupled with very low specific levels of intrinsic motivation, low specific levels of identified regulation, and high specific levels of introjected regulation, external regulation, and amotivation. This Externally Driven profile corresponded to $9.27 \%$ of the employees across samples and supports Hypothesis 4.

Profile 3 and 4 were somewhat similar in shape, and characterized employees presenting moderately low global levels of global self-determination, coupled with moderately low specific levels of identified regulation and low specific levels of introjected regulation. Profile 3 also presented moderately high specific levels of intrinsic motivation, coupled with moderately low specific levels of external regulation and amotivation. In contrast, Profile 4 presented high specific levels of intrinsic motivation, coupled with low specific levels of external regulation and average levels of amotivation. We thus decided to refer to Profile 3 , which characterized $14.82 \%$ of the participants across samples, as being Moderately Intrinsically Motivated, and to the more extreme and less frequent (10.42\%) Profile 4 as being Highly Intrinsically Motivated. These two profiles generally support Hypothesis 3.

Profile 5 characterized employees presenting moderately high global levels of self-determination, coupled with moderately high specific levels of identified regulation and external regulation, moderately low specific levels of intrinsic motivation and introjected regulation, and average levels of 
amotivation. This Value-Reward Self-Driven profile characterized $31.69 \%$ of the participants across samples who seemingly were motivated to work for a combination of self-determined reasons linked to their personal value system as well as seeking external rewards.

Profile 6, despite the fact that it characterized $13.38 \%$ of the participants across samples, presented a slightly different structure among Sample 3 (nurses) than among the other samples. Among Samples 1 (managers), 2 (hospital workers), and 4 (physiotherapists), this profile characterized employees presenting high global levels of self-determination, coupled with equally high specific levels of identified regulation, low specific levels of intrinsic motivation and external regulation, moderately low specific levels of introjected regulation, and average specific levels of amotivation. In contrast, among Sample 3 (nurses), this profile of employee presented high global levels of self-determination, coupled with very high specific levels of intrinsic motivation, high specific levels of amotivation, average specific levels of identified motivation, and low specific levels of introjected and external regulations. Thus, essentially, this Self-Driven Hedonist profile seems to tap into similar processes across samples, although this process involves intrinsic motivation for nurses relative to identified regulation for other employees, and tend to be associated with higher levels of amotivation for nurses. Taken together, Profiles 5 and 6 support Hypothesis 6. In contrast, none of the identified profiles displayed a Strongly Motivated configuration, thus failing to support Hypothesis 2.

\section{Predictors of Profile Membership}

As shown in Table 1, when the predictors were included into the model, the results supported the model of predictive similarity, which resulted in the lowest values for the CAIC, BIC, and ABIC when compared to the model in which relations between predictors and profiles were allowed to vary across samples. The results from this model of predictive similarity are reported in Table 2 . Looking first at the effects of demographic characteristics, neither work time nor tenure did predict employee likelihood of membership into any of the profiles, while age only predicted a slightly higher likelihood of membership into the Moderately Intrinsically Motivated profile (Profile 3) relative to the ValueReward Self-Driven profile (5). However, being a female was associated with a higher likelihood of membership into the Self-Driven Hedonist profile (6) relative to the Self-Driven Introjected (1), Externally Driven (2), Moderately Intrinsically Motivated (3), and Value-Reward Self-Driven (5) profiles, whereas being a male was associated with a higher likelihood of membership in the Externally Driven profile (2) relative to the Self-Driven Introjected (1), Moderately Intrinsically Motivated (3), Highly Intrinsically Motivated (4), and Value-Reward Self-Driven (5) profiles.

Turning our attention to the theoretically-driven predictors, we first note that employees' perceptions of workload and organizational support present a relatively systematic pattern of associations with profile membership. Thus, higher workload perceptions predicted a higher likelihood of membership into the Self-Driven Introjected (1) and Externally Driven (2) profiles relative to the Moderately Intrinsically Motivated (3), Highly Intrinsically Motivated (4), and Self-Driven Hedonist (6) profiles. It also predicted a higher likelihood of membership into the Value-Reward Self-Driven (5) profile relative to the Moderately Intrinsically Motivated (3) and Highly Intrinsically Motivated (4) profiles, as well as into the Self-Driven Introjected (1) profile relative to the Value-Reward Self-Driven (5) one. These results thus support Hypothesis 10. In contrast, higher levels of perceived organizational support predicted an increased likelihood of membership into the Self-Driven Introjected (1), Highly Intrinsically Motivated (4), and Value-Reward Self-Driven (5) profiles relative to the Externally Driven (2) and Self-Driven Hedonist (6) profiles, as well as into the Self-Driven Introjected (1) and Value-Reward Self-Driven (5) profiles relative to the Moderately Intrinsically Motivated (3) one. Finally, whereas employees' perceptions of supervisor support presented no associations with their likelihood of membership into any of the profiles, their perceptions of colleagues support predicted an increased likelihood of membership into all profiles (1, 3, 4, 5, and 6) relative to the Externally Driven (2) one. These associations partially support Hypothesis 11.

\section{Outcomes of Profile Membership}

As shown in Table 1, when the outcomes were included into the model, the results supported the model of explanatory similarity, which resulted in the lowest values for the CAIC, BIC, and ABIC when compared to the model in which relations between profiles and outcomes were allowed to vary across samples. This evidence of similarity, obtained at the level of the predictors and of the outcomes, further reinforces the idea that the sixth profile taps into similar psychological processes across all samples. The results from this model of explanatory similarity are reported in Table 3. 
These results first reveal that levels of presenteeism were the highest, and levels of work performance the lowest, in the Externally Driven (2) profile, followed by the Self-Driven Introjected (1) and Value-Reward Self-Driven (5) profiles which did not differ from one another, and then by the Highly Intrinsically Motivated (4) and Self-Driven Hedonist (6) profiles which also did not differ from one another. Presenteeism levels were also higher, and levels of work performance lower, in the Externally Driven (2) profile than in the Moderately Intrinsically Motivated (3) profile, which otherwise did not significantly differ from the remaining profiles on these two outcome variables. Absenteism levels, however, were far more similar across profiles, but were still higher in the Moderately Intrinsically Motivated (3) profile than in the Value-Reward Self-Driven (5) profile. Finally, turnover intentions were the highest in the Externally Driven (2) profile, followed by the Value-Reward Self-Driven (5) profile, and then equally by the Moderately Intrinsically Motivated (3) the Highly Intrinsically Motivated (4), and Self-Driven Hedonist (6) profiles which did not differ from one another. In addition, turnover intentions were higher in the Externally Driven (2) profile than in the Self-Driven Introjected (1) profile, which otherwise did not significantly differ from the remaining profiles on this outcome variable. Taken together, these results partially support Hypotheses 8 and 9 .

\section{Discussion}

Prior variable-centered research has demonstrated that the different types of behavioral regulation proposed by SDT presented moderate to strong inter-correlations generally matching a simplex pattern, while presenting well-differentiated relations with various covariates (Deci et al., 2017; Gagné \& Deci, 2005; Ryan \& Deci, 2017). Anchored in the recognition that employees' work motivation tends to be underpinned by more than one of these types of behavioral regulation, scientific attention has also tried to identify the most commonly occurring behavioral regulation profiles (Fernet et al., 2020; Gillet, Becker et al., 2017; Gillet et al., 2018; Graves et al., 2015; Howard et al., 2016; Jansen in de Wal et al., 2014; Moran et al., 2012; Van den Berghe et al., 2014; Van den Broeck et al., 2013). Despite evidence of consistency related to the nature of the motivational profiles identified as part of these research efforts, only one of these studies (Fernet et al., 2020) relied on a bifactor approach to achieve a clear disaggregation of employees' global levels of self-determined work motivation from the unique qualities associated with each specific type of behavioral regulation (Howard et al., 2018; Litalien, Morin, Gagné et al., 2017; Ryan \& Deci, 2017).

The present study was designed to contribute to this area of research via the identification of work motivation profiles among four distinct samples of employees, and to do so while relying on a proper disaggregation of workers' ratings of their global levels of self-determination (reflecting the SDT selfdetermination continuum as indicated by the items' loadings on the general factor, which followed their theoretical position on the continuum; also see Howard et al., 2018; Litalien, Morin, Gagné et al., 2017) from more specific ratings of the quality of their behavioral regulations. We expanded upon prior results obtained by Fernet et al. (2020) among nurses by directly assessing the generalizability of the profiles occurring across samples of managers, hospital employees, nurses, and physiotherapists. Finally, to better document the practical relevance of these work motivation profiles, we investigated the role of job demands (workload) and resources (perceived organizational, supervisor, and colleagues support) as predictors of profile membership, as well as the implications of these profiles in terms of attitudes and behaviors (presenteeism, turnover intentions, work performance, and absenteeism).

\section{Employees' Work Motivation Profiles}

Despite some minor differences related to the shape of one of the profiles, which we address shortly, our results revealed that six distinct profiles best represented the work motivation configurations observed across samples of managers, hospital employees, nurses, and physiotherapists. These profiles differed from one another both in terms of their global levels of self-determination but also in terms of specific levels of behavioral regulations, and displayed a configuration that could be qualified as: (1) Self-Driven Introjected; (2) Externally Driven; (3) Moderately Intrinsically Motivated; (4) Highly Intrinsically Motivated; (5) Value-Reward Self-Driven; and (6) Self-Driven Hedonist. We identified three profiles characterized by moderate to high levels of global self-determination (SelfDriven Introjected, Value-Reward Self-Driven, and Self-Driven Hedonist), and one profile characterized by low levels of global self-determination and moderate to high specific levels of introjected regulation, external regulation, and amotivation (Externally Driven). Likewise, these six motivation profiles were characterized by well-differentiated configurations of motivation, and at least 
two of them were characterized by well-differentiated specific levels of introjected and external regulations (Self-Driven Introjected and Value-Reward Self-Driven). These profiles thus generally matched our expectations and prior person-centered results (Fernet et al., 2020; Gillet et al., 2018; Howard et al., 2016; Moran et al., 2012). This similarity of results reinforces the robustness of our findings and the possible usefulness of devising interventions targeting specific profiles of employees.

Despite this similarity of results with those from prior research, these profiles also emphasize, as in the Fernet et al.'s (2020) study, the importance of adopting a finer-grained representation of work motivation by simultaneously considering global levels of self-determination and the specific nature of the different types of behavioral regulation over and above this global level of self-determination. These specific facets reflect the extent to which levels on each behavioral regulation deviate from that global level. In particular, results showed that the six profiles presented a configuration where employees' levels on specific behavioral regulations deviated from their global level of selfdetermination and from the sample average. This result suggests that motivation levels are not aligned across dimensions, which may explain why, contrary to our expectations, we did not identify a profile characterized by high and matching levels of motivation across dimensions.

The Self-Driven Hedonist profile presented a different configuration among nurses relative to other types of employees. Among nurses, this profile was characterized by high global levels of selfdetermination, coupled with very high specific levels of intrinsic motivation, and high specific levels of amotivation, while presenting average to low specific levels of identified, introjected, and external regulations. In the three other samples (managers, hospital workers, and physiotherapists), this SelfDriven Hedonist profile was characterized by similarly high global levels of self-determination. However, these levels were coupled with equally high specific levels of identified regulation, and average to low specific levels on the other forms of regulation. In summary, the key difference lies in the higher specific levels of intrinsic motivation and amotivation observed among nurses relative to the higher specific levels of identified regulation observed among managers, hospital workers, and physiotherapists. These findings are aligned with prior research suggesting that amotivation tends to be more frequent among nurses due to their constant exposition to a range of administrative duties (Sullivan, Norris, Brown, \& Scott, 2017). This Self-Driven Hedonist profile shares similarity with the Hedonist profile identified by Litalien, Gillet, Gagné, Ratelle, and Morin (2019) among undergraduate university students. This profile thus seems to present a self-driven orientation to work dominated by a desire to conduct activities that are either seen as implicitly satisfying (nurses) or as in accordance with their personal values (other employees), while simultaneously experiencing an average (others) to high (nurses) specific levels of amotivation when completing less stimulating components of their jobs (e.g., clerical work).

When considering the other profiles, they also shared similarities with those identified in previous research. Thus, the Self-Driven Introjected profile was found to share similarities with the Moderate Autonomous-High Introjected-Moderate External profile identified by Gillet et al. (2018) and with the Moderately Motivated profile identified by Fernet et al. (2020). The next two profiles, presenting Moderately Intrinsically Motivated and Highly Intrinsically Motivated configurations, rather appear to share similarities with the Moderately Autonomous profile identified by Howard et al. (2016) and with the Self-Determined profile identified by Fernet et al. (2020). The Value-Reward Self-Driven profile was found to share similarities with the Moderate Autonomous/Introjected/External profile identified by Gillet et al. (2018), with the Moderate profile identified by Gillet, Becker et al. (2017) and Moran et al. (2012), and with the Moderately Motivated profile identified by Jansen in de Wal et al. (2014). Finally, the last profile displayed a less desirable, Externally Driven, configuration, and shared similarities with the Externally Regulated profile identified by Jansen in de Wal et al. (2014), with the Low Autonomy profile identified by Moran et al. (2012), and with the Poorly Motivated profile identified by Fernet et al. (2020). Taken together, this similarity across studies supports the idea that the present profiles tap into meaningful psychological processes, just as the observed differences support the importance of adopting a more accurate representation of the multidimensionality of motivation.

By providing the first direct source of evidence that motivational profiles defined according to the recently recommended bifactor operationalization (e.g., Howard et al., 2018) generalize across samples of workers from different occupational groups, the present study represents an important step forward in motivation research. Indeed, by providing evidence of generalizability across occupational 
groups, it supports the possibility of devising generic intervention strategies likely to be relevant to many employees without having to worry that the nature of motivation profiles may change drastically across occupations. Our findings also have theoretical implications for SDT in demonstrating the value of simultaneously taking into account participants' localization on the global SDT continuum of selfdetermination, together with the unique quality of their behavioral regulations. The reliance on a more traditional approach (ignoring global levels of self-determination) would have simply resulted in the estimation of profiles matching the continuum but revealing little value to considering the unique nature of each behavioral regulation over and above that continuum, such as those reported by Howard et al. (2016) and Gillet et al. (2018). In contrast, our results show that, as expected by SDT (Howard et al., 2018; Litalien, Morin, Gagné et al., 2017), both components seem to play a role in the definition of work motivation profiles, and thus bring valuable information to our understanding of work motivation.

\section{Outcomes of Profile Membership}

The present study also contributes to our understanding of the implications of work motivation profiles in terms of employees' attitudes and behaviors. In this regard, results generally matched our expectations and previous results in supporting the role of employees' global levels of selfdetermination in the prediction of a variety of outcomes (e.g., Fernet et al., 2020; Gillet et al., 2018; Howard et al., 2016; Moran et al., 2012; Van den Broeck et al., 2013). Indeed, employees with the lowest levels of global self-determination (Externally Driven) displayed the highest levels of presenteeism and turnover intentions, and the lowest levels of work performance, whereas Self-Driven Hedonist employees presented the most desirable outcome levels (e.g., higher levels of work performance, lower levels of presenteeism and turnover intentions). More generally and despite a few differences, Externally Driven employees displayed a more maladaptive pattern of functioning than those characterized by higher levels of global self-determination. These results provide insights into how work motivation can prevent detrimental outcomes. Although scholars have begun to recognize that motivation quality has significant effects on various work outcomes (Deci et al., 2017; Gagné \& Deci, 2005), it is generally assumed that employees' levels of autonomous and controlled types of behavioral regulation are independent and mutually exclusive. The present results challenge this assumption, suggesting that global levels of self-determination might be a core motivational driver of work behaviors, and one that plays a role across occupational groups.

However, not all profiles systematically differed on all outcomes in a way that fully matched our expectations (Ryan \& Deci, 2017). For instance, the levels of presenteeism and work performance observed in the Self-Driven Hedonist profile were impossible to distinguish from those observed in the High Intrinsically Motivated one. Similarly, the levels of turnover intentions observed in the SelfDriven Hedonist profile were impossible to distinguish from those observed in the High Intrinsically Motivated and Moderately Intrinsically Motivated ones. Furthermore, the combination of moderately low levels of global self-determination and moderately high to high specific levels of intrinsic motivation (High Intrinsically Motivated and Moderately Intrinsically Motivated) seemed to be more adaptive than the combination of moderately high global levels of self-determination and moderate to low specific levels of intrinsic motivation (Value-Reward Self-Driven and Self-Driven Introjected).

Contrary to our expectations, our findings revealed that the profile characterized by the highest global levels of self-determination (Self-Driven Hedonist) was associated with outcome levels similar to those observed in profiles characterized by moderately low levels of global self-determination but moderately high to high specific levels of intrinsic motivation. Due to our bifactor operationalization of work motivation, these unexpected findings suggest that pure intrinsic motivation might be able to buffer the negative effects of lacking a more widespread global self-determination tendency. This observation is aligned with prior studies demonstrating the positive role of intrinsic motivation in the prediction of various outcomes (Liu, Hau, \& Zheng, 2019; Waaler, Halvari, Skjesol, \& Bagøien, 2013). These findings are also consistent with those reported by Litalien, Morin, Gagné et al. (2017) and Howard et al. (2018) showing that low specific levels of intrinsic motivation were associated with higher levels of ill-being and lower levels of satisfaction. However, it remains to be seen how practically important these unique regulation qualities are in comparison to global levels of selfdetermination when considering a broader range of outcomes, occupations, and work contexts.

Moreover, whereas turnover intentions were impossible to distinguish between the Highly Intrinsically Motivated profile and the Self-Driven Introjected one, this latter profile presented higher 
presenteeism and lower work performance than the former. These results confirm that intrinsic motivation is associated with more adaptive outcomes than introjected regulation (Deci et al., 2017; Liu et al., 2019; Waaler et al., 2013), while also suggesting that the harmful effects of introjected regulation may be limited to specific outcomes, as demonstrated in previous studies (Gillet, Becker et al., 2017; Gillet et al., 2018). Yet, the results also show that the levels of presenteeism, turnover intentions, and work performance observed in the Self-Driven Introjected profile were impossible to distinguish from those observed in the Moderately Intrinsically Motivated and Value-Reward SelfDriven ones. This result supports previous reports suggesting that the harmful effects of introjected regulation may be offset when combined with high specific levels of intrinsic motivation or global levels of self-determination (Gillet, Becker et al., 2017; Gillet et al., 2018; Moran et al., 2012), and the need to consider introjected and external regulations as distinct forms of controlled regulation likely to have widely divergent implications (Gagné et al., 2015; Wang et al., 2016).

Finally, the absenteeism levels were impossible to distinguish across profiles, with the exception of being higher in the Moderately Intrinsically Motivated profile than in the Value-Reward Self-Driven one. This is consistent with the idea that many factors out of employees' control (e.g., sickness, traffic, childcare) might play a role in absenteeism (Johns \& Al Hajj, 2016), thus leading to weaker associations with work motivation (Nicholson, 2007).

Altogether, these results clearly support the central importance of workers' levels of global selfdetermination. However, the identification of distinct Moderately Intrinsically Motivated and Highly Intrinsically Motivated profiles, and the slight outcome differences observed between them also reinforce the role played by the unique qualities of employees' behavioral regulations, although less marked than that of the global self-determination factor. Implications are thus well-aligned with SDT operationalization of motivation (Ryan \& Deci, 2017) in supporting both the key role played by employees' position on the self-determination continuum, while also supporting the importance of considering the unique qualities of each behavioral regulation. While our results related to the role played by the unique qualities of the specific regulations factors were limited in the current study, these results still serve as a "proof of concept". In doing so, our results also reinforce the importance for future research to consider a broader range of desirable (e.g., organizational citizenship behaviors, well-being) and undesirable (e.g., work-family conflict, counterproductive behaviors) outcomes in order to better document the unique roles played by global, and specific, aspects of work motivation.

\section{Determinants of Profile Membership}

A final objective of this study was to investigate possible determinants of employee membership into the various work motivation profiles. Looking first at the effects of demographic characteristics, neither work time nor tenure did predict employee likelihood of membership into any of the profiles. In contrast, age predicted an increased likelihood of membership into the Moderately Intrinsically Motivated profile relative to the Value-Reward Self-Driven one. This result is consistent with the idea that global levels of self-determination tend to decrease as a function of age (e.g., Corpus, McClinticGilbert, \& Hayenga, 2009; Gillet, Vallerand, \& Lafrenière, 2012). Moreover, being a female was associated with a higher likelihood of membership into the profile characterized by the highest levels of global self-determination (Self-Driven Hedonist), whereas being a male was associated with a higher likelihood of membership in the profile characterized by the lowest levels of global selfdetermination (Externally Driven). These results are in line with those obtained in prior variablecentered studies showing that females tend to report higher levels of autonomous motivation than males (Bonneville-Roussy et al., 2017; Vallerand et al., 1997), and in past person-centered research demonstrating that men were underrepresented in a profile characterized by high levels of intrinsic motivation coupled with low levels of external regulation and amotivation (Gillet, Vallerand, \& Paty, 2013). However, it is noteworthy that all the four samples are female-dominated (e.g., $95 \%$ of females in Sample 3). Future research is thus needed to generalize these findings to other more representative samples of workers taken from a variety of work settings.

Consistent with the view that the work environment entails conditions that direct and energize workers' behaviors (Deci et al., 2017), our findings shed new light on modifiable work characteristics involved in the prediction of membership into the diverse work motivation profiles. More precisely, our results revealed that workload predicted an increased likelihood of membership into the profiles characterized by low global levels of self-determination (Externally Driven) and by high specific levels of introjected regulation (Self-Driven Introjected) relative to the other profiles. It also predicted 
a higher likelihood of membership into the Value-Reward Self-Driven profile (characterized by moderately high external regulation) relative to the Moderately Intrinsically Motivated and Highly Intrinsically Motivated profiles (characterized by moderately low to low external regulation). Although the detrimental effects of job demands, such as workload, have been abundantly demonstrated (e.g., Bakker \& Demerouti, 2007), our findings provide empirical support for these negative effects in relation to employees' work motivation profiles. These results thus enrich and match those from past studies showing workload to decrease autonomous forms of motivation, and to foster controlled types of behavioral regulation and amotivation (Kim \& Beehr, 2018; Trépanier et al., 2013). These associations are likely due to the thwarting of psychological needs for autonomy, competence, and relatedness associated with job demands (Gillet, Forest, Benabou, \& Bentein, 2015; Gillet, Fouquereau, Huyghebaert, \& Colombat, 2015).

More generally, these results suggest that the effects of workload might be more pronounced when global levels of self-determination are considered than when specific behavioral regulations are considered. Although previous research relying on a bifactor operationalization of motivation has documented the outcome implications of participants' global and specific levels of work motivation (Fernet et al., 2020; Howard et al., 2018; Litalien, Morin, Gagné et al., 2017), the examination of the nomological network of these global and specific factors has rarely considered predictors. As such, the present results add to those previously reported by Fernet et al. (2020) in which no association was found between a global measure of job demands and profile membership among nurses, to demonstrate that more specific forms of job demands (i.e., workload in the present study), had a role to play in predicting profile membership among nurses, but also among other occupational groups. However, further work on determinants of general and specific factors of motivation is still required to further document their complete nomological network, and more specifically to determine what factors may be responsible for membership in either the Externally Driven or Self-Driven Hedonist profiles.

Results related to job resources displayed a different pattern of associations with profile membership. Thus, employees' perceptions of colleagues support predicted a decreased likelihood of membership into the Externally Driven profile relative to the five other profiles (characterized by higher levels of global self-determination). These results are in line with research showing that employees' perceptions of social support predicted various positive motivational outcomes (Battistelli et al., 2017; Moran et al., 2012). The effects of perceived organizational support were, however, more surprising. Indeed, higher levels of perceived organizational support predicted an increased likelihood of membership into the Self-Driven Introjected, Highly Intrinsically Motivated, and Value-Reward Self-Driven profiles relative to the Externally Driven and Self-Driven Hedonist ones. In other words, perceived organizational support predicted a decreased likelihood of membership into the profiles characterized by very low (Externally Driven) or very high (Self-Driven Hedonist) global levels of self-determination. These findings provide support for the premise that work motivation stems from the relationships workers share with their organization (Fernet et al., 2020).

Interestingly, prior studies (Gillet, Gagné et al., 2013) suggested that, in some circumstances, perceived organizational support could be positively related to both autonomous and controlled forms of motivation. Moreover, prior variable-centered results have revealed curvilinear relations between perceived organizational support and a variety of motivational outcomes (Burnett, Chiaburu, Shapiro, \& Li, 2015; Gigliotti, Vardaman, Marshall, \& Gonzalez, 2019; Harris \& Kacmar, 2018). More specifically, these studies have shown that the most desirable outcomes tend to be associated with moderate to moderately high levels of perceived organizational support. In line with this perspective, Gillet, Morin, Huart, Colombat, and Fouquereau (2019) recently found that perceived organizational support was negatively linked to specific levels of imbalance in the satisfaction of employees' need for competence. This suggests that high levels of perceived organizational support might lead employees to believe that their organization has doubts regarding their competence, ultimately leading to negative consequences. Interestingly, similar curvilinear relations have been reported regarding the relations between affective commitment to the organization, customers, and colleagues and measures of in role performance, cynicism, and professional efficacy (Morin, Vandenberghe, Turmel, Madore, \& Maïano 2013). It would thus be interesting for future studies to more systematically probe for possible nonlinearity when assessing the effects of perceived organizational support, possibly via the adoption of a person-centered perspective simultaneously considering various forms of social support perceptions.

Furthermore, employees' perceptions of supervisor support did not predict their likelihood of 
membership into any of the profiles. This result differs from our expectations (Gillet, Fouquereau et al., 2012), which could possibly be explained by our adoption of a multivariate perspective in which three various sources of social support at work were simultaneously considered. This approach allowed us to identify the most potent predictors of profile membership once the variance shared among these various sources of social support was considered. Indeed, as shown in Table S11 of the online supplements, these sources of social support were found to be moderately correlated with one another and to present similar univariate associations with the levels of global self-determination. More generally, our findings further encourage researchers to look into how various sources of social support at work - rather than to focus on global measures of social support (Moran et al., 2012) or job resources (Fernet et al., 2020) - uniquely contribute to employees' motivation profiles.

Taken together, our results are aligned with Ng and Sorensen's (2008) findings, which showed that the effects of different sources of social support may sometimes be very dissimilar. Future research needs to more extensively look at positive workplace characteristics that might curb low levels of global self-determination and try to unpack the mechanisms underlying the relations between perceived organizational and supervisor support and work motivation.

\section{Practical Implications}

From an intervention perspective, the present research shows that it is possible to target the workers who are most likely to present an adaptive motivation profile as opposed to those who are at risk for persistent motivational deficits. Importantly, it also suggests that these more, and less, desirable motivational profiles seem to generalize across a variety of occupational groups. In addition, our results also support the need to find ways to promote global levels of self-determination (relative to any specific type of behavioral regulation) via encouraging the internalization process whereby employees can come to perceive a stronger match between their own values and professional goals and those of the organization for which they work (Fernet et al., 2020). Our results also show that managers ought to be particularly attentive to workers exposed to low levels of perceived colleagues support. Indeed, these individuals are subjected to the lowest levels of global self-determination which expose them to higher risks of maladaptive functioning. Therefore, changes in a work organization designed to increase the level of colleagues support sustainably might prove particularly useful to help employees internalize in a self-driven manner the skills, values, and behaviors needed to perform their job (Ryan \& Deci, 2017). Despite these implications, it is highly unlikely that employees characterized by the Externally Driven profile would be able to rapidly vault to profiles characterized by higher levels of global self-determination (e.g., Self-Driven Hedonist) on the basis of short-term interventions with no training transfer efforts (Fernet et al., 2020). For this reasons, a strategy of small steps with gradual and progressive changes would be recommended as the most effective.

Interestingly, the three sources of social support (i.e., organization, supervisor, and colleagues) tend to aligned with one another for most employees (Caesens, Gillet, Morin, Houle, \& Stinglhamber, 2019). This observation is aligned with the trickle-down effect (Eisenberger \& Stinglhamber, 2011), suggesting that social support from one source tends to spread out to other sources, and with the idea that perceived organizational support may elicit among employees the belief that the organization expects them to be supportive toward others (e.g., Frear, Donsbach, Theilgard, \& Shanock, 2017; Shanock \& Eisenberger, 2006). Thus, initiatives aiming to increase any one source of social support at work are likely to have widespread benefits. Among possible ways to achieve this objective, top management might promote a supportive culture, for instance, by promoting fairness in the application of policies (Eisenberger \& Stinglhamber, 2011). Furthermore, informal mentoring activities and social events might also help to build a stronger workplace support climate among colleagues (Newman, Thanacoody, \& Hui, 2012). The endpoint of these strategies is to create a workplace characterized by supportive and positive interactions among colleagues in an ongoing manner (Newman et al., 2012). More generally, organizations might profit from interventions such as promoting psychological need satisfaction in the workplace (Gillet, Morin, \& Reeve, 2017; Gillet, Morin, Choisay, \& Fouquereau, 2019). Among ways to do this, top management could reduce employee work overload and promote justice and fairness in terms of policy implementation and rewards distribution (Gagné \& Deci, 2005).

\section{Implications for Theory, Research, and Assessment}

From a theoretical perspective, SDT (Ryan \& Deci, 2017) has always advocated the apparently ambiguous proposition that employees' motivation was characterized by a combination of meaningfully distinct forms of motivation (i.e., a multidimensional approach), and yet that these 
behavioral regulations would be organized along a single underlying continuum (i.e., a onedimensional approach). Recent research has shown that it was possible for SDT to "have its cake and eat it too" (Howard et al., 2018; Litalien, Morin, Gagné et al., 2017), showing that levels of global selfdetermination reflecting the self-determination continuum were able to co-exist with types of motivation retaining a meaningful level of specificity and explanatory power. The current study adds to this body of research by supporting this dual nature of workers' motivation (Fernet et al., 2020; Howard et al., 2018; Litalien, Morin, Gagné et al., 2017). The present research also shows that it is possible to identify workers' profiles that simultaneously consider the levels of global selfdetermination alongside the unique quality of the specific forms of motivation over and above that global level. Modeling profiles in this manner allows scholars to avoid conflating the degree of selfdetermination with regulation-specific characteristics. In doing so, this approach makes it possible to more clearly identify global levels of self-determination as the crucial component underlying relations with predictors and outcomes, while also making it possible to more clearly assess the added-value of each specific type of motivation. However, additional research is needed on the nature, determinants, and outcomes of these global and specific facets of work motivation to expand our understanding of the motivational processes in the work area.

From a research perspective, this study reinforces the need for SDT researchers to incorporate similar methods as part of their routine set of statistical analyses. Beyond motivation, previous research has also shown the suitability of bifactor models to provide a more accurate representation of multiple constructs known to be closely related to work motivation, such as need satisfaction and frustration (Gillet, Morin, Choisay, \& Fouquereau, 2019; Gillet, Morin, Huart et al., 2019; TóthKirály, Morin, Bőthe, Orosz, \& Rigó, 2018), psychological health and well-being (Morin, Boudrias et al., 2016, 2017), work engagement (Gillet, Caesens, Morin, \& Stinglhamber, 2019; Gillet, Morin, Jeoffrion, \& Fouquereau, 2020), and workplace commitment (Perreira et al., 2018). The present study demonstrates the importance of incorporating this perspective into the initial stages of any investigation relying on these constructs to identify global and specific factors. Failure to consider that is likely to lead to erroneous conclusion regarding the unique, and combined, impact of the various dimensions. Ignoring this form of multidimensionality is thus likely to lead to a biased view of the validity of the work motivation construct and of the reality under study. For applied researchers interested in work motivation, this means that the ability to obtain a clear and valid estimate of the way work motivation ratings related to other constructs of interest is likely to be biased, and more importantly to lead to biased recommendations for practice.

Finally, from an assessment perspective, in order to avoid work motivation estimates reflecting a confusing mixture of global and specific variance likely to be tainted by multicollinearity, researchers and practitioners are thus invited to consider adopting a bifactor-ESEM representation of work motivation. This recommendation strongly advocates a latent variable approach to research. Yet, this recommendation is not as easy to transpose to the professional context where practitioners and organizations need to be able to score motivation questionnaires. In these contexts, automated scoring procedures relying on calculations similar to those involved in the generation of the factor scores used in the present study will need to be developed. As noted by Perreira et al. (2018), the Mplus statistical package could be used in such a manner on the basis of the parameter estimates obtained in the present study. A key advantage of this approach is that the resulting scores will be directly estimated in standardized units, and thus interpretable as a function of the sample mean and standard deviation, just like normed scores, making it easier to identify the most likely profile membership of employees. Yet, as with any norm, this consideration reinforces the importance for future research to rely on more representative samples prior to the development of any practically-useful scoring procedure.

However, this recommendation is limited to the availability of samples of participants and cannot be applied to individual participants. As such, this option might be limited to research purposes, or to large scale organizational assessment contexts where numbers, as well as resources (i.e., financial and statistical) are sufficient. We acknowledge that this is unlikely to be the case for many professional applications of motivation measurement. For this context, traditional scoring procedures will need to be maintained, but ideally coupled with the acknowledgement that they might not provide an optimal bifactor representation of work motivation, at least, pending the development or automated scoring procedures, such as those already used for other types of measurement. It is our hope that, upon reading this study, some statisticians may be motivated, ideally for intrinsic reasons, to devise such an 
automated scoring platform, and perhaps to make it available online free of charge.

\section{Limitations and Directions for Future Research}

Limitations have to be kept in mind when considering the implications of the present results. First, we relied on self-report measures, which may have been impacted by social desirability and self-report biases. Future research should consider relying on more objective indicators of individual and organizational functioning (e.g., job performance, turnover) together with informant-reported (e.g., manager) measures of absenteeism. Second, the present study relied on four convenience samples of French workers, which cannot be considered to be representative of the population of French workers. Additional person-centered research should thus be conducted to assess the generalizability of the profiles and of their associations with predictors and outcomes, across distinct samples of employees (e.g., office workers, teleworkers), and in different cultures and countries (Morin, Meyer et al., 2016). Such evidence of generalizability would help to demonstrate the robustness of our findings and the value of implementing intervention strategies based on such person-centered results. Importantly, the ability of person-centered analyses to identify multiple profiles, as well as smaller and yet meaningful profiles, is known to be influenced by sample size. Thus, although evidence of profile similarity lends credibility to the generalizability of the current set of profiles, it remains possible that the current samples might have made it impossible to identify additional, and possibly smaller, profiles.

Third, in line with Meyer and Morin's (2016) recommendations, we examined covariates defined a priori as predictors (i.e., workload, as well as perceived organizational, supervisor, and colleagues support) or outcomes (i.e., presenteeism, absenteeism, turnover intentions, and work performance) on the basis of a theoretical rationale drawn from prior research (e.g., Deci et al., 2017; Gagné \& Deci, 2005). Although our analytical approach made it possible to rule out possible effects of predictors on profile membership, our study design and the limitations inherent to our analytical method did not allow us to assess reversed causality, reciprocity, or spuriousness, nor the possible role of profile membership in the prediction of changes in outcome levels. Therefore, future longitudinal research would gain from examining more systematically the direction of the associations among predictors, outcomes, and profiles within the context of a longitudinal research design. Indeed, longitudinal research makes it possible to address the joint issues of within-person and within-sample profile stability (Gillet, Morin, \& Reeve, 2017; Kam, Morin, Meyer, \& Topolnytsky, 2016). Future research may also consider the possible mechanisms at play in explaining these potential profile transitions. Fourth, we only looked into the role of demographic characteristics, workload, and social support at work as determinants of employees' work motivation profiles. Yet, it would be worthwhile for future research to investigate other determinants inherent to the work environment (e.g., leadership behaviors) or individual orientations (i.e., job crafting, perfectionism).

Finally, although we relied on factor scores providing some degree of protection against unreliability, the preliminary analyses from which these factor scores were generated resulted in the estimation of a more weakly defined specific identified regulation factor across all four samples. This result implies that, in the present study, ratings on the three items used to evaluate identified regulation provided a much better reflection of employees' global levels of self-determination than of the specific facet of identified regulation. In plain language, this means that ratings of identified regulation mainly serve to define global levels of self-determination in the four present samples, with limited evidence of discrepancies between individual levels of identified regulation and of global self-determination.

Nevertheless, it would be interesting for future investigations to assess more extensively the situations, occupations, and professional contexts which may lead to more or less frequent misalignments between employees' levels of global self-determination and their specific ratings of identified regulation.

\section{Conclusion}

The present study was able to identify six distinct work motivation profiles which appeared consistently among four distinct samples of employees. The nature of the identified profiles supported the idea that the global level of self-determined work motivation, as well as the specific quality of employees' behavioral regulations at work, both played a role in the definition of these profiles, and thus were both important to our ability to achieve a comprehensive understanding of employees' work motivation. Further supporting the relevance of these profiles, systematic outcome differences were found between them, showing that belonging to profiles characterized by high levels of global selfdetermination or by high specific levels of intrinsic motivation tended to be systematically linked to 
more desirable outcomes, when these motivations were not simultaneously coupled with high specific levels of introjected regulation, external regulation, and amotivation. Finally, our results supported the value of interventions designed to increase colleagues support, as well as to help make workloads more manageable, as possible ways to nurture more desirable motivation profiles among employees.

\section{References}

Andela, M., Truchot, D., \& Van der Doef, M. (2016). Job stressors and burnout in hospitals: The mediating role of emotional dissonance. International Journal of Stress Management, 23, 298-317.

Baeriswyl, S., Krause, A., Elfering, A., \& Berset, M. (2017). How workload and coworker support relate to emotional exhaustion: The mediating role of sickness presenteeism. International Journal of Stress Management, 24, 52-73.

Bakker, A.B., \& Demerouti, E. (2007). The Job Demands-Resources model: State of the art. Journal of Managerial Psychology, 22, 309-328.

Battistelli, A., Galletta, M., Odoardi, C., Núñez, J., \& Ntalianis, F. (2017). Proposal for a version of MWMS across Mediterranean countries: A validation study in Greece, Italy, and Spain. European Journal of Psychological Assessment, 33, 104-115.

Bauer, D.J., \& Curran, P.J. (2003). Distributional assumptions of growth mixture models overextraction of latent trajectory classes. Psychological Methods, 8, 338-363.

Bentein, K., Vandenberghe, C., Vandenberg, R., \& Stinglhamber, F. (2005). The role of change in the relationship between commitment and turnover: A latent growth modeling approach. Journal of Applied Psychology, 90, 468-482.

Bonifas, R.P. (2015). Resident-to-resident aggression in nursing homes: Social worker involvement and collaboration with nursing colleagues. Health \& Social Work, 40, e101-109.

Bonneville-Roussy, A., Evans, P., Verner-Filion, J., Vallerand, R.J., \& Bouffard, T. (2017). Motivation and coping with the stress of assessment: Gender differences in outcomes for university students. Contemporary Educational Psychology, 48, 28-42.

Burnett, M.F., Chiaburu, D.S., Shapiro, D.L., \& Li, N. (2015). Revisiting how and when perceived organizational support enhances taking charge: An inverted U-shaped perspective. Journal of Management, 41, 1805-1826.

Caesens, G., Gillet, N., Morin, A.J.S., Houle, S.A., \& Stinglhamber, F. (2019). A person- centred perspective on social support in the workplace. Applied Psychology: An International Review. Advance online publication. https://doi.org/10.1111/apps.12196

Caesens, G., Stinglhamber, F., Demoulin, S., De Wilde, M., \& Mierop, A. (2019). Perceived organizational support and workplace conflict: The mediating role of failure-related trust. Frontiers in Psychology, 9, Article 2704.

Caesens, G., Stinglhamber, F., \& Luypaert, G. (2014). The impact of work engagement and workaholism on well-being: The role of work-related social support. Career Development International, 19, 813-835.

Chambel, M.J., Castanheira, F., Oliveira-Cruz, F., \& Lopes, S. (2015). Work context support and Portuguese soldiers' well-being: The mediating role of autonomous motivation. Military Psychology, 27, 297-310.

Chemolli, E., \& Gagné, M. (2014). Evidence against the continuum structure underlying motivation measures derived from self-determination theory. Psychological Assessment, 26, 575-585.

Corpus, J.H., McClintic-Gilbert, M.S., \& Hayenga, A.O. (2009). Within-year changes in children's intrinsic and extrinsic motivational orientations: Contextual predictors and academic outcomes. Contemporary Educational Psychology, 34, 154-166.

De Cooman, R., Stynen, D., Van den Broeck, A., Sels, L., \& De Witte, H. (2013). How job characteristics relate to need satisfaction and autonomous motivation: Implications for work effort. Journal of Applied Social Psychology, 43, 1342-1352.

Deci, E.L., \& Ryan, R.M. (2000). The "what" and "why" of goal pursuits: Human needs and the selfdetermination of behavior. Psychological Inquiry, 11, 227-268.

Deci, E.L., Olafsen, A.H., \& Ryan, R.M. (2017). Self-determination theory in work organizations: The state of a science. Annual Review of Organizational Psychology \& Organizational Behavior, 4, 19-43.

Diallo, T.M.O, Morin, A.J.S., \& Lu, H. (2016). Impact of misspecifications of the latent variancecovariance and residual matrices on the class enumeration accuracy of growth mixture models. Structural Equation Modeling, 23, 507-531. 
Diallo, T.M.O, Morin, A.J.S., \& Lu, H. (2017). The impact of total and partial inclusion or exclusion of active and inactive time invariant covariates in growth mixture models. Psychological Methods, $22,166-190$.

Donoso, L.M.B., Demerouti, E., Garrosa Hernández, E., Moreno-Jiménez, B., \& Carmona Cobo, I. (2015). Positive benefits of caring on nurses' motivation and well-being: A diary study about the role of emotional regulation abilities at work. International Journal of Nursing Studies, 52, 804816.

Eisenberger, R., \& Stinglhamber, F. (2011). Perceived organizational support: Fostering enthusiastic and productive employees. Washington, DC: American Psychological Association.

Eisenberger, R., Huntington, R., Hutchison, S., \& Sowa, D. (1986). Perceived organizational support. Journal of Applied Psychology, 71, 500-507.

Enders, C.K. (2010). Applied missing data analysis. New York: Guilford.

Fernet, C., Litalien, D., Morin, A.J.S., Austin, S., Gagné, M., Lavoie-Tremblay, M., \& Forest, J. (2020). On the temporal stability of work motivation profiles: A latent transition analysis. European Journal of Work and Organizational Psychology, 29, 49-63.

Fernet, C., Trépanier, S.-G., Austin, S., Gagné, M., \& Forest, J. (2015). Transformational leadership and optimal functioning at work: On the mediating role of employees' perceived job characteristics and motivation. Work \& Stress, 29, 11-31.

Fernet, C., Trépanier, S.-G., Austin, S., \& Levesque-Côté, J. (2016). Committed, inspiring, and healthy teachers: How do school environment and motivational factors facilitate optimal functioning at career start? Teaching and Teacher Education, 59, 481-491.

Fouquereau, E., Morin, A.J.S., Lapointe, É., Mokounkolo, R., \& Gillet, N. (2019). Emotional labour profiles: Associations with key predictors and outcomes. Work \& Stress, 33, 268-294.

Frear, K.A., Donsbach, J., Theilgard, N., \& Shanock, L.R. (2018). Supported supervisors are more supportive, but why? A multilevel study of mechanisms and outcomes. Journal of Business and Psychology, 33, 55-69.

Gagné, M., \& Deci, E.L. (2005). Self-determination theory and work motivation. Journal of Organizational Behavior, 26, 331-362.

Gagné, M., \& Forest, J. (2008). The study of compensation systems through the lens of selfdetermination theory: Reconciling 35 years of debate. Canadian Psychology, 49, 225-232.

Gagné, M., Forest, J., Vansteenkiste, M., Crevier-Braud, L., van den Broeck, A., Aspeli, A.K., Bellerose, J., Benabou, C., Chemolli, E., Güntert, S.T., Halvari, H., Indiyastuti, D.L., Johnson, P. A., Molstad, M.H., Naudin, M., Ndao, A., Olafsen, A.H., Roussel, P., Wang, Z., \& Westbye, C. (2015). The Multidimensional Work Motivation Scale: Validation evidence in seven languages and nine countries. European Journal of Work and Organizational Psychology, 24, 178-196.

Gigliotti, R., Vardaman, J., Marshall, D.R., \& Gonzalez, K. (2019). The role of perceived organizational support in individual change readiness. Journal of Change Management, 19, 86-100.

Gillet, N., Becker, C., Lafrenière, M.-A., Huart, I., \& Fouquereau, E. (2017). Organizational support, job resources, soldiers' motivational profiles, work engagement, and affect. Military Psychology, 29, 418-433.

Gillet, N., Caesens, G., Morin, A.J.S., \& Stinglhamber, F. (2019). Complementary variable- and person-centred approaches to the dimensionality of work engagement: A longitudinal investigation. European Journal of Work and Organizational Psychology, 28, 239-258.

Gillet, N., Forest, J., Benabou, C., \& Bentein, K. (2015). The effects of organizational factors, psychological need satisfaction and thwarting, and affective commitment on workers' well-being and turnover intentions. Le Travail Humain, 78, 119-140.

Gillet, N., Fouquereau, E., Forest, J., Brunault, P., \& Colombat, P. (2012). The impact of organizational factors on psychological needs and their relations with well-being. Journal of Business and Psychology, 27, 437-450.

Gillet, N., Fouquereau, E., Huyghebaert, T., \& Colombat, P. (2015). The effects of job demands and organizational resources through psychological need satisfaction and thwarting. The Spanish Journal of Psychology, 18, Article E28.

Gillet, N., Fouquereau, E., Vallerand, R.J., Abraham, J., \& Colombat, P. (2018). The role of workers' motivational profiles in affective and organizational factors. Journal of Happiness Studies, 19, 1151-1174. 
Gillet, N., Gagné, M., Sauvagère, S., \& Fouquereau, E. (2013). The role of supervisor autonomy support, organizational support, and autonomous and controlled motivation in predicting employees' satisfaction and turnover intentions. European Journal of Work and Organizational Psychology, 22, 450-460.

Gillet, N., Huyghebaert-Zouaghi, T., Réveillère, C., Colombat, P., \& Fouquereau, E. (2020). The effects of job demands on nurses' burnout and presenteeism through sleep quality and relaxation. Journal of Clinical Nursing, 29, 583-592.

Gillet, N., Morin, A.J.S., Choisay, F., \& Fouquereau, E. (2019). A person-centered representation of basic need satisfaction balance at work. Journal of Personnel Psychology, 18, 113-128.

Gillet, N., Morin, A.J.S., Huart, I., Colombat, P., \& Fouquereau, E. (2019). The forest and the trees: Investigating the globality and specificity of employees' basic need satisfaction at work. Journal of Personality Assessment. Advance online publication. https://doi.org/10.1080/00223891.2019.1591426

Gillet, N., Morin, A.J.S, Jeoffrion, C., \& Fouquereau, E. (2020). A person-centered perspective on the combined effects of global and specific levels of job engagement. Group \& Organization Management. Advance online publication. https://doi.org/10.1177/1059601119899182

Gillet, N., Morin, A.J.S., \& Reeve, J. (2017). Stability, change, and implications of students' motivation profiles: A latent transition analysis. Contemporary Educational Psychology, 51, 222-239.

Gillet, N., Vallerand, R.J., \& Lafrenière, M.-A.K. (2012). Intrinsic and extrinsic school motivation as a function of age: The mediating role of autonomy support. Social Psychology of Education, 15, 77-95.

Gillet, N., Vallerand, R.J., \& Paty, B. (2013). Situational motivational profiles and performance with elite performers. Journal of Applied Social Psychology, 43, 1200-1210.

Graves, L.M., Cullen, K.L., Lester, H.F., Ruderman, M.N., \& Gentry, W.A. (2015). Managerial motivational profiles: Composition, antecedents, and consequences. Journal of Vocational Behavior, 87, 32-42.

Gray, B. (2010). Emotional labour, gender and professional stereotypes of emotional and physical contact, and personal perspectives on the emotional labour of nursing. Journal of Gender Studies, $19,349-360$.

Guay, F., Morin, A.J.S., Litalien, D., Valois, P., \& Vallerand, R.J. (2015). Application of exploratory structural equation modeling to evaluate the Academic Motivation Scale. Journal of Experimental Education, 83, 51-82.

Harris, K.J., \& Kacmar, K.M. (2018). Is more always better? An examination of the nonlinear effects of perceived organizational support on individual outcomes. The Journal of Social Psychology, $158,187-200$.

Henderson, A. (2001). Emotional labor and nursing: An under-appreciated aspect of caring work. Nursing Inquiry, 8, 130-138.

Henson, J.M., Reise, S.P., \& Kim, K.H. (2007). Detecting mixtures from structural model differences using latent variable mixture modeling: A comparison of relative model fit statistics. Structural Equation Modeling, 14, 202-226.

Hipp, J.R., \& Bauer, D.J. (2006). Local solutions in the estimation of growth mixture models. Psychological Methods, 11, 36-53.

Howard, J., Gagné, M., \& Bureau, J.S. (2017). Testing a continuum structure of self-determined motivation: A meta-analysis. Psychological Bulletin, 143, 1346-1377.

Howard, J., Gagné, M., Morin, A.J.S., \& Van den Broeck, A. (2016). Motivation profiles at work: A self-determination theory approach. Journal of Vocational Behavior, 95-96, 74-89.

Howard, J., Gagné, M., Morin, A.J.S., \& Forest, J. (2018). Using bifactor exploratory structural equation modeling to test for a continuum structure of motivation. Journal of Management, 44, 2638-2664.

Ilies, R., Huth, M., Ryan, A.M., \& Dimotakis, N. (2015). Explaining the links between workload, distress, and work-family conflict among school employees: Physical, cognitive, and emotional fatigue. Journal of Educational Psychology, 107, 1136-1149.

Jansen in de Wal, J., den Brok, P.J., Hooijer, J.G., Martens, R.L., \& van den Beemt, A. (2014). Teachers' engagement in professional learning: Exploring motivational profiles. Learning and Individual Differences, 36, 27-36.

Johns, G., \& Al Hajj, R. (2016). Frequency versus time lost measures of absenteeism: Is the voluntariness distinction an urban legend? Journal of Organizational Behavior, 37, 456-479. 
Kam, C., Morin, A.J.S., Meyer, J.P., \& Topolnytsky, L. (2016). Are commitment profiles stable and predictable? A latent transition analysis. Journal of Management, 42, 1462-1490.

Kessler, R.C., Barber, C., Beck, A., Berglund, P., Cleary, P.D., McKenas, D., \& Pronk, N. (2003). The world health organization health and work performance questionnaire (HPQ). Journal of Occupational and Environmental Medicine, 45, 156-174.

Kim, M., \& Beehr, T.A. (2018). Challenge and hindrance demands lead to employees' health and behaviours through intrinsic motivation. Stress and Health, 34, 367-378.

Koopman, C., Pelletier, K.R., Murray, J.F., Sharda, C.E., Berger, M.L., Turpin, R.S., Hackleman, P., Gibson, P., Holmes, D.M., \& Bendel, T. (2002) Stanford Presenteeism Scale: Health status and employee productivity. Journal of Occupational and Environmental Medicine, 44, 14-20.

Kurtessis, J.N., Eisenberger, R., Ford, M.T., Buffardi, L.C., Stewart, K.A., \& Adis, C.S. (2017). Perceived organizational support: A meta-analytic evaluation of organizational support theory. Journal of Management, 43, 1854-1884.

Kuvaas, B. (2006). Work performance, affective commitment, and work motivation: The roles of pay administration and pay level. Journal of Organizational Behavior, 27, 365-385.

Lindsay, R., Hanson, L., Taylor, M., \& McBurney, H. (2008). Workplace stressors experienced by physiotherapists working in regional public hospitals. Australian Journal of Rural Health, 16, 194-200.

Litalien, D., Gillet, N., Gagné, M., Ratelle, C.F., \& Morin, A.J.S. (2019). Self-determined motivation profiles among undergraduate students: A robust test of profile similarity as a function of gender and age. Learning and Individual Differences, 70, 39-52.

Litalien, D., Morin, A.J.S., \& McInerney, D.M. (2017). Achievement goal profiles among adolescent males and females. Developmental Psychology, 53, 731-751.

Litalien, D., Morin, A.J.S., Gagné, M., Vallerand, R.J., Losier, G.F., \& Ryan, R.M. (2017). Evidence of a continuum structure of academic self-determination: A two-study test using a bifactor-ESEM representation of academic motivation. Contemporary Educational Psychology, 51, 67-82.

Liu, Y., Hau, K.-T., \& Zheng, X. (2019). Do both intrinsic and identified motivations have long-term effects? The Journal of Psychology: Interdisciplinary and Applied, 153, 288-306.

Lo, Y., Mendell, N., \& Rubin, D. (2001). Testing the number of components in a normal mixture. Biometrika, 88, 767-778.

Marsh, H.W., Lüdtke, O., Trautwein, U., \& Morin, A.J.S. (2009). Classical latent profile analysis of academic self-concept dimensions: Synergy of person- and variable-centered approaches to theoretical models of self-concept. Structural Equation Modeling, 16, 191-225.

McLachlan, G., \& Peel, D. (2000). Finite mixture models. New York, NY: Wiley.

McVicar, A. (2016). Scoping the common antecedents of job stress and job satisfaction for nurses (2000-2013) using the job demands-resources model of stress. Journal of Nursing Management, 24, E112-E136.

Meyer, J.P., \& Morin, A.J.S. (2016). A person-centered approach to commitment research: Theory, research, and methodology. Journal of Organizational Behavior, 37, 584-612.

Millsap, R.E. (2011). Statistical approaches to measurement invariance. New York: Taylor \& Francis.

Moran, C.M., Diefendorff, J.M., Kim, T.-Y., \& Liu, Z.-Q. (2012). A profile approach to selfdetermination theory motivations at work. Journal of Vocational Behavior, 81, 354-363.

Morin, A.J.S., \& Wang, J.C.K. (2016). A gentle introduction to mixture modeling using physical fitness data. In N. Ntoumanis \& N. Myers (Eds.), An introduction to intermediate and advanced statistical analyses for sport and exercise scientists (pp. 183-210). London, UK: Wiley.

Morin, A.J.S., Arens, A.K., \& Marsh, H.W. (2016). A bifactor exploratory structural equation modeling framework for the identification of distinct sources of construct-relevant psychometric multidimensionality. Structural Equation Modeling, 23, 116-139.

Morin, A.J.S., Boudrias, J.-S., Marsh, H.W., Madore, I., \& Desrumaux, P. (2016). Further reflections on disentangling shape and level effects in person-centered analyses: An illustration aimed at exploring the dimensionality of psychological health. Structural Equation Modeling, 23, 438-454.

Morin, A.J.S., Boudrias, J.-S., Marsh, H.W., McInerney, D.M., Dagenais-Desmarais, V., Madore, I., \& Litalien, D. (2017). Complementary variable- and person-centered approaches to the dimensionality of psychometric constructs: Application to psychological wellbeing at work. Journal of Business and Psychology, 32, 395-419.

Morin, A.J.S., Maïano, C., Nagengast, B., Marsh, H.W., Morizot, J., \& Janosz, M. (2011). Growth 
mixture modeling of adolescents trajectories of anxiety: The impact of untested invariance assumptions on substantive interpretations. Structural Equation Modeling, 18, 613-648.

Morin, A.J.S., Meyer, J.P., Creusier, J., \& Biétry, F. (2016). Multiple-group analysis of similarity in latent profile solutions. Organizational Research Methods, 19, 231-254.

Morin, A.J.S., Vandenberghe, C., Turmel, M.-J., Madore, I., \& Maïano, C. (2013). Probing into commitment's nonlinear relationships to work outcomes. Journal of Managerial Psychology, 28, 202-223.

Morin, A.J.S., \& Wang, J.C.K. (2016). A gentle introduction to mixture modeling using physical fitness data. In N. Ntoumanis \& N. Myers (Eds.), An introduction to intermediate and advanced statistical analyses for sport and exercise scientists (pp. 183-210). London, UK: Wiley.

Muthén, B.O. (2003). Statistical and substantive checking in growth mixture modeling: Comment on Bauer and Curran (2003). Psychological Methods, 8, 369-377.

Muthén, L.K., \& Muthén, B. (2018). Mplus user's guide. Los Angeles: Muthén \& Muthén.

Newman, A., Thanacoody, R., \& Hui, W. (2012). The effects of perceived organizational support, perceived supervisor support and intra-organizational network resources on turnover intentions: A study of Chinese employees in multinational enterprises. Personnel Review, 41, 56-72.

Ng, T.W.H., \& Sorensen, K.L. (2008). Toward a further understanding of the relationships between perceptions of support and work attitudes: A meta-analysis. Group \& Organization Management, $33,243-268$

Nicholson, N. (2007). Absence behaviour and attendance motivation: A conceptual synthesis. Journal of Management Studies, 14, 231-252.

Nylund, K.L., Asparouhov, T., \& Muthén, B. (2007). Deciding on the number of classes in latent class analysis and growth mixture modeling: A Monte Carlo simulation study. Structural Equation Modeling, 14, 535-569.

Olafsen, A.H., \& Halvari, H. (2017). Motivational mechanisms in the relation between job characteristics and employee functioning. The Spanish Journal of Psychology, 20, Article E38.

Parker, S.L., Jimmieson, N.L., \& Amiot, C.E. (2010). Self-determination as a moderator of demands and control. Journal of Vocational Behavior, 76, 52-67.

Perreira, T.A., Morin, A.J.S., Hebert, M., Gillet, N., Houle, S.A., \& Berta, W. (2018). The short form of the Workplace Affective Commitment Multidimensional Questionnaire (WACMQ-S): A bifactor-ESEM approach among healthcare professionals. Journal of Vocational Behavior, 106, 62-83.

Peugh, J., \& Fan, X. (2013). Modeling unobserved heterogeneity using latent profile analysis: A Monte Carlo simulation. Structural Equation Modeling, 20, 616-639.

Podsakoff, N.P., LePine, J.A., \& LePine, M.A. (2007). Differential challenge stressor-hindrance stressor relationships with job attitudes, turnover intentions, turnover, and withdrawal behavior: A meta-analysis. Journal of Applied Psychology, 92, 438-454.

Ratelle, C.F., Guay, F., Vallerand, R.J., Larose, S., \& Senécal, C. (2007). Autonomous, controlled, and amotivated types of academic motivation: A person-oriented analysis. Journal of Educational Psychology, 99, 734-746.

Raykov, T., \& Marcoulides, G.A. (2004). Using the delta method for approximate interval estimation of parameter functions in SEM. Structural Equation Modeling, 11, 621-637.

Ryan, R.M., \& Deci, E.L. (2017). Self-determination theory: Basic psychological needs in motivation, development, and wellness. New York, NY: Guilford Press.

Sandrin, É., Gillet, N., Fernet, C., Leloup, M., \& Depin- Rouault, C. (2019). Effects of motivation and workload on firefighters' perceived health, stress, and performance. Stress and Health, 35, 447-456.

Shanock, L.R., \& Eisenberger, R. (2006). When supervisors feel supported: Relationships with subordinates' perceived supervisor support, perceived organizational support, and performance. Journal of Applied Psychology, 91, 689-695.

Sheldon, K.M., Osin, E.N., Gordeeva, T.O., Suchkov, D.D., \& Sychev, O.A. (2017). Evaluating the dimensionality of self-determination theory's relative autonomy continuum. Personality and Social Psychology Bulletin, 43, 1215-1238.

Skrondal, A., \& Laake, P. (2001). Regression among factor scores. Psychometrika, 66, 563-576.

Spector, P.E., \& Jex, S.M. (1998). Development of four self-report measures of job stressors and strain: Interpersonal conflict at work scale, organizational constraints scale, quantitative workload inventory, and physical symptoms. Journal of Occupational Health Psychology, 3, 356-367. 
Spector, P.E., Liu, C., \& Sanchez, J.I. (2015). Methodological and substantive issues in conducting multinational and cross-cultural research. Annual Review of Organizational Psychology and Organizational Behavior, 2, 101-131.

Sullivan, S.C., Norris, M.R., Brown, L.M., \& Scott, K.J. (2017). Nurse manager perspective of staff participation in unit level shared governance. Journal of Nursing Management, 25, 624-631.

Tein, J.-Y., Coxe, S., \& Cham, H. (2013). Statistical power to detect the correct number of classes in latent profile analysis. Structural Equation Modeling, 20, 640-657.

Thibault Landry, A., Gagné, M., Forest, J., Guerrero, S., Séguin, M., \& Papachristopoulos, K. (2017). The relation between financial incentives, motivation, and performance: An integrative SDT-based investigation. Journal of Personnel Psychology, 16, 61-76.

Tofighi, D., \& Enders, C. (2008). Identifying the correct number of classes in growth mixture models. In G.R. Hancock \& K.M. Samuelsen (Eds.), Advances in latent variable mixture models (pp. 317341). Charlotte: Information Age.

Tóth-Király, I., Morin, A.J.S., Bőthe, B., Orosz, G., \& Rigó, A. (2018). Investigating the multidimensionality of need fulfillment: A bifactor exploratory structural equation modeling representation. Structural Equation Modeling, 25, 267-286.

Trépanier, S.-G., Fernet, C., \& Austin, S. (2013). The moderating role of autonomous motivation in the job demands-strain relation: A two sample study. Motivation and Emotion, 37, 93-105.

Trépanier, S.-G., Forest, J., Fernet, C., \& Austin, S. (2015). On the psychological and motivational processes linking job characteristics to employee functioning: Insights from self-determination theory. Work \& Stress, 29, 286-305.

Valero, D., \& Hirschi, A. (2016). Latent profiles of work motivation in adolescents in relation to work expectations, goal engagement, and changes in work experiences. Journal of Vocational Behavior, 93, 67-80.

Vallerand, R.J. (1997). Toward a hierarchical model of intrinsic and extrinsic motivation. In M.P. Zanna (Ed.), Advances in experimental social psychology, Vol. 29 (pp. 271-360). Cambridge, MA: Academic Press.

Vallerand, R.J., Fortier, M.S., \& Guay, F. (1997). Self-determination and persistence in a real-life setting: Toward a motivational model of high school dropout. Journal of Personality and Social Psychology, 72, 1161-1176.

van Beek, I., Taris, T.W., \& Schaufeli, W.B. (2011). Workaholic and work engaged employees: Dead ringers or worlds apart? Journal of Occupational Health Psychology, 16, 468-482.

Van den Berghe, L., Soenens, B., Aelterman, N., Cardon, G., Tallir, I.B., \& Haerens, L. (2014). Within-person profiles of teachers' motivation to teach: Associations with need satisfaction at work, need-supportive teaching, and burnout. Psychology of Sport and Exercise, 15, 407-417.

Van den Broeck, A., Ferris, D.L., Chang, C.-H., \& Rosen, C.C. (2016). A review of self-determination theory's basic psychological needs at work. Journal of Management, 42, 1195-1229.

Van den Broeck, A., Lens, W., De Witte, H., \& Van Coillie, H. (2013). Unraveling the importance of the quantity and the quality of workers' motivation for well-being: A person-centered perspective. Journal of Vocational Behavior, 82, 69-78.

van der Heijden, B.I.J.M., Kümmerling, A., van Dam, K., van der Schoot, E., Estryn-Béhar, M., \& Hasselhorn, H.M. (2010). The impact of social support upon intention to leave among female nurses in Europe: Secondary analysis of data from the NEXT survey. International Journal of Nursing Studies, 47, 434-445.

Waaler, R., Halvari, H., Skjesol, K., \& Bagøien, T.E. (2013). Autonomy support and intrinsic goal progress expectancy and its links to longitudinal study effort and subjective wellbeing: The differential mediating effect of intrinsic and identified regulations and the moderator effects of effort and intrinsic goals. Scandinavian Journal of Educational Research, 57, 325-341.

Wang, J.C.K., Morin, A.J.S., Ryan, R.M., \& Liu, W.C. (2016). Students' motivational profiles in the physical education context. Journal of Sport \& Exercise Psychology, 38, 612-630.

Williams, G.C., Halvari, H., Niemiec, C.P., Sørebø, Ø., Olafsen, A.H., \& Westbye, C. (2014). Managerial support for basic psychological needs, somatic symptom burden and work-related correlates: A self-determination theory perspective. Work \& Stress, 28, 404-419.

Yang, C. (2006). Evaluating latent class analyses in qualitative phenotype identification. Computational Statistics \& Data Analysis, 50, 1090-1104. 
Zyphur, M.J. (2009). When mindsets collide: Switching analytical mindsets to advance organization science. The Academy of Management Review, 34, 677-688. 


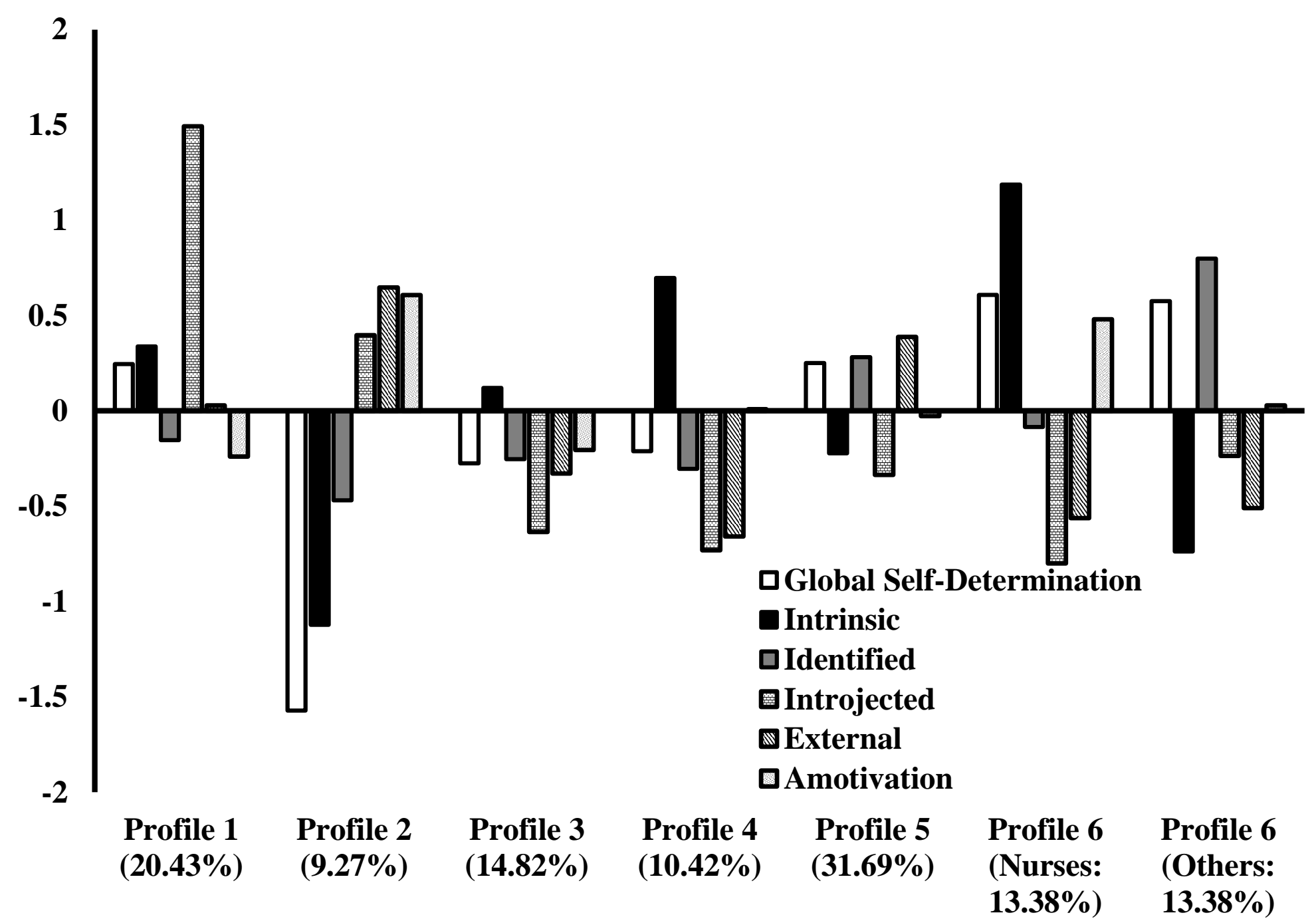

Figure 1. Final 6-Profile Solution of Partial Similarity Across Samples

Note. Profile indicators are estimated from factor scores with a grand mean of 0 and a standard deviation of 1; Profile 1: Self-Driven Introjected; Profile 2: Externally Driven;

Profile 3: Moderately Intrinsically Motivated; Profile 4: Highly Intrinsically Motivated; Profile 5: Value-Reward Self-Driven; Profile 6: Self-Driven Hedonist. 


\section{Table 1}

Fit Results from the Multi-Group Tests of Profile Similarity

\begin{tabular}{|c|c|c|c|c|c|c|c|c|}
\hline & LL & $\# \mathrm{fp}$ & SC & AIC & CAIC & BIC & ABIC & Entropy \\
\hline \multicolumn{9}{|l|}{ Multi-Group Similarity } \\
\hline Configural Similarity & -7476.821 & 311 & 1.0969 & 15575.641 & 17456.419 & 17145.419 & 16157.585 & 949 \\
\hline Structural Similarity & -7891.096 & 203 & 1.0224 & 16188.192 & 17415.838 & 17212.838 & 16568.046 & .928 \\
\hline Partial Structural Similarity & -7731.395 & 209 & 1.0674 & 15880.790 & 17144.721 & 16935.721 & 16271.871 & .929 \\
\hline Dispersion Similarity & -7943.600 & 101 & 1.2389 & 16089.199 & 16699.998 & 16598.998 & 16278.190 & 930 \\
\hline Distributional Similarity & -7996.121 & 86 & 1.3701 & 16164.242 & 16684.329 & 16598.329 & 16325.165 & .928 \\
\hline \multicolumn{9}{|c|}{ Predictive Similarity: Predictors } \\
\hline Freely Estimated & -17663.559 & 209 & 2.0940 & 35745.118 & 37009.049 & 36800.049 & 36136.199 & 934 \\
\hline Predictive Similarity & -17760.107 & 89 & 1.0418 & 35698.214 & 36236.443 & 36147.443 & 35864.751 & 929 \\
\hline \multicolumn{9}{|c|}{ Explanatory Similarity: Outcomes } \\
\hline Freely Estimated & -17482.639 & 112 & 1.870 & 35189.278 & 35866.600 & 35754.600 & 35398.853 & 933 \\
\hline Explanatory Similarity & -17588.670 & 45 & 2.9626 & 35267.340 & 35539.478 & 35494.478 & 35351.544 & .928 \\
\hline
\end{tabular}

Note. $\mathrm{LL}=$ Loglikelihood; \#fp = Number of free parameters; Scaling: Scaling correction factor; AIC = Akaïke information criterion; BIC = Bayesian information criterion CAIC $=$ Consistent AIC; ABIC $=$ Sample-size adjusted BIC 
Table 2

Results from the Multinomial Logistic Regression Evaluating the Effects of Predictors on Latent Profile Membership (Predictive Similarity)

\begin{tabular}{|c|c|c|c|c|c|c|c|c|c|c|}
\hline \multirow[b]{2}{*}{ Predictor } & \multicolumn{2}{|c|}{ Latent profile 1 Vs 6} & \multicolumn{2}{|c|}{ Latent profile 2 Vs 6} & \multicolumn{2}{|c|}{ Latent profile 3 Vs 6} & \multicolumn{2}{|c|}{ Latent profile 4 Vs 6} & \multicolumn{2}{|c|}{ Latent profile 5 Vs 6} \\
\hline & Coef. (SE) & OR & Coef. (SE) & OR & Coef. (SE) & OR & Coef. (SE) & OR & Coef. (SE) & OR \\
\hline Sex & $-.683(.338)^{*}$ & .505 & $-1.735(.389)^{* * *}$ & .176 & $-.715(.360) *$ & .489 & $-.452(.389)$ & .636 & $-.693(.342)^{*}$ & .500 \\
\hline Work Time & $.420(.360)$ & 1.522 & $-.438(.610)$ & .645 & $.302(.398)$ & 1.353 & $-.304(.495)$ & .738 & $.105(.350)$ & 1.111 \\
\hline Age & $.060(.145)$ & 1.062 & $.231(.193)$ & 1.260 & $.241(.154)$ & 1.273 & $.066(.167)$ & 1.068 & $-.075(.137)$ & .928 \\
\hline Tenure & $-.191(.165)$ & .826 & $-.092(.178)$ & .912 & $-.082(.166)$ & .921 & $.142(.174)$ & 1.153 & $-.017(.144)$ & .983 \\
\hline Workload & $.275(.107) * *$ & 1.317 & $.225(.105) *$ & 1.252 & $-.169(.113)$ & .845 & $-.138(.133)$ & .871 & $.061(.097)$ & 1.063 \\
\hline POS & $.507(.140)^{* *}$ & 1.660 & $.205(.174)$ & 1.228 & $.253(.157)$ & 1.288 & $.508(.165)^{* *}$ & 1.662 & $.543(.139) * *$ & 1.721 \\
\hline PSS & $-.063(.159)$ & .939 & $-.258(.201)$ & .773 & $-.270(.174)$ & .763 & $-.287(.185)$ & .751 & $-.166(.155)$ & .847 \\
\hline \multirow[t]{2}{*}{$\underline{\mathrm{PCS}}$} & $-.132(.133)$ & .876 & $-.448(.159)^{* *}$ & .639 & $.011(.149)$ & 1.011 & $-.101(.159)$ & .904 & $-.129(.130)$ & .879 \\
\hline & \multicolumn{2}{|c|}{ Latent profile 1 Vs 5} & \multicolumn{2}{|c|}{ Latent profile $2 \mathrm{Vs} 5$} & \multicolumn{2}{|c|}{ Latent profile $3 \mathrm{Vs} 5$} & \multicolumn{2}{|c|}{ Latent profile $4 \mathrm{Vs} 5$} & \multicolumn{2}{|c|}{ Latent profile 1 Vs 4} \\
\hline Predictor & Coef. (SE) & OR & Coef. (SE) & OR & Coef. (SE) & OR & Coef. (SE) & OR & Coef. (SE) & OR \\
\hline Sex & $.010(.237)$ & 1.010 & $-1.042(.290)^{* *}$ & .353 & $-.022(.263)$ & .978 & $.241(.287)$ & 1.273 & $-.231(.309)$ & .794 \\
\hline Work Time & $.315(.320)$ & 1.370 & $-.541(.604)$ & .582 & $.197(.359)$ & 1.218 & $-.409(.455)$ & .664 & $.724(.457)$ & 2.063 \\
\hline Age & $.135(.120)$ & 1.145 & $.306(.179)$ & 1.358 & $.316(.127)^{*}$ & 1.372 & $.141(.141)$ & 1.151 & $-.006(.154)$ & .994 \\
\hline Tenure & $-.174(.146)$ & .840 & $-.076(.165)$ & .927 & $-.065(.153)$ & .937 & $.159(.156)$ & 1.172 & $-.333(.180)$ & .717 \\
\hline Workload & $.214(.088)^{*}$ & 1.239 & $.165(.121)$ & 1.179 & $-.229(.097) *$ & .795 & $-.199(.098) *$ & .820 & $.413(.129) * *$ & 1.511 \\
\hline POS & $-.036(.106)$ & .965 & $-.337(.152)^{*}$ & .714 & $-.290(.131)^{*}$ & .748 & $-.035(.136)$ & .966 & $-.001(.143)$ & .999 \\
\hline PSS & $.103(.127)$ & 1.108 & $-.092(.179)$ & .912 & $-.104(.141)$ & .901 & $-.121(.153)$ & .886 & $.224(.164)$ & 1.251 \\
\hline \multirow[t]{2}{*}{$\underline{\mathrm{PCS}}$} & $-.003(.101)$ & .997 & $-.318(.132)^{*}$ & .728 & $.140(.118)$ & 1.150 & $.029(.131)$ & 1.029 & $-.031(.138)$ & .969 \\
\hline & \multicolumn{2}{|c|}{ Latent profile 2 Vs 4} & \multicolumn{2}{|c|}{ Latent profile $3 \mathrm{Vs} 4$} & \multicolumn{2}{|c|}{ Latent profile $1 \mathrm{Vs} 3$} & \multicolumn{2}{|c|}{ Latent profile $2 \mathrm{Vs} 3$} & \multicolumn{2}{|c|}{ Latent profile $1 \mathrm{Vs} 2$} \\
\hline$\underline{\text { Predictor }}$ & Coef. (SE) & OR & Coef. (SE) & $\mathrm{OR}$ & Coef. (SE) & OR & Coef. (SE) & OR & Coef. (SE) & OR \\
\hline Sex & $-1.283(.347)^{* *}$ & .277 & $-.263(.333)$ & .769 & $.032(.280)$ & 1.033 & $-1.020(.319)^{* *}$ & .361 & $1.052(.311)^{* *}$ & 2.863 \\
\hline Work Time & $-.132(.674)$ & .876 & $.605(.492)$ & 1.831 & $.118(.356)$ & 1.125 & $-.737(.604)$ & .479 & $.856(.596)$ & 2.354 \\
\hline Age & $.165(.197)$ & 1.179 & $.175(.161)$ & 1.191 & $-.181(.137)$ & .834 & $-.010(.183)$ & .990 & $-.171(.187)$ & .843 \\
\hline Tenure & $-.234(.189)$ & .791 & $-.224(.181)$ & .799 & $-.109(.175)$ & .897 & $-.010(.181)$ & .990 & $-.099(.189)$ & .906 \\
\hline Workload & $.363(.151)^{*}$ & 1.438 & $-.031(.138)$ & .969 & $.443(.107)^{* *}$ & 1.557 & $.394(.136)^{* *}$ & 1.483 & $.049(.131)$ & 1.050 \\
\hline POS & $-.302(.149)^{*}$ & .739 & $-.255(.163)$ & .775 & $.253(.122)^{*}$ & 1.288 & $-.048(.169)$ & .953 & $.301(.146)^{*}$ & 1.351 \\
\hline PSS & $.030(.203)$ & 1.030 & $.017(.175)$ & 1.017 & $.207(.150)$ & 1.230 & $.012(.192)$ & 1.012 & $.195(.187)$ & 1.215 \\
\hline PCS & $-.347(.162)^{*}$ & .707 & $.111(.154)$ & 1.117 & $-.143(.123)$ & .867 & $-.458(.148)^{* *}$ & .633 & $.315(.139) *$ & 1.370 \\
\hline
\end{tabular}

Note. SE: Standard error of the coefficient; OR: Odds ratio; the coefficients and OR reflects the effects of the predictors on the likelihood of membership into the first listed profile relative to the second listed profile; POS: Perceived organizational support; PSS: Perceived supervisor support; PCS: Perceived colleagues support; POS, PSS, PCS, and workload are estimated from factor scores with a grand mean of 0 and a standard deviation of 1; Profile 1: Self-Driven Introjected; Profile 2: Externally Driven; Profile 3: Moderately Intrinsically Motivated; Profile 4: Highly Intrinsically Motivated; Profile 5: Value-Reward Self-Driven; Profile 6: Self-Driven Hedonist. 


\section{Table 3}

Associations between Profile Membership and the Outcomes (Explanatory Similarity)

\begin{tabular}{|c|c|c|c|c|c|c|c|}
\hline & Profile 1 & Profile 2 & Profile 3 & Profile 4 & Profile 5 & Profile 6 & Tests of significance \\
\hline Presenteeism & $\begin{array}{c}.064 \\
{[-.081 ; .209]}\end{array}$ & $\begin{array}{c}.525 \\
{[.206 ; .843]}\end{array}$ & $\begin{array}{c}-.140 \\
{[-.325 ; .046]}\end{array}$ & $\begin{array}{c}-.352 \\
{[-.480 ;-.225]}\end{array}$ & $\begin{array}{c}-.088 \\
{[-.204 ; .028]}\end{array}$ & $\begin{array}{c}-.307 \\
{[-.443 ;-.171]}\end{array}$ & $\begin{array}{c}2>1=5>4=6 ; 2>3 ; \\
1=3=5 ; 3=4=6\end{array}$ \\
\hline Turnover Intentions & $\begin{array}{c}-.069 \\
{[-.199 ; .060]}\end{array}$ & $\begin{array}{c}.740 \\
{[.545 ; .935]}\end{array}$ & $\begin{array}{c}-.204 \\
{[-.365 ;-.043]}\end{array}$ & $\begin{array}{c}-.227 \\
{[-.389 ;-.066]}\end{array}$ & $\begin{array}{c}.057 \\
{[-.054 ; .169]}\end{array}$ & $\begin{array}{c}-.214 \\
{[-.376 ;-.052]}\end{array}$ & $\begin{array}{c}2>5>3=4=6 ; 2>1 ; \\
1=5 ; 1=3=4=6\end{array}$ \\
\hline Work Performance & $\begin{array}{c}7.367 \\
{[7.154 ; 7.579]}\end{array}$ & $\begin{array}{c}6.289 \\
{[5.811 ; 6.766]}\end{array}$ & $\begin{array}{c}7.612 \\
{[7.427 ; 7.797]}\end{array}$ & $\begin{array}{c}7.782 \\
{[7.573 ; 7.992]}\end{array}$ & $\begin{array}{c}7.406 \\
{[7.272 ; 7.539]}\end{array}$ & $\begin{array}{c}7.769 \\
{[7.553 ; 7.985]}\end{array}$ & $\begin{array}{c}4=6>1=5>2 ; 3>2 ; 3=4= \\
6 ; 1=3=5\end{array}$ \\
\hline Absenteeism & $\begin{array}{c}10.310 \\
{[.096 ; 20.523]}\end{array}$ & $\begin{array}{c}6.978 \\
{[2.186 ; 11.770]}\end{array}$ & $\begin{array}{c}7.332 \\
{[3.092 ; 11.572]}\end{array}$ & $\begin{array}{c}3.279 \\
{[1.627 ; 4.932]}\end{array}$ & $\begin{array}{c}2.474 \\
{[1.428 ; 3.519]}\end{array}$ & $\begin{array}{c}2.975 \\
{[1.356 ; 4.594]}\end{array}$ & $\begin{array}{c}3>5 ; 1=2=3=4=6 \\
1=2=5=6\end{array}$ \\
\hline
\end{tabular}

Note. CI $=95 \%$ confidence interval; Presenteeism and turnover intentions are estimated from factor scores with a grand mean of 0 and a standard deviation of 1 ; Profile 1 : Self-Driven Introjected; Profile 2: Externally Driven; Profile 3: Moderately Intrinsically Motivated; Profile 4: Highly Intrinsically Motivated; Profile 5: Value-Reward SelfDriven; Profile 6: Self-Driven Hedonist. 


\section{Online Supplemental Materials for:}

\section{A Test of Work Motivation Profile Similarity across Four Distinct Samples of Employees}

\section{Authors' note:}

These online technical appendices are to be posted on the journal website and hot-linked to the manuscript. If the journal does not offer this possibility, these materials can alternatively be posted on one of our personal websites (we will adjust the in-text reference upon acceptance).

We would also be happy to have some of these materials brought back into the main manuscript, or included as published appendices if you deem it useful. We developed these materials to provide additional technical information and to keep the main manuscript from becoming needlessly long. 


\section{A Bifactor Operationalization of Work Motivation \\ Preliminary Measurement Models}

As noted in the main manuscript, accumulating research evidence suggests that ratings of motivation are best represented as simultaneously reflecting respondents' global quantity of selfdetermined motivation in a way that is fully aligned with the self-determination theory (SDT) continuum hypothesis (Ryan \& Deci, 2017), together with specific factors reflecting the unique quality of each type of behavioral regulation over and above that global quantity. So far, that conclusion has been supported in the work (Howard, Gagné, Morin, \& Forest, 2018), vocational (Gillet et al., 2018), and education (Litalien et al., 2017) domains. Importantly, research in which these two layers of measurement cannot be properly disentangled carries the risk of leading to an overly similar assessment of the relative contribution of each motivation type, making it impossible to clearly identify the unique contribution of each of them over and above that of participants' global quantity of self-determination (Gillet et al., 2018; Howard et al., 2018; Litalien et al., 2017).

This multidimensional operationalization of motivation is typically achieved via the estimation of bifactor Exploratory Structural Equation Models (bifactor-ESEM) measurement models (e.g., Morin, Arens, \& Marsh, 2016; Reise, 2012). In bifactor models, all motivation items are used to define an overarching G-factor reflecting participants' global quantity of self-determination (with factor loadings ranging from negative to high and positive depending on the position of that item on the hypothetical SDT continuum of motivation). In addition, all subscale-specific items were used to define $S$-factors reflecting the unique quality associated with each type of motivation left unexplained by the G-factor. In ESEM models (Morin, Marsh, \& Nagengast, 2013), all cross-loadings between the behavioral regulation subscales are freely estimated, based on accumulating statistical research evidence showing that this free estimation provides a way to achieve a greater level of precision in the estimation of multidimensional latent constructs (Asparouhov, Muthén, \& Morin, 2015). Early research evidence has supported the value of ESEM in helping to achieve an improved representation of motivation (i.e., more closely aligned with the continuum hypothesis) in the academic area relative to more classical confirmatory factor analyses (CFA; Guay, Morin, Litalien, Valois, \& Vallerand, 2015; Litalien, Guay, \& Morin, 2015). However, this early ESEM representation has been superseded by the combined bifactor-ESEM framework given its ability to provide a direct estimate of the global self-determination continuum (Gillet et al., 2018; Howard et al., 2008; Litalien et al., 2017).

\section{Preliminary Measurement Models: Estimation}

Preliminary measurement models were estimated with Mplus 8 (Muthén \& Muthén, 2017) using the robust Maximum Likelihood (MLR) estimator, which provides parameter estimates, standard errors, and goodness-of-fit indices that are robust to the non-normality of the response scales used in the present study. These models were estimated using Full Information Maximum Likelihood (FIML; Enders, 2010) procedures to account for the limited amount of missing responses present at the item level (Sample 1: 0\% to 5.2\%; Sample 2: 0\% to 5.6\%; Sample 3: 0\% to 4.6\%; Sample 4: 0\% to 4.6\%). Due to the complexity of the models underlying all constructs assessed in the present study, preliminary analyses were conducted separately for the motivation measure and for the multi-items predictor (workload, perceived organizational, supervisor, and colleagues support) and outcome (presenteeism and turnover intentions) measures.

For the motivation measure, a bifactor-ESEM model (e.g., Morin et al., 2016) including one global factor (G-factor: Global quantity of self-determination) and five specific orthogonal factors (S-factors: Intrinsic motivation, identified regulation, introjected regulation, external regulation, and amotivation) was estimated. This modeling decision is based on accumulated evidence supporting the superiority of this approach within all studies in which a bifactor-ESEM representation of motivation was contrasted with alternative solutions (Howard et al., 2018; Litalien et al., 2017). Yet, to support this decision, we still estimated comparable CFA, bifactor-CFA, and ESEM solutions. In CFA, each item was only allowed to load on the factor it was assumed to measure and no cross-loadings were allowed, and all factors were allowed to freely correlate. In bifactor-CFA, each item was allowed to define one global factor, as well as one specific factor corresponding to the CFA solution, and all factors were set to be orthogonal (Morin et al., 2016; Reise, 2012). ESEM solutions were estimated using an oblique target rotation, whereas bifactor-ESEM models were estimated using an orthogonal target rotation in line with bifactor model assumptions of orthogonality (Morin et al., 2016; Reise, 2012). Target rotation is a confirmatory approach to rotation in which all main loadings are specified a priori (as in CFA) but allowing for the 
free estimation of all cross-loadings which are "targeted" to be as close to zero as possible.

After having separately estimated all four models in each of the four samples, we verified that the measurement models operated in the same manner across groups, through sequential tests of measurement invariance (Millsap, 2011). More precisely, we assessed: (1) configural invariance; (2) weak invariance (loadings); (3) strong invariance (loadings and intercepts); (4) strict invariance (loadings, intercepts, and uniquenesses); (5) invariance of the latent variance-covariance matrix (loadings, intercepts, uniquenesses, and latent variances and covariances); and (6) latent means invariance (loadings, intercepts, uniquenesses, latent variances and covariances, and latent means). Factor scores were saved from the most invariant of those models.

For the predictors and outcomes, a six-factor CFA model was specified to reflect participants' ratings of workload, perceived organizational, supervisor, and colleagues support, presenteeism, and turnover intentions. Each item was only allowed to load on the factor it was assumed to measure and no crossloadings were allowed, and all factors were allowed to freely correlate. This model also included a priori correlated uniquenesses to account for the strictly parallel wording of the items forming the three support subscales (Marsh et al., 2013; Stinglhamber \& Vandenberghe, 2004), as well as one orthogonal method factor to account for the negative wording of six of the items (Marsh, Scalas, \& Nagengast, 2010).

Given the known oversensitivity of the chi-square test of exact fit $\left(\chi^{2}\right)$ to sample size and minor model misspecifications (e.g., Marsh, Hau, \& Grayson, 2005), we relied on sample-size independent goodness-of-fit indices to describe the fit of the alternative models (Hu \& Bentler, 1999): The comparative fit index (CFI), the Tucker-Lewis index (TLI), as well as the root mean square error of approximation (RMSEA) and its $90 \%$ confidence interval. Values greater than .90 for the CFI and TLI indicate adequate model fit, although values greater than .95 are preferable. Values smaller than .08 or .06 for the RMSEA respectively support acceptable and excellent model fit. Like the chisquare, chi-square difference tests present a known sensitivity to sample size and minor model misspecifications so that recent studies suggest complementing this information with changes in CFIs and RMSEAs (Chen, 2007; Cheung \& Rensvold, 2002) in the context of tests of measurement invariance. A $\Delta$ CFI of .010 or less, a $\Delta$ TLI of .010 or less, and a $\triangle$ RMSEA of .015 or less between a more restricted model and the previous one support the invariance hypothesis.

\section{Preliminary Measurement Models: Results}

The goodness-of-fit results from all motivation models are reported in Table S1. These results clearly support the adequacy of the a priori bifactor-ESEM model underlying the motivation measures (with all CFI $\geq .95$, all TLI $\geq .90$, and all RMSEA $\leq .06$ ) and its superiority relative to the ESEM models $(\triangle \mathrm{CFI}=.024$ to $.055 ; \Delta \mathrm{TLI}=.37$ to $.100 ; \Delta \mathrm{RMSEA}=.012$ to .032$)$ which even failed to achieve a satisfactory level of fit to the data in two out of four samples according to the TLI. In contrast, neither the CFA nor the bifactor-CFA solutions were able to achieve a satisfactory level of model fit in any of the samples. Morin et al. (2016) mention that sometimes some of these alternative models would result in a highly similar level of model fit, in which cases a detailed examination of parameter estimates is required to select the optimal model. In contrast, in the present study, the superiority of the bifactor-ESEM solution is obvious from the perspective of model fit, and fully aligned with the results from previous research.

This solution was thus retained for tests of measurement invariance. The results from these tests, reported in the bottom section of Table S1, supported the configural and weak invariance of the model, but not its strong invariance $(\triangle \mathrm{CFI} / \mathrm{TLI} \geq .010)$. We thus pursued tests of partial strong invariance, in which the equality constraints across groups had to be relaxed on two item intercepts in Sample 3 (i.e., nurses). Likewise, strict invariance was not supported, but a model of partial strict invariance in which the equality constraints across groups had to be relaxed on two items uniquenenesses in Sample 2 (i.e., hospital employees), five items in Sample 3 (i.e., nurses), and one item in Sample 4 (i.e., physiotherapists) was supported by the data. Subsequent steps showed that neither the invariance of the latent variances and covariances or of the latent means was supported across groups. However, models of partial invariance in which equality constraints on the latent variance-covariance and mean matrices had to be relaxed in Sample 3 (i.e., nurses) were supported by the data. These solutions revealed slightly lower levels of variability on most factors among the nurse sample, accompanied by lower levels of global self-determination (-.416 SD lower than in the other samples) and higher specific levels of intrinsic motivation (.772 SD higher than in the other samples). 
These results globally show that the measurement models underlying our constructs can be considered to be roughly equivalent across groups, leading to the estimation of similar constructs. They also showed that the construct variability and means differed across groups on some constructs. Factor scores used in the main analyses were extracted from the final model of partial latent means invariance. Although only (partial) strict measurement invariance is required to ensure that measurement of the constructs remains equivalent across time waves for models based on factor scores (e.g., Millsap, 2011), there are advantages to saving factor scores from a model of complete measurement invariance, which provides time specific measures that are directly comparable based on a mean of 0 and a standard deviation of 1 across samples. To achieve a similar level of comparability for the factors associated with non-invariant latent means and variance, factor scores were saved from a model in which the scale of these factors was set using a grand mean of 0 and a grand variance of 1 (across all samples).

Parameter estimates from this final model of partial latent means invariance are reported in Tables S2 (Sample 1), S3 (Sample 2), S4 (Sample 3), and S4 (Sample 4). When interpreting a bifactor-ESEM results, it is important to keep in mind that, because bifactor models rely on two factors to explain the covariance present at the item level for each specific item, factor loadings on G-and S-Factors are typically lower than their first-order counterparts (e.g., Morin et al., 2016). As such, the critical question when interpreting a bifactor solution is whether the G-factor really taps into a meaningful amount of covariance shared among all items, and whether there remains sufficient covariance at the subscale level unexplained by the G-factor to result in the estimation of meaningful S-factors.

The results from the bifactor-ESEM solutions revealed a well-defined G-Factor across groups $(\omega=$ .803 to .818 ) that provides a clear representation of the hypothesized self-determination continuum with strong positive loadings from the intrinsic $(\lambda=.524$ to .688$)$ items, moderately strong positive loadings from the identified ( $\lambda=.269$ to .546$)$ items, small to moderate positive loadings from the introjection ( $\lambda=.038$ to .433$)$ items, small or negative loadings from the external ( $\lambda=-.245$ to .358$)$ items, and moderate negative loadings from the amotivation $(\lambda=-.609$ to -.258$)$ items. Over and above this G-Factor, items associated with the amotivation $(\lambda=.495$ to $.898, \omega=.724$ to .771$)$, external $(\lambda=.277$ to $.750, \omega=.579$ to .794$)$, introjected $(\lambda=.200$ to $.936, \omega=.731$ to .779$)$, and intrinsic ( $\lambda=.430$ to $.546, \omega=.659$ to .724$)$ S-factors retained a satisfactory level of specificity. In contrast, the identified regulation S-factor appeared to be more weakly defined $(\lambda=.112$ to $.334, \omega=$ .192 to .235 ) suggesting that identified regulation ratings mainly served to define global levels of selfdetermination, and only retained a limited amount of specificity when these global levels were taken into account. The fact that this S-Factor retained less specificity does not mean that it has no meaning, especially when modelled using an approach that explicitly controls for both measurement error and associations with the global self-determination construct, such as the approach taken in the present study. It is noteworthy that previous research using the same instrument reported virtually identical (Howard et al., 2018) or very similar (Gillet et al., 2018) bifactor-ESEM results.

Finally, the results also support the adequacy of the model underlying the predictor and outcome measures $(\mathrm{CFI}=.935 ; \mathrm{TLI}=.925 ; \mathrm{RMSEA}=.055$ : See Table S6). The tests of measurement invariance conducted on responses to these predictor and outcome measures closely match the results obtained for the motivation model, revealing support for a model of weak, partial strong (equality constraints across samples had to be relaxed on seven item intercepts in total), partial strict (equality constraints across samples had to be relaxed on nine item uniquenesses in total), partial latent variance-covariance (eight specific equality constraints had to be relaxed across samples in the latent variance-covariance matrix), and partial latent means (equality constraints had to be relaxed on eleven latent means across samples) invariance across samples.

These results thus globally show that the measurement models underlying our constructs can be considered to be roughly equivalent across groups, leading to the estimation of similar constructs. They also showed that the construct variability and means differed across groups on some constructs. The final invariant parameter estimates from the model of partial latent means invariance, from which factor scores were extracted from the main analyses, are reported in reported in Tables S7 (Sample 1), S8 (Sample 2), S9 (Sample 3) and S10 (Sample 4). These results reveal well-defined factors for all constructs considered here: (a) workload ( $\lambda=.453$ to $.796, \omega=.724$ to .828$)$; (b) perceived organizational support ( $\lambda=.486$ to $.946, \omega=.816$ to .882$)$; (c) perceived supervisor support $(\lambda=.630$ to $.905, \omega=.866$ to .866$)$; (d) perceived colleagues support ( $\lambda=.620$ to $.895, \omega=.837$ to .879$)$; (e) 
presenteeism ( $\lambda=.756$ to $.918, \omega=.922$ to .860$)$; and (f) turnover intentions $(\lambda=.808$ to $.973, \omega=.875$ to .925). The correlations between all variables used in the main analyses (i.e., the factor scores from these final measurement models and single-item measures) are reported in Table S11.

\section{References used in this supplement}

Asparouhov, T., Muthén, B.O., \& Morin, A.J.S. (2015). Bayesian Structural equation modeling with cross-loadings and residual covariances. Journal of Management, 41, 1561-1577.

Chen, F.F. (2007). Sensitivity of goodness of fit indexes to lack of measurement. Structural Equation Modeling, 14, 464-504.

Cheung, G.W., \& Rensvold, R.B. (2002). Evaluating goodness-of fit indexes for testing measurement invariance. Structural Equation Modeling, 9, 233-255.

Enders, C.K. (2010). Applied missing data analysis. New York, NY: Guilford.

Gillet, N., Morin, A.J.S., Huart, I., Odry, D., Chevalier, S., Coillot, H., \& Fouquereau, E. (2018). Selfdetermination trajectories during police officers' vocational training program: A growth mixture analysis. Journal of Vocational Behavior, 109, 27-43.

Guay, F., Morin, A.J.S., Litalien, D., Valois, P., \& Vallerand, R.J. (2015). Application of exploratory structural equation modeling to evaluate the academic motivation scale. The Journal of Experimental Education, 83, 51-82.

Howard, J.L., Gagné, M., Morin, A.J.S., \& Forest, J. (2018). Using bifactor exploratory structural equation modeling to test for a continuum structure of motivation. Journal of Management, 44, 2638-2664.

Hu, L.T., \& Bentler, P.M. (1999). Cutoff criteria for fit indexes in covariance structure analysis: Conventional criteria versus new alternatives. Structural Equation Modeling, 6, 1-55.

Litalien, D., Guay, F., \& Morin, A.J.S. (2015). Motivation for PhD studies: Scale development and validation. Learning and Individual Differences, 41, 1-13.

Litalien, D., Morin, A.J.S., Gagné, M., Vallerand, R.J., Losier, G.F., \& Ryan, R.M. (2017). Evidence of a continuum structure of academic self-determination: A two-study test using a bifactor-ESEM representation of academic motivation. Contemporary Educational Psychology, 51, 67-82.

Marsh, H.W., Abduljabbar, A.S., Abu-Hilal, M., Morin, A.J.S., Abdelfattah, F., Leung, K.C., Xu, M.K., Nagengast, B., \& Parker, P. (2013). Factor structure, discriminant and convergent validity of TIMSS math and science motivation measures: A comparison of USA and Saudi Arabia. Journal of Educational Psychology, 105, 108-128.

Marsh, H.W., Hau, K., \& Grayson, D. (2005). Goodness of fit evaluation in structural equation modeling. In A. Maydeu-Olivares \& J. McArdle (Eds.), Contemporary psychometrics. Mahwah, NJ: Erlbaum.

Marsh, H.W., Scalas, L.F., \& Nagengast, B. (2010). Longitudinal tests of competing factor structures for the Rosenberg self-esteem scale: Traits, ephemeral artifacts, and stable response styles. Psychological Assessment, 22, 366-381.

Morin, A.J.S., Arens, A., \& Marsh, H.W. (2016). A bifactor exploratory structural equation modeling framework for the identification of distinct sources of construct-relevant psychometric multidimensionality. Structural Equation Modeling, 23, 116-139.

Morin, A.J.S., Marsh, H.W., \& Nagengast, B. (2013). Exploratory structural equation modeling. In G. R. Hancock \& R. O. Mueller (Eds.), Structural equation modeling: A second course (pp. 395-436). Greenwich, CO: IAP.

Millsap, R. (2011). Statistical approaches to measurement invariance. New York, NY: Taylor \& Francis.

Muthén, L.K., \& Muthén, B.O. (2017). Mplus user's guide. Los Angeles, CA: Muthén \& Muthén.

Reise, S.P. (2012). The rediscovery of bifactor measurement models. Multivariate Behavioral Research, 47, 667-696.

Ryan, R.M., \& Deci, E.L. (2017). Self-determination theory: Basic psychological needs in motivation, development, and wellness. New York, NY: Guilford.

Stinglhamber, F., \& Vandenberghe, C. (2003) Organizations and supervisors as sources of support and targets of commitment. Journal of Organizational Behavior, 24, 251-270. 


\section{Table S1}

Goodness-of-Fit Statistics of the Preliminary Measurement Models (Motivation)

\begin{tabular}{|c|c|c|c|c|c|c|c|c|c|c|}
\hline Description & $\chi^{2}(d f)$ & CFI & TLI & RMSEA & $90 \% \mathrm{CI}$ & $\mathrm{CM}$ & $\Delta \chi^{2}(d f)$ & $\Delta \mathrm{CFI}$ & $\Delta$ TLI & $\overline{\Delta \text { RMSEA }}$ \\
\hline \multicolumn{11}{|l|}{ Sample 1} \\
\hline CFA & $540.990(142)^{*}$ & .802 & .761 & .098 & {$[.090 ; .107]$} & - & - & - & - & - \\
\hline Bifactor-CFA & $822.457(133)^{*}$ & .658 & .560 & .133 & {$[.125 ; .142]$} & - & - & - & - & - \\
\hline ESEM & $243.114(86)^{*}$ & .922 & .845 & .079 & {$[.068 ; .091]$} & - & - & - & - & - \\
\hline Bifactor-ESEM & $118.376(72)^{*}$ & .977 & .945 & .047 & {$[.031 ; .062]$} & - & - & - & - & - \\
\hline \multicolumn{11}{|l|}{ Sample 2} \\
\hline CFA & $462.697(142)^{*}$ & .779 & .734 & .095 & {$[.086 ; .105]$} & - & - & - & - & - \\
\hline Bifactor-CFA & $549.275(133)^{*}$ & .713 & .632 & .112 & {$[.102 ; .122]$} & - & - & - & - & - \\
\hline ESEM & $151.041(86)^{*}$ & .955 & .911 & .055 & {$[.040 ; .069]$} & - & - & - & - & - \\
\hline Bifactor-ESEM & $102.768(72)^{*}$ & .979 & .950 & .041 & {$[.021 ; .059]$} & - & - & - & - & - \\
\hline \multicolumn{11}{|l|}{ Sample 3} \\
\hline CFA & $458.268(142)^{*}$ & .743 & .690 & .097 & {$[.087 ; .107]$} & - & - & - & - & - \\
\hline Bifactor-CFA & $473.771(133)^{*}$ & .723 & .644 & .104 & {$[.094 ; .114]$} & - & - & - & - & - \\
\hline ESEM & $170.285(86)^{*}$ & .931 & .864 & .064 & {$[.050 ; .078]$} & - & - & - & - & - \\
\hline Bifactor-ESEM & $115.887(72)^{*}$ & .964 & .915 & .051 & {$[.033 ; .067]$} & - & - & - & - & - \\
\hline \multicolumn{11}{|l|}{ Sample 4} \\
\hline CFA & $564.277(142)^{*}$ & .790 & .747 & .089 & {$[.082 ; .097]$} & - & - & - & - & - \\
\hline Bifactor-CFA & $566.932(133)^{*}$ & .784 & .722 & .094 & {$[.086 ; .102]$} & - & - & - & - & - \\
\hline ESEM & $181.849(86)^{*}$ & .952 & .905 & .055 & {$[.044 ; .066]$} & - & - & - & - & - \\
\hline Bifactor-ESEM & $121.013(72)^{*}$ & .976 & .942 & .043 & {$[.029 ; .056]$} & - & - & - & - & - \\
\hline \multicolumn{11}{|l|}{ Multi-Group Models } \\
\hline M1. Confígural invariance & $457.564(288)^{*}$ & .975 & .940 & .045 & {$[.037 ; .053]$} & - & - & - & - & - \\
\hline M2. Weak invariance & $752.939(522) *$ & .966 & .955 & .039 & {$[.033 ; .045]$} & M1 & $309.322(234)^{*}$ & -.009 & +.015 & -.006 \\
\hline M3. Strong invariance & $874.163(561)^{*}$ & .953 & .943 & .044 & {$[.038 ; .050]$} & M2 & $126.008(39)^{*}$ & -.013 & -.012 & +.005 \\
\hline M4. Partial strong invariance & $832.937(559)^{*}$ & .959 & .950 & .041 & {$[.035 ; .047]$} & M2 & $81.723(37)^{*}$ & -.007 & -.005 & +.002 \\
\hline M5. Strict invariance & $1297.004(616) *$ & .899 & .888 & .062 & {$[.057 ; .067]$} & M4 & $246.815(57)^{*}$ & -.060 & -.062 & +.021 \\
\hline M6. Partial strict invariance & $926.949(608)^{*}$ & .953 & .947 & .043 & {$[.037 ; .048]$} & M4 & $81.272(49)^{*}$ & -.006 & -.003 & +.002 \\
\hline M7. Latent variance-covariance invariance & $1161.906(671)^{*}$ & .927 & .926 & .050 & {$[.046 ; .055]$} & M6 & $191.059(63)^{*}$ & -.026 & -.021 & +.007 \\
\hline M8. Partial latent variance-covariance invariance & $997.194(824) *$ & .947 & .945 & .043 & {$[.038 ; .048]$} & M6 & $68.339(42)^{*}$ & -.006 & -.002 & .000 \\
\hline M9. Latent means invariance & $1182.679(668)^{*}$ & .924 & .922 & .052 & {$[.047 ; .057]$} & M8 & $218.625(18)^{*}$ & -.023 & -.023 & +.009 \\
\hline M10. Partial latent means invariance & $1077.859(662)^{*}$ & .938 & .936 & .047 & {$[.042 ; .052]$} & M8 & $112.431(12)^{*}$ & -.009 & -.009 & +.004 \\
\hline
\end{tabular}

Note. $* p<.01 ; \chi^{2}$ : Robust chi-square test of exact fit; $d f$ : Degrees of freedom; CFI: Comparative fit index; TLI: Tucker-Lewis index; RMSEA: Root mean square error of

approximation; $90 \% \mathrm{CI}$ : 90\% confidence interval; CM: Comparison model; $\Delta$ : Change in fit relative to the CM. 
Table S2

Standardized Factor Loadings $(\lambda)$ and Uniquenesses $(\delta)$ from the Bifactor-ESEM Solution (Motivation, Partial Means, Sample 1)

\begin{tabular}{|c|c|c|c|c|c|c|c|}
\hline Items & $\begin{array}{l}G \\
\lambda\end{array}$ & $\begin{array}{c}\text { S-IM } \\
\lambda\end{array}$ & $\begin{array}{c}\text { S-IDR } \\
\lambda\end{array}$ & $\begin{array}{c}\text { S-INR } \\
\lambda\end{array}$ & $\begin{array}{c}\text { S-EXR } \\
\lambda\end{array}$ & $\begin{array}{c}\text { S-AMO } \\
\lambda\end{array}$ & $\delta$ \\
\hline \multicolumn{8}{|l|}{$\overline{\mathrm{IM}}$} \\
\hline Item 1 & .597 & .467 & .159 & -.094 & -.165 & -.038 & .363 \\
\hline Item 2 & .688 & .498 & .209 & -.115 & -.153 & -.002 & .200 \\
\hline Item 3 & .601 & .526 & .185 & -.104 & -.169 & -.052 & .285 \\
\hline \multicolumn{8}{|l|}{ IDR } \\
\hline Item 1 & .304 & -.223 & .334 & .317 & 207 & -.007 & .603 \\
\hline Item 2 & .546 & .481 & .267 & -.054 & -.148 & -.044 & .373 \\
\hline Item 3 & .356 & .177 & .136 & .181 & -.008 & .041 & .788 \\
\hline \multicolumn{8}{|l|}{ INR } \\
\hline Item 1 & .362 & -.371 & .451 & .447 & .349 & .003 & .207 \\
\hline Item 2 & .433 & .057 & .280 & .240 & .190 & .027 & .636 \\
\hline Item 3 & .038 & .166 & -.111 & .927 & .135 & .028 & .080 \\
\hline Item 4 & .218 & -.028 & -.038 & .636 & .175 & .000 & .515 \\
\hline \multicolumn{8}{|l|}{ EXR } \\
\hline Item 1 & .040 & -.071 & .292 & .333 & .606 & -.078 & .425 \\
\hline Item 2 & .001 & .072 & .182 & .293 & .750 & -.077 & .307 \\
\hline Item 3 & -.172 & .106 & .082 & .373 & .588 & .094 & .459 \\
\hline Item 4 & .255 & -.140 & -.271 & .021 & .403 & .154 & .655 \\
\hline Item 5 & .336 & -.188 & -.362 & .081 & .499 & .173 & .435 \\
\hline Item 6 & .264 & -.096 & -.264 & .107 & .477 & .177 & .581 \\
\hline \multicolumn{8}{|l|}{ AMO } \\
\hline Item 1 & -.258 & -.095 & .025 & .137 & .372 & .530 & .486 \\
\hline Item 2 & -.305 & -.047 & .018 & .175 & .384 & .758 & .152 \\
\hline Item 3 & -.272 & -.072 & -.022 & .180 & .261 & .495 & .575 \\
\hline$\omega$ & .818 & .724 & .235 & .779 & .794 & .724 & \\
\hline
\end{tabular}

Note. $\mathrm{G}=$ Global factor estimated as part of a bifactor model; $\mathrm{S}=$ Specific factor estimated as part of a bifactor model; $\lambda$ : Factor loading; $\delta$ : Item uniqueness; $\omega$ : Omega coefficient of model-based composite reliability; IM = Intrinsic motivation; IDR = Identified regulation; INR = Introjected regulation; $\mathrm{EXR}=$ External regulation; $\mathrm{AMO}=$ Amotivation; non-significant parameters $(p \geq .05)$ are marked in italics. 
Table S3

Standardized Factor Loadings $(\lambda)$ and Uniquenesses $(\delta)$ from the Bifactor-ESEM Solution (Motivation, Partial Means, Sample 2)

\begin{tabular}{|c|c|c|c|c|c|c|c|}
\hline & $\mathrm{G}$ & S-IM & S-IDR & S-INR & S-EXR & S-AMO & \\
\hline Items & $\lambda$ & $\lambda$ & $\lambda$ & $\lambda$ & $\lambda$ & $\lambda$ & $\delta$ \\
\hline \multicolumn{8}{|l|}{$\overline{\mathrm{IM}}$} \\
\hline Item 1 & .597 & .467 & .159 & -.094 & -.165 & -.038 & .363 \\
\hline Item 2 & .594 & .430 & .180 & -.100 & -.132 & -.001 & .402 \\
\hline Item 3 & .601 & .526 & .185 & -.104 & -.169 & -.052 & .285 \\
\hline \multicolumn{8}{|l|}{ IDR } \\
\hline Item 1 & .304 & -.223 & .334 & .317 & .207 & -.007 & .603 \\
\hline Item 2 & .471 & .416 & .231 & -.046 & -.128 & -.038 & .532 \\
\hline Item 3 & .356 & .177 & .136 & .181 & -.008 & .041 & .788 \\
\hline \multicolumn{8}{|l|}{ INR } \\
\hline Item 1 & .362 & -.371 & .451 & .447 & .349 & .003 & .207 \\
\hline Item 2 & .433 & .057 & .280 & .240 & .190 & .027 & .636 \\
\hline Item 3 & .038 & .166 & -.111 & .927 & .135 & .028 & .080 \\
\hline Item 4 & .218 & -.028 & -.038 & .636 & .175 & .000 & .515 \\
\hline \multicolumn{8}{|l|}{ EXR } \\
\hline Item 1 & .040 & -.071 & .292 & .333 & .606 & -.078 & .425 \\
\hline Item 2 & .001 & .072 & .182 & .293 & .750 & -.077 & .307 \\
\hline Item 3 & -.172 & .106 & .082 & .373 & .588 & .094 & .459 \\
\hline Item 4 & .255 & -.140 & -.271 & .021 & .403 & .154 & .655 \\
\hline Item 5 & .336 & -.188 & -.362 & .081 & .499 & .173 & .435 \\
\hline Item 6 & .264 & -.096 & -.264 & .107 & .477 & .177 & .581 \\
\hline \multicolumn{8}{|l|}{ AMO } \\
\hline Item 1 & -.258 & -.095 & .025 & .137 & .372 & .530 & .486 \\
\hline Item 2 & -.305 & -.047 & .018 & .175 & .384 & .758 & .152 \\
\hline Item 3 & -.272 & -.072 & -.022 & .180 & .261 & .495 & .575 \\
\hline$\omega$ & .803 & .659 & .204 & .779 & .794 & .724 & \\
\hline
\end{tabular}

Note. $\mathrm{G}=$ Global factor estimated as part of a bifactor model; $\mathrm{S}=$ Specific factor estimated as part of a bifactor model; $\lambda$ : Factor loading; $\delta$ : Item uniqueness; $\omega$ : Omega coefficient of model-based composite reliability; IM = Intrinsic motivation; IDR = Identified regulation; INR = Introjected regulation; EXR = External regulation; $\mathrm{AMO}=$ Amotivation; non-significant parameters $(p \geq .05)$ are marked in italics. 
Table S4

Standardized Factor Loadings $(\lambda)$ and Uniquenesses $(\delta)$ from the Bifactor-ESEM Solution (Motivation, Partial Means, Sample 3)

\begin{tabular}{|c|c|c|c|c|c|c|c|}
\hline Items & $\begin{array}{l}\mathrm{G} \\
\lambda\end{array}$ & $\begin{array}{c}\text { S-IM } \\
\lambda\end{array}$ & $\begin{array}{c}\text { S-IDR } \\
\lambda\end{array}$ & $\begin{array}{c}\text { S-INR } \\
\lambda\end{array}$ & $\begin{array}{c}\text { S-EXR } \\
\lambda\end{array}$ & $\begin{array}{c}\text { S-AMO } \\
\lambda\end{array}$ & $\delta$ \\
\hline \multicolumn{8}{|l|}{ IM } \\
\hline Item 1 & .524 & .487 & .141 & -.077 & -.082 & -.024 & .360 \\
\hline Item 2 & .546 & .469 & .168 & -.086 & -.069 & -.001 & .313 \\
\hline Item 3 & .526 & .546 & .164 & -.085 & -.084 & -.033 & .281 \\
\hline \multicolumn{8}{|l|}{ IDR } \\
\hline Item 1 & .269 & -.234 & .300 & .262 & .104 & -.005 & .607 \\
\hline Item 2 & .475 & .497 & .236 & -.044 & -.073 & -.028 & .364 \\
\hline Item 3 & .315 & .186 & .112 & .150 & -.004 & .026 & .791 \\
\hline \multicolumn{8}{|l|}{ INR } \\
\hline Item 1 & .322 & -.392 & .407 & .372 & .177 & .002 & .211 \\
\hline Item 2 & .387 & .060 & .253 & .200 & .097 & .018 & .653 \\
\hline Item 3 & .041 & .212 & -.121 & .936 & .083 & .022 & .119 \\
\hline Item 4 & .210 & -.032 & -.036 & .571 & .095 & .000 & .611 \\
\hline \multicolumn{8}{|l|}{ EXR } \\
\hline Item 1 & .042 & -.087 & .309 & .324 & .359 & -.058 & .593 \\
\hline Item 2 & .001 & .102 & .221 & .328 & .511 & -.067 & .567 \\
\hline Item 3 & -.245 & .179 & .118 & .498 & .477 & .097 & .544 \\
\hline Item 4 & .372 & -.243 & -.401 & .029 & .335 & .162 & .604 \\
\hline Item 5 & .358 & -.238 & -.391 & .081 & .303 & .134 & .638 \\
\hline Item 6 & .270 & -.116 & -.273 & .102 & .277 & .130 & .779 \\
\hline \multicolumn{8}{|l|}{ AMO } \\
\hline Item 1 & -.461 & -.202 & .045 & .229 & .379 & .687 & .646 \\
\hline Item 2 & -.499 & -.092 & .029 & .267 & .358 & .898 & .523 \\
\hline Item 3 & -.609 & -.190 & -.050 & .376 & .332 & .802 & .523 \\
\hline$\omega$ & .812 & .703 & .192 & .731 & .579 & .771 & \\
\hline
\end{tabular}

Note. $\mathrm{G}=$ Global factor estimated as part of a bifactor model; $\mathrm{S}=$ Specific factor estimated as part of a bifactor model; $\lambda$ : Factor loading; $\delta$ : Item uniqueness; $\omega$ : Omega coefficient of model-based composite reliability; IM = Intrinsic motivation; IDR = Identified regulation; INR = Introjected regulation; EXR = External regulation; $\mathrm{AMO}=$ Amotivation; non-significant parameters $(p \geq .05)$ are marked in italics. 
Table S5

Standardized Factor Loadings $(\lambda)$ and Uniquenesses $(\delta)$ from the Bifactor-ESEM Solution (Motivation, Partial Means, Sample 4)

\begin{tabular}{|c|c|c|c|c|c|c|c|}
\hline Items & $\begin{array}{l}\mathrm{G} \\
\lambda\end{array}$ & $\begin{array}{c}\text { S-IM } \\
\lambda\end{array}$ & $\begin{array}{c}\text { S-IDR } \\
\lambda\end{array}$ & $\begin{array}{c}\text { S-INR } \\
\lambda\end{array}$ & $\begin{array}{c}\text { S-EXR } \\
\lambda\end{array}$ & $\begin{array}{c}\text { S-AMO } \\
\lambda\end{array}$ & $\delta$ \\
\hline \multicolumn{8}{|l|}{$\mathrm{IM}$} \\
\hline Item 1 & .597 & .467 & .159 & -.094 & -.165 & -.038 & .363 \\
\hline Item 2 & .688 & .498 & .209 & -.115 & -.153 & -.002 & .200 \\
\hline Item 3 & .601 & .526 & .185 & -.104 & -.169 & -.052 & .285 \\
\hline \multicolumn{8}{|l|}{ IDR } \\
\hline Item 1 & .304 & -.223 & .334 & .317 & .207 & -.007 & .603 \\
\hline Item 2 & .546 & .481 & .267 & -.054 & -.148 & -.044 & .373 \\
\hline Item 3 & .356 & .177 & .136 & .181 & -.008 & .041 & .788 \\
\hline \multicolumn{8}{|l|}{ INR } \\
\hline Item 1 & .362 & -.371 & .451 & .447 & .349 & .003 & .207 \\
\hline Item 2 & .433 & .057 & .280 & .240 & .190 & .027 & .636 \\
\hline Item 3 & .038 & .166 & -.111 & .927 & .135 & .028 & .080 \\
\hline Item 4 & .218 & -.028 & -.038 & .636 & .175 & .000 & .515 \\
\hline \multicolumn{8}{|l|}{ EXR } \\
\hline Item 1 & .040 & -.071 & .292 & .333 & .606 & -.078 & .425 \\
\hline Item 2 & .001 & .072 & .182 & .293 & .750 & -.077 & .307 \\
\hline Item 3 & -.153 & .094 & .073 & .333 & .524 & .084 & .570 \\
\hline Item 4 & .255 & -.140 & -.271 & .021 & .403 & .154 & .655 \\
\hline Item 5 & .336 & -.188 & -.362 & .081 & .499 & .173 & .435 \\
\hline Item 6 & .264 & -.096 & -.264 & .107 & .477 & .177 & .581 \\
\hline \multicolumn{8}{|l|}{ AMO } \\
\hline Item 1 & -.258 & -.095 & .025 & .137 & .372 & .530 & .486 \\
\hline Item 2 & -.305 & -.047 & .018 & .175 & .384 & .758 & .152 \\
\hline Item 3 & -.272 & -.072 & -.022 & .180 & .261 & .495 & .575 \\
\hline$\omega$ & .815 & .724 & .235 & .779 & .781 & .724 & \\
\hline
\end{tabular}

Note. $\mathrm{G}=$ Global factor estimated as part of a bifactor model; $\mathrm{S}=$ Specific factor estimated as part of a bifactor model; $\lambda$ : Factor loading; $\delta$ : Item uniqueness; $\omega$ : Omega coefficient of model-based composite reliability; IM = Intrinsic motivation; IDR = Identified regulation; INR = Introjected regulation; $\mathrm{EXR}=$ External regulation; $\mathrm{AMO}=$ Amotivation; non-significant parameters $(p \geq .05)$ are marked in italics. 
Table S6

Goodness-of-Fit Statistics of the Preliminary Measurement Models (Predictors and Outcomes)

\begin{tabular}{|c|c|c|c|c|c|c|c|c|c|c|}
\hline Description & $\chi^{2}(d f)$ & CFI & TLI & RMSEA & $90 \% \mathrm{CI}$ & $\mathrm{CM}$ & $\Delta \chi^{2}(d f)$ & $\Delta \mathrm{CFI}$ & $\Delta \mathrm{TLI}$ & $\triangle \triangle \mathrm{RMSEA}$ \\
\hline M1. Configural invariance & $1949.770(1052)^{*}$ & .935 & .925 & .055 & {$[.051 ; .058]$} & - & - & - & 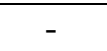 & - \\
\hline M2. Weak invariance & $2100.200(1127)^{*}$ & .930 & .919 & .055 & {$[.051 ; .058]$} & M1 & $146.828(75)^{*}$ & -.005 & -.006 & .000 \\
\hline M3. Strong invariance & $2492.257(1184)^{*}$ & .906 & .896 & .062 & {$[.059 ; .065]$} & M2 & $401.058(57)^{*}$ & -.024 & -.023 & +.007 \\
\hline M4. Partial strong invariance & $2226.726(1177)^{*}$ & .924 & .916 & .056 & {$[.052 ; .059]$} & M2 & $126.433(50)^{*}$ & -.006 & -.003 & +.001 \\
\hline M5. Strict invariance & $3429.390(1255)^{*}$ & .843 & .837 & .078 & {$[.075 ; .081]$} & M4 & $671.300(78)^{*}$ & -.081 & -.079 & -.022 \\
\hline M6. Partial strict invariance & $2366.666(1246)^{*}$ & .919 & .916 & .056 & {$[.053 ; .059]$} & M4 & $134.976(69)^{*}$ & -.005 & .000 & .000 \\
\hline M7. Latent variance-covariance invariance & $2729.356(1321)^{*}$ & .898 & .900 & .061 & {$[.058 ; .064]$} & M6 & $351.685(75)^{*}$ & -.021 & -.016 & +.005 \\
\hline M8. Partial latent variance-covariance invariance & $2566.886(1313)^{*}$ & .910 & .910 & .058 & {$[.054 ; .061]$} & M6 & $197.013(67)^{*}$ & -.009 & -.006 & +.002 \\
\hline M9. Latent means invariance & $3244.281(1334)^{*}$ & .862 & .866 & .071 & {$[.068 ; .074]$} & M8 & $807.499(21)^{*}$ & -.048 & -.044 & +.013 \\
\hline M10. Partial latent means invariance & $2591.788(1323)^{*}$ & .908 & .910 & .058 & {$[.054 ; .061]$} & M8 & $25.742(10)^{*}$ & -.002 & .000 & .000 \\
\hline
\end{tabular}

Note. ${ }^{*} p<.01 ; \chi^{2}$ : Robust chi-square test of exact fit; $d f$ : Degrees of freedom; CFI: Comparative fit index; TLI: Tucker-Lewis index; RMSEA: Root mean square error of approximation; $90 \% \mathrm{CI}$ : $90 \%$ confidence interval; CM: Comparison model; $\Delta$ : Change in fit relative to the CM. 
Table S7

Standardized Factor Loadings ( $\lambda$ ), Uniquenesses $(\delta)$, and Correlations from the CFA Solution (Predictors and Outcomes) in Sample 1

\begin{tabular}{|c|c|c|c|c|c|c|c|}
\hline Items & $\begin{array}{c}\text { Workload } \\
\lambda\end{array}$ & $\begin{array}{c}\text { Presenteeism } \\
\lambda\end{array}$ & $\begin{array}{c}\text { Turnover } \\
\lambda\end{array}$ & $\begin{array}{c}\text { POS } \\
\lambda\end{array}$ & $\begin{array}{c}\text { PSS } \\
\lambda\end{array}$ & $\begin{array}{c}\mathrm{PCS} \\
\lambda\end{array}$ & $\delta$ \\
\hline \multicolumn{8}{|l|}{ Workload } \\
\hline Item 1 & .704 & & & & & & .504 \\
\hline Item 2 & .796 & & & & & & .367 \\
\hline Item 3 & .626 & & & & & & .609 \\
\hline Item 4 & .637 & & & & & & .594 \\
\hline Item 5 & .735 & & & & & & .459 \\
\hline \multicolumn{8}{|l|}{ Presenteeism } \\
\hline Item 1 & & .906 & & & & & .178 \\
\hline Item 2 & & .906 & & & & & .179 \\
\hline Item 3 & & .883 & & & & & .219 \\
\hline Item 4 & & .891 & & & & & .206 \\
\hline Item 5 & & .918 & & & & & .158 \\
\hline Item 6 & & .854 & & & & & .270 \\
\hline \multicolumn{8}{|c|}{ Turnover Intentions } \\
\hline Item 1 & & & .811 & & & & .342 \\
\hline Item 2 & & & .973 & & & & .053 \\
\hline Item 3 & & & .902 & & & & .187 \\
\hline \multicolumn{8}{|l|}{ POS } \\
\hline Item 1 & & & & .946 & & & .105 \\
\hline Item 2 & & & & .486 & & & .712 \\
\hline Item 3 & & & & .789 & & & .377 \\
\hline Item 4 & & & & .489 & & & .458 \\
\hline \multicolumn{8}{|l|}{ PSS } \\
\hline Item 1 & & & & & .905 & & .181 \\
\hline Item 2 & & & & & .667 & & .471 \\
\hline Item 3 & & & & & .853 & & .272 \\
\hline Item 4 & & & & & .630 & & .519 \\
\hline \multicolumn{8}{|l|}{ PCS } \\
\hline Item 1 & & & & & & .858 & .263 \\
\hline Item 2 & & & & & & .668 & .533 \\
\hline Item 3 & & & & & & .812 & .341 \\
\hline Item 4 & & & & & & .620 & .562 \\
\hline$\omega$ & .828 & .960 & .925 & .816 & .866 & .837 & \\
\hline Correlations & 1 & 2 & 3 & 4 & 5 & 6 & \\
\hline 1. Workload & - & & & & & & \\
\hline 2. Presenteeism & .181 & - & & & & & \\
\hline 3. Turnover & .176 & .129 & - & & & & \\
\hline 4. POS & -.333 & -.039 & -.339 & - & & & \\
\hline 5. PSS & -.148 & -.013 & -.253 & .596 & - & & \\
\hline 6. PCS & -.066 & -.071 & -.104 & .229 & .267 & - & \\
\hline
\end{tabular}

Note. $\lambda$ : Factor loading; $\delta$ : Item uniqueness; $\omega$ : Omega coefficient of model-based composite reliability; POS $=$ Perceived organizational support; PSS $=$ Perceived supervisor support PCS $=$ Perceived colleagues support; non-significant parameters $(p \geq .05)$ are marked in italics. 
Table S8

Standardized Factor Loadings ( $\lambda$ ), Uniquenesses $(\delta)$, and Correlations from the CFA Solution (Predictors and Outcomes) in Sample 2

\begin{tabular}{|c|c|c|c|c|c|c|c|}
\hline Items & $\begin{array}{c}\text { Workload } \\
\lambda\end{array}$ & $\begin{array}{c}\text { Presenteeism } \\
\lambda\end{array}$ & $\begin{array}{c}\text { Turnover } \\
\lambda\end{array}$ & $\begin{array}{c}\text { POS } \\
\lambda\end{array}$ & $\begin{array}{c}\text { PSS } \\
\lambda\end{array}$ & $\begin{array}{c}\text { PCS } \\
\lambda\end{array}$ & $\delta$ \\
\hline \multicolumn{8}{|l|}{ Workload } \\
\hline Item 1 & .591 & & & & & & .650 \\
\hline Item 2 & .676 & & & & & & .544 \\
\hline Item 3 & .453 & & & & & & .795 \\
\hline Item 4 & .599 & & & & & & .641 \\
\hline Item 5 & .608 & & & & & & .630 \\
\hline \multicolumn{8}{|l|}{ Presenteeism } \\
\hline Item 1 & & .906 & & & & & .178 \\
\hline Item 2 & & .906 & & & & & .179 \\
\hline Item 3 & & .883 & & & & & .219 \\
\hline Item 4 & & .891 & & & & & .206 \\
\hline Item 5 & & .918 & & & & & .158 \\
\hline Item 6 & & .854 & & & & & .270 \\
\hline \multicolumn{8}{|c|}{ Turnover Intentions } \\
\hline Item 1 & & & .811 & & & & .342 \\
\hline Item 2 & & & .890 & & & & .208 \\
\hline Item 3 & & & .808 & & & & .347 \\
\hline \multicolumn{8}{|l|}{ POS } \\
\hline Item 1 & & & & .880 & & & .225 \\
\hline Item 2 & & & & .598 & & & .299 \\
\hline Item 3 & & & & .865 & & & .252 \\
\hline Item 4 & & & & .601 & & & .384 \\
\hline \multicolumn{8}{|l|}{ PSS } \\
\hline Item 1 & & & & & .905 & & .181 \\
\hline Item 2 & & & & & .667 & & .471 \\
\hline Item 3 & & & & & .853 & & .272 \\
\hline Item 4 & & & & & .630 & & .519 \\
\hline \multicolumn{8}{|l|}{ PCS } \\
\hline Item 1 & & & & & & .895 & .199 \\
\hline Item 2 & & & & & & .732 & .446 \\
\hline Item 3 & & & & & & .858 & .264 \\
\hline Item 4 & & & & & & .688 & .481 \\
\hline$\omega$ & .724 & .960 & .875 & .882 & .866 & .879 & \\
\hline Correlations & 1 & 2 & 3 & 4 & 5 & 6 & \\
\hline 1. Workload & - & & & & & & \\
\hline 2. Presenteeism & .132 & - & & & & & \\
\hline 3. Turnover & .128 & .129 & - & & & & \\
\hline 4. POS & .150 & -.029 & -.253 & - & & & \\
\hline 5. PSS & -.108 & -.013 & -.253 & .445 & - & & \\
\hline 6. PCS & -.040 & -.059 & -.086 & -.196 & .222 & - & \\
\hline
\end{tabular}

Note. $\lambda$ : Factor loading; $\delta$ : Item uniqueness; $\omega$ : Omega coefficient of model-based composite reliability; POS $=$ Perceived organizational support PSS $=$ Perceived supervisor support PCS $=$ Perceived colleagues support; non-significant parameters $(p \geq .05)$ are marked in italics. 
Table S9

Standardized Factor Loadings ( $\lambda$ ), Uniquenesses $(\delta)$, and Correlations from the CFA Solution (Predictors and Outcomes) in Sample 3

\begin{tabular}{|c|c|c|c|c|c|c|c|}
\hline & Workload & Presenteeism & Turnover & POS & PSS & PCS & \\
\hline Items & $\lambda$ & $\lambda$ & $\lambda$ & & $\lambda$ & & $\delta$ \\
\hline \multicolumn{8}{|l|}{ Workload } \\
\hline Item 1 & .591 & & & & & & .651 \\
\hline Item 2 & .675 & & & & & & .544 \\
\hline Item 3 & .453 & & & & & & .795 \\
\hline Item 4 & .599 & & & & & & .641 \\
\hline Item 5 & .608 & & & & & & .630 \\
\hline \multicolumn{8}{|l|}{ Presenteeism } \\
\hline Item 1 & & .833 & & & & & .305 \\
\hline Item 2 & & .833 & & & & & .307 \\
\hline Item 3 & & .798 & & & & & .363 \\
\hline Item 4 & & .810 & & & & & .344 \\
\hline Item 5 & & .851 & & & & & .275 \\
\hline Item 6 & & .756 & & & & & .429 \\
\hline \multicolumn{8}{|c|}{ Turnover Intentions } \\
\hline Item 1 & & & .811 & & & & .342 \\
\hline Item 2 & & & .973 & & & & .053 \\
\hline Item 3 & & & .808 & & & & .347 \\
\hline \multicolumn{8}{|l|}{ POS } \\
\hline Item 1 & & & & .946 & & & .105 \\
\hline Item 2 & & & & .486 & & & .712 \\
\hline Item 3 & & & & .789 & & & .377 \\
\hline Item 4 & & & & .489 & & & .458 \\
\hline \multicolumn{8}{|l|}{ PSS } \\
\hline Item 1 & & & & & .905 & & .181 \\
\hline Item 2 & & & & & .667 & & .471 \\
\hline Item 3 & & & & & .853 & & .272 \\
\hline Item 4 & & & & & .630 & & .519 \\
\hline \multicolumn{8}{|l|}{ PCS } \\
\hline Item 1 & & & & & & .858 & .263 \\
\hline Item 2 & & & & & & .668 & .533 \\
\hline Item 3 & & & & & & .812 & .341 \\
\hline Item 4 & & & & & & .620 & .562 \\
\hline$\omega$ & .724 & .922 & .901 & .816 & .866 & .837 & \\
\hline Correlations & 1 & 2 & 3 & 4 & 5 & 6 & \\
\hline 1. Workload & - & & & & & & \\
\hline 2. Presenteeism & .189 & - & & & & & \\
\hline 3. Turnover & .128 & .184 & - & & & & \\
\hline 4. POS & -.244 & -.056 & -.339 & - & & & \\
\hline 5. PSS & -.109 & -.019 & -.253 & .596 & - & & \\
\hline 6. PCS & -.049 & -.101 & -.104 & .229 & .267 & - & \\
\hline
\end{tabular}

Note. $\lambda$ : Factor loading; $\delta$ : Item uniqueness; $\omega$ : Omega coefficient of model-based composite reliability; POS $=$ Perceived organizational support PSS $=$ Perceived supervisor support PCS $=$ Perceived colleagues support; non-significant parameters $(p \geq .05)$ are marked in italics. 
Table S10

Standardized Factor Loadings ( $\lambda$ ), Uniquenesses $(\delta)$, and Correlations from the CFA Solution (Predictors and Outcomes) in Sample 4

\begin{tabular}{|c|c|c|c|c|c|c|c|}
\hline Items & $\begin{array}{c}\text { Workload } \\
\lambda\end{array}$ & $\begin{array}{c}\text { Presenteeism } \\
\lambda\end{array}$ & $\begin{array}{c}\text { Turnover } \\
\lambda\end{array}$ & $\begin{array}{c}\mathrm{POS} \\
\lambda\end{array}$ & $\begin{array}{c}\text { PSS } \\
\lambda\end{array}$ & $\begin{array}{c}\text { PCS } \\
\lambda\end{array}$ & $\delta$ \\
\hline \multicolumn{8}{|l|}{ Workload } \\
\hline Item 1 & .704 & & & & & & .504 \\
\hline Item 2 & .796 & & & & & & .367 \\
\hline Item 3 & .626 & & & & & & .609 \\
\hline Item 4 & .637 & & & & & & .594 \\
\hline Item 5 & .735 & & & & & & .459 \\
\hline \multicolumn{8}{|l|}{ Presenteeism } \\
\hline Item 1 & & .830 & & & & & .312 \\
\hline Item 2 & & .758 & & & & & .426 \\
\hline Item 3 & & .883 & & & & & .219 \\
\hline Item 4 & & .891 & & & & & .206 \\
\hline Item 5 & & .918 & & & & & .158 \\
\hline Item 6 & & .854 & & & & & .270 \\
\hline \multicolumn{8}{|c|}{ Turnover Intentions } \\
\hline Item 1 & & & .811 & & & & .342 \\
\hline Item 2 & & & .973 & & & & .053 \\
\hline Item 3 & & & .902 & & & & .187 \\
\hline \multicolumn{8}{|l|}{ POS } \\
\hline Item 1 & & & & .946 & & & .105 \\
\hline Item 2 & & & & .486 & & & .712 \\
\hline Item 3 & & & & .789 & & & .377 \\
\hline Item 4 & & & & .489 & & & .458 \\
\hline \multicolumn{8}{|l|}{ PSS } \\
\hline Item 1 & & & & & .905 & & .181 \\
\hline Item 2 & & & & & .667 & & .471 \\
\hline Item 3 & & & & & .853 & & .272 \\
\hline Item 4 & & & & & 630 & & .519 \\
\hline \multicolumn{8}{|l|}{ PCS } \\
\hline Item 1 & & & & & & .858 & .263 \\
\hline Item 2 & & & & & & .668 & .533 \\
\hline Item 3 & & & & & & .812 & .341 \\
\hline Item 4 & & & & & & .620 & .562 \\
\hline$\omega$ & .828 & .943 & .925 & .816 & .866 & .837 & \\
\hline$\overline{\text { Correlations }}$ & 1 & 2 & 3 & 4 & 5 & 6 & \\
\hline 1. Workload & - & & & & & & \\
\hline 2. Presenteeism & .181 & - & & & & & \\
\hline 3. Turnover & .176 & .129 & - & & & & \\
\hline 4. POS & -.333 & -.039 & -.339 & - & & & \\
\hline 5. PSS & -.148 & -.013 & -.253 & .596 & - & & \\
\hline 6. PCS & -.066 & -.071 & -.104 & .229 & .498 & - & \\
\hline
\end{tabular}

Note. $\lambda$ : Factor loading; $\delta$ : Item uniqueness; $\omega$ : Omega coefficient of model-based composite reliability; POS = Perceived organizational support; PSS = Perceived supervisor support; PCS = Perceived colleagues support; non-significant parameters $(p \geq .05)$ are marked in italics. 
Table S11

Correlations between Variables Used in the Present Study across Samples

\begin{tabular}{|c|c|c|c|c|c|c|c|c|c|c|c|c|c|c|c|c|c|}
\hline Variable & 1 & 2 & 3 & 4 & 5 & 6 & 7 & 8 & 9 & 10 & 11 & 12 & 13 & 14 & 15 & 16 & 17 \\
\hline \multicolumn{18}{|l|}{ Sample 1} \\
\hline 1. Sex & - & & & & & & & & & & & & & & & & \\
\hline 2. Age & .007 & - & & & & & & & & & & & & & & & \\
\hline 3. Work time & .073 & -.019 & - & & & & & & & & & & & & & & \\
\hline 4. Tenure & -.018 & $.394 * *$ & .025 & - & & & & & & & & & & & & & \\
\hline 5. G-factor ${ }^{1}$ & .061 & -.102 & -.016 & -.009 & - & & & & & & & & & & & & \\
\hline 6. IM S-factor ${ }^{1}$ & .023 & .107 & .088 & .092 & .109 & - & & & & & & & & & & & \\
\hline 7. ID S-factor ${ }^{1}$ & .062 & -.007 & .016 & .009 & .037 & .005 & - & & & & & & & & & & \\
\hline 8. IN S-factor ${ }^{1}$ & -.028 & -.060 & .006 & -.087 & .035 & .043 & $-.154 *$ & - & & & & & & & & & \\
\hline 9. EX S-factor ${ }^{1}$ & $-.259 * *$ & $-.234 * *$ & .019 & $-.191 * *$ & -.011 & -.098 & $-.130 *$ & .099 & - & & & & & & & & \\
\hline 10. AM S-factor ${ }^{1}$ & .004 & -.078 & -.024 & -.029 & -.038 & .010 & $-.123 *$ & .009 & .101 & - & & & & & & & \\
\hline 11. Workload ${ }^{1}$ & $.154 * *$ & -.017 & .018 & -.051 & -.087 & -.079 & .109 & .085 & .007 & -.062 & - & & & & & & \\
\hline 12. $\mathrm{POS}^{1}$ & -.034 & -.109 & .068 & -.077 & $.349 * *$ & $.181 * *$ & -.107 & -.057 & -.070 & -.098 & $-.390 * *$ & - & & & & & \\
\hline 13. $\mathrm{PSS}^{1}$ & -.003 & $-.115^{*}$ & .025 & -.112 & $.290 * *$ & .110 & -.021 & .041 & -.105 & -.105 & $-.202 * *$ & $.722 * *$ & - & & & & \\
\hline 14. $\mathrm{PCS}^{1}$ & $.177 * *$ & -.050 & $.116^{*}$ & -.032 & $.175^{* *} *$ & -.022 & .015 & -.026 & $-.149 *$ & -.012 & -.090 & $.277 * *$ & $.251 * *$ & - & & & \\
\hline 15. Presenteeism ${ }^{1}$ & .016 & -.038 & .074 & -.071 & -.094 & -.068 & -.050 & $.164 * *$ & .103 & .010 & $.197 * *$ & $-.167 * *$ & -.097 & $-.181 * *$ & - & & \\
\hline 16. Turnover ${ }^{1}$ & .028 & -.087 & -.023 & -.065 & $-.249 * *$ & $-.201 * *$ & .078 & -.031 & .109 & .112 & $.165 * *$ & $-.434 * *$ & $-.412 * *$ & $-.203 * *$ & $.263 * *$ & - & \\
\hline 17. Performance & -.017 & .011 & -.098 & -.035 & .051 & $.122 *$ & .018 & -.106 & -.108 & .027 & $-.164 * *$ & .114 & .076 & .114 & $-.516 * *$ & $-.139 *$ & - \\
\hline 18. Absenteeism ${ }^{1}$ & -.043 & .064 & -.066 & -.034 & .039 & .107 & .012 & .079 & -.007 & .034 & -.016 & $.119 *$ & $.126^{*}$ & -.007 & $.133^{*}$ & -.051 & $-.397 * *$ \\
\hline
\end{tabular}

Sample 2

2. Age

3. Work time

4. Tenure

5. G-factor ${ }^{1}$

6. IM S-factor

7. ID S-factor

8. IN S-factor

9. EX S-factor ${ }^{1}$

10. AM S-factor

11. Workload ${ }^{1}$

12. POS $^{1}$

$-.100 *-15 \%$

$\begin{array}{ll}.203 * * & -.155 * \\ -.240 * * & .358 * *\end{array}$

$.243 * *-.139 *$

$-.029$

$.098-.171 * *$

$\begin{array}{lllll}.031 & -.031 & .025 & .011 & .256 * *\end{array}$

$\begin{array}{llllll}.056 & .061 & -.063 & -.132 * & .171 * * & -.050\end{array}$

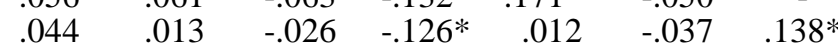

$\begin{array}{llllllll}-.200 * * & -.088 & -.126 * & -.067 & -.074 & -.162 * & .214 * * & .022 \\ -.029 & -.004 & .029 & -.024 & -.056 & .162 * & .091 & .004\end{array}$

$\begin{array}{lllllllll}-.029 & -.004 & .029 & -.024 & -.056 & .162 * & .091 & .004 & .215^{* *}\end{array}$

$\begin{array}{llllllllll}.218 * * & .046 & .014 & -.205 * * & .057 & -.039 & .138 * & .283 * * & .078 & .056\end{array}$

$\begin{array}{lllllllllll}.010 & .108 & -.187 * * & -.277 * * & -.027 & -.048 & .111 & .100 & .064 & -.017 & .225 * *\end{array}$

$\begin{array}{lllllll}-.179 * * & -.074 & -.093 & .008 & -.053 & -.063 & -.004\end{array}$

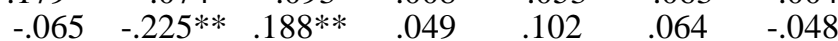

15. Presenteeism

16. Turnover ${ }^{1}$

$\begin{array}{ccccccccccccc}.059 & .071 & .074 & -.009 & -.145 & -.056 & -.026 & .134 * & .207 * * & .158^{*} & .189 * * & .061 & .053 \\ .094 & .031 & .076 & .004 & -.248^{* *} & -.165 * * & .123 & .111 & .084 & .087 & .372 * * & -.017 & -.047\end{array}$

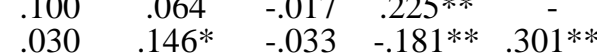

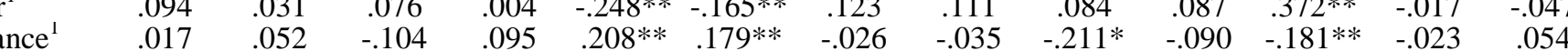

18. Absenteeism ${ }^{1}$

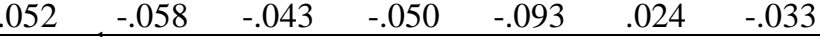

$.054 \quad .014$

$092 \quad-.017 \quad .002$

$.054 \quad .068-.296 * *-.246 *$

$\begin{array}{lccc}.068 & -.296 * * & -.246 * * & - \\ .032 & .248 * * & .125 & -.058\end{array}$

Note. $* p<.05 ; * *<<.01 ;{ }^{1}$ : indicators are estimated from factor scores with a standard deviation of 1 and a mean of $0 ; \mathrm{G}=\mathrm{Global}$ factor from a bifactor

model; $\mathrm{S}=$ Specific factor from a bifactor model; IM = Intrinsic motivation; ID = Identified regulation; IN = Introjected regulation; EX = External regulation; AM = Amotivation; POS = Perceived organizational support; PSS = Perceived supervisor support; PCS = Perceived colleagues support; NM = Not measured 
Table S11 (Continued)

Correlations between Variables Used in the Present Study across Samples

\begin{tabular}{|c|c|c|c|c|c|c|c|c|c|c|c|c|c|c|c|c|c|}
\hline Variable & 1 & 2 & 3 & 4 & 5 & 6 & 7 & 8 & 9 & 10 & 11 & 12 & 13 & 14 & 15 & 16 & 17 \\
\hline \multicolumn{18}{|l|}{ Sample 3} \\
\hline 1. Sex & - & & & & & & & & & & & & & & & & \\
\hline 2. Age & -.002 & - & & & & & & & & & & & & & & & \\
\hline 3. Work time & .032 & $.189 * *$ & - & & & & & & & & & & & & & & \\
\hline 4. Tenure & -.070 & $.603 * *$ & $.159 *$ & - & & & & & & & & & & & & & \\
\hline 5. G-factor ${ }^{1}$ & .044 & $-.203 * *$ & -.069 & -.028 & - & & & & & & & & & & & & \\
\hline 6. IM S-factor ${ }^{1}$ & .050 & -.013 & .004 & .039 & $.204 * *$ & - & & & & & & & & & & & \\
\hline 7. ID S-factor ${ }^{1}$ & .068 & -.126 & -.053 & .003 & $.508 * *$ & -.111 & - & & & & & & & & & & \\
\hline 8. IN S-factor ${ }^{1}$ & .072 & $156^{*}$ & .126 & .056 & -.013 & $-.158^{*}$ & .022 & _ & & & & & & & & & \\
\hline 9. EX S-factor ${ }^{1}$ & -.100 & $-.128^{*}$ & .005 & -.047 & .119 & $-.433 * *$ & .000 & $.255^{* *}$ & - & & & & & & & & \\
\hline 10. AM S-factor ${ }^{1}$ & -.048 & $-.145^{*}$ & -.098 & -.011 & $.572 * *$ & $.380 * *$ & $.383 * *$ & $-.307 * *$ & $-.222 * *$ & - & & & & & & & \\
\hline 11. Workload ${ }^{1}$ & .039 & -.070 & -.024 & $-.162 *$ & -.110 & -.119 & -.025 & .022 & -.032 & -.070 & - & & & & & & \\
\hline 12. $\operatorname{POS}^{1}$ & -.006 & -.101 & -.045 & -.072 & $.283 * *$ & .055 & $.192 * *$ & .057 & $.191 * *$ & $.164^{*}$ & $-.235 * *$ & - & & & & & \\
\hline 13. PSS $^{1}$ & -.016 & -.048 & .016 & -.041 & $171 * *$ & .121 & .054 & -.016 & .013 & $.148 *$ & .048 & $424 * *$ & _ & & & & \\
\hline 14. $\mathrm{PCS}^{1}$ & -.044 & -.100 & -.101 & $-.154 *$ & $.195 * *$ & $.207 * *$ & .077 & -.016 & -.005 & .113 & -.022 & .045 & .089 & & & & \\
\hline 15. Presenteeism ${ }^{1}$ & .048 & .110 & $.171 * *$ & .001 & -.072 & -.083 & -.052 & .039 & .060 & -.045 & $.152^{*}$ & .075 & .056 & -.124 & - & & \\
\hline 16. Turnover ${ }^{1}$ & -.022 & -.016 & -.020 & -.037 & $-.269 * *$ & $-.210 * *$ & $-.164 *$ & .067 & .048 & $-.137 *$ & $.165^{*}$ & $-.271 * *$ & $-.149 *$ & -.016 & .101 & - & \\
\hline 17. Performance ${ }^{1}$ & -.018 & $.187 * *$ & .042 & $.213 * *$ & $.145^{*}$ & $.302 * *$ & .070 & $-.159 *$ & $-.267 * *$ & $.133 *$ & $-.177 * *$ & .061 & .095 & $.131 *$ & $-.250 * *$ & $-.232 * *$ & - \\
\hline 18. Absenteeism ${ }^{1}$ & -.034 & .054 & .071 & .102 & $\begin{array}{l}-.042 \\
-.04\end{array}$ & .039 & -.062 & .065 & -.041 & -.088 & .029 & -.014 & .014 & -.014 & $324 * *$ & -.016 & .005 \\
\hline
\end{tabular}

Sample 4

1. Sex

3. Work time

4. Tenure

5. G-factor ${ }^{1}$

6. IM S-factor

7. ID S-factor

8. IN S-factor

9. EX S-factor ${ }^{1}$

10. AM S-factor

11. Workload ${ }^{1}$

12. POS $^{1}$

15. PCS

16. Turnover ${ }^{1}$

$-082$

NM NM

$\mathrm{NM} \quad \mathrm{NM}$

$.068-.166 * * \quad \mathrm{NM}$

$-.062 \quad .073$

$075-156 * * \quad \mathrm{NM}$

$-.001-.132 *$

$-.001-.132$

$-.031 \quad-.110 * \quad \mathrm{NM}$

$\begin{array}{cc}-.084 & -.001 \\ -.006 & .059\end{array}$

$\begin{array}{lll}.006 & .059 & \mathrm{NM} \\ .078 & -.101 & \mathrm{NM}\end{array}$

$.078-.188 * *$

$.036-.274 *$

18. Performance

$\begin{array}{ll}-.089 & -.019\end{array}$ $.075 \quad .131 *$

$\begin{array}{lll}- & \\ & \mathrm{NM} & .130 *\end{array}$

NM $\quad .471 * *-.189 * *$

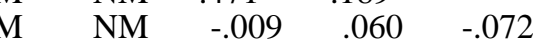

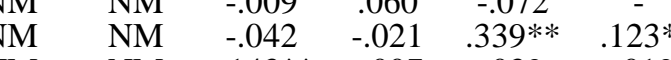

$\begin{array}{lllllll}\text { NM } & -.143^{* *} & -.007 & .039 & -.019 & .039\end{array}$

$\begin{array}{lllll}\mathrm{NM} & .043 & -.079 & .087 & .159 * *\end{array}$

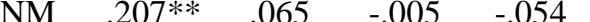

NM 232** $\quad 076 \quad 066$

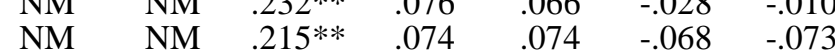

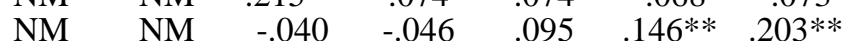

$\begin{array}{llllll}\mathrm{NM} & -.040 & -.046 & .095 & .146 * * & .203^{* *} \\ \mathrm{NM} & -.238 * * & -.191 * * & -.017 & .145^{* *} & .108^{*}\end{array}$

$\begin{array}{ccccc}.236 * * & .014 & .0138 * * & -.172 * * & -.054 \\ -.051 & -.083 & .016 & -.050 & -.017\end{array}$

$-.014$

$-.014-.498 * *$

$025-282 * * 798 *$

$\begin{array}{llll}.030 & -.117 * & 410 * * & 626 * *\end{array}$

$\begin{array}{lllll}.038 & .265 * * & -.082 & -.042 & -.078\end{array}$

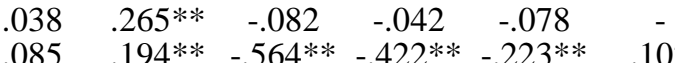

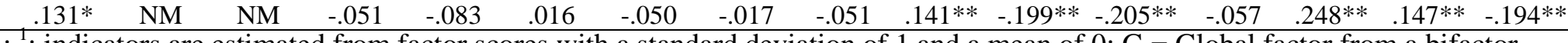

$\mathrm{AM}=$ Amotivation; POS = Perceived organizational support; PSS = Perceived supervisor support; PCS = Perceived colleagues support; NM = Not measured. 

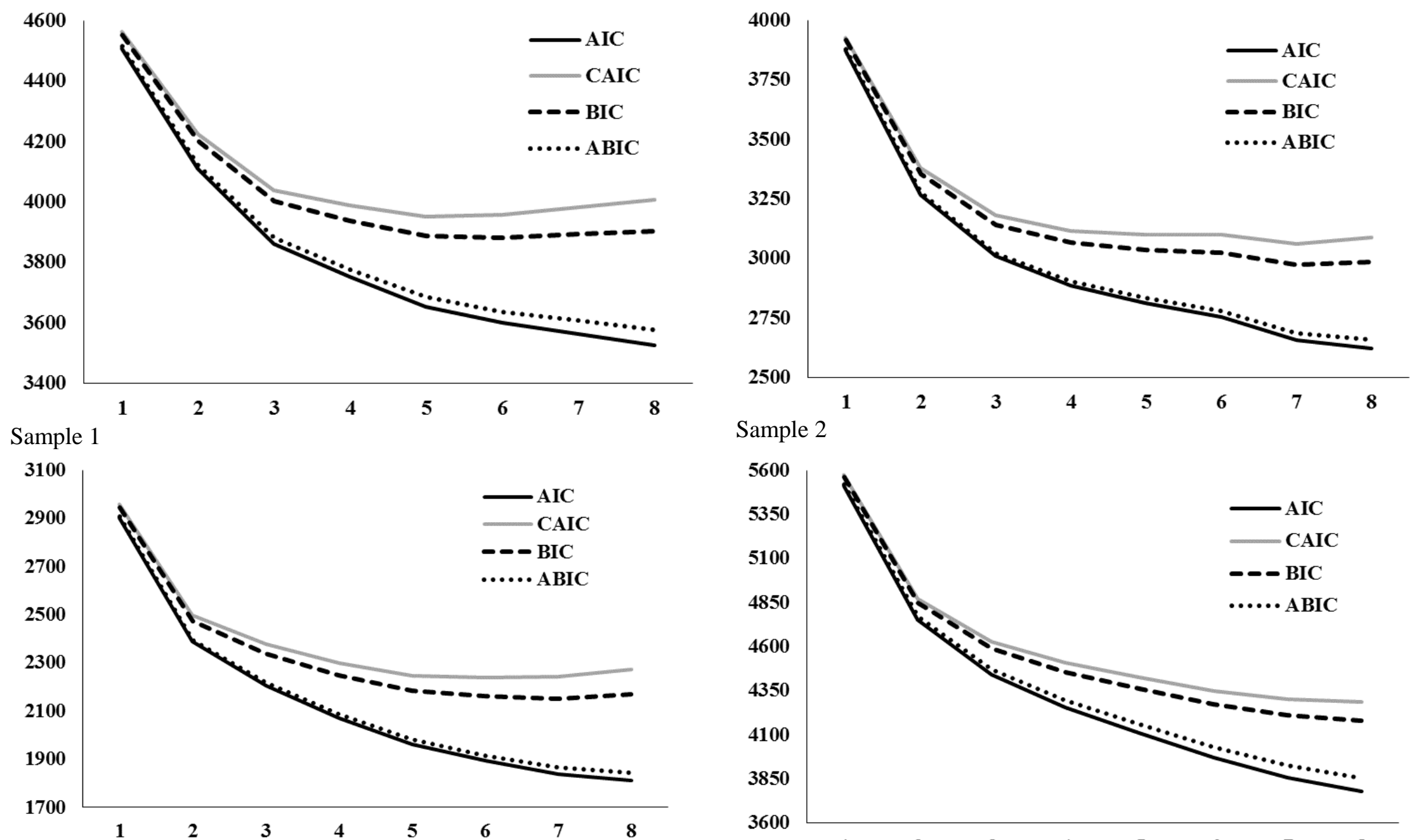

Sample 2

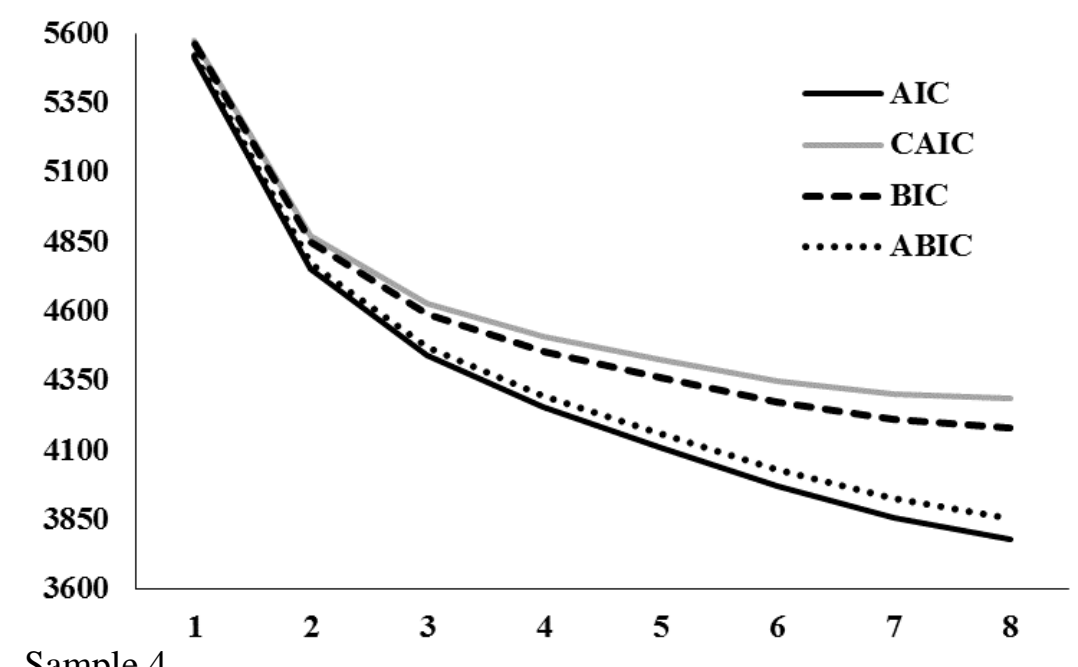

Sample 3

Sample 4

Figure S1

Elbow Plot of the Value of the Information Criteria for Solutions Including Different Numbers of Latent Profiles 
Table S12

Results from the Latent Profile Analysis Models

\begin{tabular}{|c|c|c|c|c|c|c|c|c|c|c|}
\hline Model & LL & $\# \mathrm{fp}$ & Scaling & AIC & CAIC & BIC & ABIC & Entropy & aLMR & BLRT \\
\hline \multicolumn{11}{|l|}{ Sample 1} \\
\hline 1 Profile & -2242.208 & 12 & 1.290 & 4508.416 & 4564.496 & 4552.496 & 4514.441 & $\mathrm{Na}$ & $\mathrm{Na}$ & $\mathrm{Na}$ \\
\hline 2 Profiles & -2029.401 & 25 & 1.086 & 4108.803 & 4225.636 & 4200.636 & 4121.356 & .807 & $<.001$ & $<.001$ \\
\hline 3 Profiles & -1892.804 & 38 & 1.014 & 3861.608 & 4039.195 & 4001.195 & 3880.689 & .873 & $<.001$ & $<.001$ \\
\hline 4 Profiles & -1824.430 & 51 & .971 & 3750.860 & 3989.200 & 3938.200 & 3776.468 & .897 & $<.001$ & $<.001$ \\
\hline 5 Profiles & -1762.284 & 64 & 1.010 & 3652.568 & 3951.661 & 3887.661 & 3684.704 & .912 & .007 & $<.001$ \\
\hline 6 Profiles & -1722.241 & 77 & .975 & 3598.482 & 3958.328 & 3881.328 & 3637.146 & .902 & .010 & $<.001$ \\
\hline 7 Profiles & -1690.808 & 90 & .997 & 3561.616 & 3982.215 & 3892.215 & 3606.806 & .897 & .191 & $<.001$ \\
\hline 8 Profiles & -1659.276 & 103 & 1.022 & 3524.552 & 4005.904 & 3902.904 & 3576.270 & .909 & .431 & $<.001$ \\
\hline \multicolumn{11}{|l|}{ Sample 2} \\
\hline 1 Profile & -1924.475 & 12 & 1.550 & 3872.949 & 3927.159 & 3915.159 & 3877.118 & $\mathrm{Na}$ & $\mathrm{Na}$ & $\mathrm{Na}$ \\
\hline 2 Profiles & -1608.785 & 25 & 1.367 & 3267.569 & 3380.506 & 3355.506 & 3276.254 & .969 & .001 & $<.001$ \\
\hline 3 Profiles & -1466.095 & 38 & 1.089 & 3008.191 & 3179.854 & 3141.854 & 3021.392 & .897 & $<.001$ & $<.001$ \\
\hline 4 Profiles & -1391.957 & 51 & 1.004 & 2885.913 & 3116.303 & 3065.303 & 2903.630 & .919 & .060 & $<.001$ \\
\hline 5 Profiles & -1341.381 & 64 & 1.042 & 2810.761 & 3099.878 & 3035.878 & 2832.995 & .916 & .051 & $<.001$ \\
\hline 6 Profiles & -1299.657 & 77 & 1.178 & 2753.314 & 3101.158 & 3024.158 & 2780.064 & .918 & .209 & $<.001$ \\
\hline 7 Profiles & -1237.621 & 90 & 1.032 & 2655.243 & 3061.814 & 2971.814 & 2686.509 & .929 & .024 & $<.001$ \\
\hline 8 Profiles & -1207.709 & 103 & .996 & 2621.417 & 3086.715 & 2983.715 & 2657.199 & .919 & .127 & $<.001$ \\
\hline \multicolumn{11}{|l|}{ Sample 3} \\
\hline 1 Profile & -1439.299 & 12 & 1.290 & 2902.598 & 2956.214 & 2944.214 & 2906.179 & $\mathrm{Na}$ & $\mathrm{Na}$ & $\mathrm{Na}$ \\
\hline 2 Profiles & -1168.496 & 25 & 1.158 & 2386.992 & 2498.694 & 2473.694 & 2394.453 & .903 & $<.001$ & $<.001$ \\
\hline 3 Profiles & -1065.326 & 38 & 1.414 & 2206.652 & 2376.438 & 2338.438 & 2217.991 & .894 & .343 & $<.001$ \\
\hline 4 Profiles & -984.758 & 51 & 1.316 & 2071.517 & 2299.388 & 2248.388 & 2086.736 & .916 & .189 & $<.001$ \\
\hline 5 Profiles & -917.054 & 64 & 1.091 & 1962.108 & 2246.064 & 2184.064 & 1981.206 & .926 & .052 & $<.001$ \\
\hline 6 Profiles & -869.759 & 77 & 1.067 & 1893.518 & 2237.559 & 2160.559 & 1916.496 & .933 & .324 & $<.001$ \\
\hline 7 Profiles & -829.360 & 90 & 1.058 & 1838.720 & 2240.846 & 2150.846 & 1865.577 & .934 & .056 & $<.001$ \\
\hline 8 Profiles & -802.790 & 103 & 1.023 & 1811.581 & 2271.791 & 2168.791 & 1842.317 & .936 & .163 & $<.001$ \\
\hline \multicolumn{11}{|l|}{ Sample 4} \\
\hline 1 Profile & -2744.580 & 12 & 1.863 & 5513.159 & 5572.218 & 5560.218 & 5522.146 & $\mathrm{Na}$ & $\mathrm{Na}$ & $\mathrm{Na}$ \\
\hline 2 Profiles & -2349.909 & 25 & 1.422 & 4749.818 & 4872.857 & 4847.857 & 4768.540 & .944 & $<.001$ & $<.001$ \\
\hline 3 Profiles & -2181.595 & 38 & 1.212 & 4439.190 & 4626.210 & 4588.210 & 4467.647 & .896 & .005 & $<.001$ \\
\hline 4 Profiles & -2076.366 & 51 & 1.159 & 4254.732 & 4505.732 & 4454.732 & 4292.924 & .909 & .009 & $<.001$ \\
\hline 5 Profiles & -1990.380 & 64 & 1.236 & 4108.760 & 4423.741 & 4359.741 & 4156.688 & .868 & .270 & $<.001$ \\
\hline 6 Profiles & -1907.459 & 77 & 1.138 & 3968.919 & 4347.880 & 4270.880 & 4026.582 & .902 & .059 & $<.001$ \\
\hline 7 Profiles & -1838.458 & 90 & 1.175 & 3856.916 & 4299.858 & 4209.858 & 3924.314 & .910 & .412 & $<.001$ \\
\hline 8 Profiles & -1785.507 & 103 & 1.047 & 3777.013 & 4283.936 & 4180.936 & 3854.147 & .924 & .058 & $<.001$ \\
\hline
\end{tabular}

Note: LL: LogLikelihood; \#fp: Number of free parameters; Scaling: Scaling correction factor; AIC: Akaïke Information Criteria; CAIC: Constant AIC; BIC: Bayesian

Information Criteria; ABIC: Sample-size adjusted BIC; aLMR: Adjusted Lo-Mendel-Rubin likelihood ratio test; BLRT: Bootstrap Likelihood Ratio Test. 
Table S13

Detailed Results from the Final Latent Profile Solution

\begin{tabular}{|c|c|c|c|c|}
\hline & $\begin{array}{c}\text { Profile } 1 \\
\text { Mean }[\mathrm{CI}]\end{array}$ & $\begin{array}{c}\text { Profile } 2 \\
\text { Mean }[\mathrm{CI}]\end{array}$ & $\begin{array}{c}\text { Profile } 3 \\
\text { Mean }[\mathrm{CI}]\end{array}$ & $\begin{array}{c}\text { Profile } 4 \\
\text { Mean }[\mathrm{CI}]\end{array}$ \\
\hline Global & $.246[.146 ; .346]$ & $-1.573[-1.826 ;-1.321]$ & $-.275[-.631 ; .082]$ & $-.212[-.387 ;-.037]$ \\
\hline Intrinsic & $.338[.237 ; .438]$ & $-1.123[-1.388 ;-.857]$ & $.120[-.060 ; .301]$ & $.697[.455 ; .938]$ \\
\hline Identified & $-.153[-.260 ;-.047]$ & $-.470[-.694 ;-.246]$ & $-.253[-.556 ; .050]$ & $-.305[-.490 ;-.120]$ \\
\hline Extrinsic & $.029[-.123 ; .182]$ & $.648[.404 ; .891]$ & $-.328[-.641 ;-.015]$ & $-.658[-.682 ;-.634]$ \\
\hline \multirow[t]{2}{*}{ Amotivation } & $-.239[-.336 ;-.143]$ & $.607[.209 ; 1.006]$ & $-.205[-.476 ; .067]$ & $.009[-.038 ; .055]$ \\
\hline & Variance $[\mathrm{CI}]$ & Variance $[\mathrm{CI}]$ & Variance $[\mathrm{CI}]$ & Variance $[\mathrm{CI}]$ \\
\hline Identified & $.550[.442 ; .658]$ & $.958[.660 ; 1.256]$ & $.249[.136 ; .362]$ & $.057[.007 ; .106]$ \\
\hline Introjected & $.394[.280 ; .508]$ & $.725[.531 ; .919]$ & $.011[-.001 ; .023]$ & $.007[.001 ; .013]$ \\
\hline Extrinsic & $1.041[.851 ; 1.232]$ & $1.008[.730 ; 1.286]$ & $.084[.018 ; .149]$ & $.004[.000 ; .009]$ \\
\hline \multirow[t]{3}{*}{ Amotivation } & $.449[.337 ; .561]$ & $3.827[2.547 ; 5.107]$ & .051 [.022; .079] & .011 [.006; .017] \\
\hline & Profile 5 & Profile 6 (Nurses) & Profile 6 (Others) & \\
\hline & Mean $[\mathrm{CI}]$ & Mean $[\mathrm{CI}]$ & Mean $[\mathrm{CI}]$ & \\
\hline Global & $.251[.120 ; .382]$ & $.609[.470 ; .749]$ & $.575[.380 ; .770]$ & \\
\hline \multirow[t]{2}{*}{ Amotivation } & $-.027[-.124 ; .070]$ & $.481[.420 ; .542]$ & $.029[-.032 ; .089]$ & \\
\hline & Variance $[\mathrm{CI}]$ & Variance $[\mathrm{CI}]$ & Variance $[\mathrm{CI}]$ & \\
\hline Global & $.661[.515 ; .807]$ & $.123[.071 ; .174]$ & $.123[.071 ; .174]$ & \\
\hline Intrinsic & $.537[.443 ; .632]$ & $.267[-.011 ; .545]$ & $.267[-.011 ; .545]$ & \\
\hline Identified & $.669[.530 ; .808]$ & $.165[.011 ; .320]$ & $.165[.011 ; .320]$ & \\
\hline Introjected & .128 [.095; .162] & $.036[.019 ; .054]$ & $.036[.019 ; .054]$ & \\
\hline Extrinsic & $.478[.398 ; .559]$ & $.039[.022 ; .056]$ & $.039[.022 ; .056]$ & \\
\hline Amotivation & $.498[.367 ; .628]$ & $.029[.022 ; .036]$ & $.029[.022 ; .036]$ & \\
\hline
\end{tabular}


Table S14

Classification Accuracy: Average Probability of Membership into Each Latent Profile (Column) as a Function of the Most Likely Profile Membership (Row)

\begin{tabular}{|c|c|c|c|c|c|c|}
\hline & Profile 1 & Profile 2 & Profile 3 & Profile 4 & Profile 5 & Profile 6 \\
\hline \multicolumn{7}{|l|}{ Sample 1} \\
\hline Profile 2 & .045 & .861 & .005 & .000 & .088 & .000 \\
\hline Profile 3 & .000 & .002 & .868 & .023 & .101 & .006 \\
\hline Profile 5 & .021 & .027 & .028 & .000 & .911 & .013 \\
\hline Profile 6 & .000 & .000 & .006 & .000 & .061 & .933 \\
\hline \multicolumn{7}{|l|}{ Sample 2} \\
\hline Profile 3 & .000 & .003 & .842 & .039 & .078 & .038 \\
\hline Profile 4 & .000 & .000 & .033 & .967 & .000 & .000 \\
\hline Profile 5 & .016 & .036 & .028 & .000 & .905 & .015 \\
\hline Profile 6 & .001 & .000 & .034 & .000 & .085 & .879 \\
\hline \multicolumn{7}{|l|}{ Sample 3} \\
\hline Profile 1 & .935 & .035 & .000 & .000 & .030 & .000 \\
\hline Profile 2 & .011 & .896 & .000 & .000 & .093 & .000 \\
\hline \multicolumn{7}{|l|}{ Sample 4} \\
\hline Profile 1 & .950 & .021 & .000 & .000 & .028 & .000 \\
\hline Profile 2 & .012 & .946 & .000 & .000 & .042 & .000 \\
\hline Profile 3 & .000 & .000 & .881 & .042 & .050 & .027 \\
\hline Profile 4 & .000 & .000 & .073 & .924 & .002 & .001 \\
\hline Profile 5 & .033 & .021 & .022 & .000 & .918 & .006 \\
\hline Profile 6 & .002 & .000 & .022 & .000 & .070 & .906 \\
\hline
\end{tabular}

Note. Profile indicators are estimated from factor scores with a grand mean of 0 and a standard deviation of 1; Profile 1: Self-Driven Introjected; Profile 2: Externally Driven; Profile 3: Moderately Intrinsically Motivated; Profile 4: Highly Intrinsically Motivated; Profile 5: Value-Reward Self-Driven; Profile 6: Self-Driven Hedonist. 